Carlos do Carmo Pagani Júnior

\title{
Projeto e otimização de filtros modais usando redes de sensores piezelétricos
}

Dissertação apresentada à Escola de Engenharia de São Carlos da Universidade de São Paulo, para obtenção do título de Mestre em Engenharia Mecânica

Área de concentração: Dinâmica de Máquinas e Sistemas

Orientador: Prof. Dr. Marcelo Areias Trindade

São Carlos

2009 


\section{Agradecimentos}

Agradeço a Deus pela saúde e disposição para a realização deste trabalho. Ao meu orientador Marcelo Areias Trindade pela confiança, parceria no trabalho e incentivo incondicional à produção acadêmica. À minha esposa Elisângela e à minha mãe Aparecida Mércia pela motivação. Aos professores Volnei Tita, Flavio Donizeti Marques e Alexandre Delbem pela presteza e contribuição positiva ao trabalho. Ao Ricardo Afonso Angélico pelas primeiras noções sobre teoria dos elementos finitos. Aos amigos Júliana Lopes, Tatiane Corrêa de Godoy, Heinsten Frederich Leal dos Santos e Marcelo Gustavo de Souza pelo companheirismo demonstrado durante o mestrado. Ao técnico Leandro Pedrassolli, à bibliotecária Helena e às secretárias Cristina e Ana Paula pelo auxílio irrestrito que prestaram, tornando possível a elaboração desta dissertação.

Gostaria também de agradecer antecipadamente aos membros da Banca, por dedicarem o seu tempo à avaliação deste trabalho, e ao apoio financeiro prestado pela Coordenação de Aperfeiçoamento de Pessoal de Nível Superior - CAPES, na forma de uma bolsa regular de mestrado. 


\section{Resumo}

PAGANI JR., C.C. (2009). Projeto e otimização de filtros modais usando redes de sensores piezelétricos. 153 p. Dissertação (Mestrado) - Escola de Engenharia de São Carlos, Universidade de São Carlos, São Carlos, 2009.

Filtros modais permitem que se identifique a contribuição de cada modo de vibrar na resposta dinâmica de uma estrutura, o que pode simplificar o projeto de sistemas dinâmicos em diversas aplicações como controle de vibrações, controle de forma, monitoramento de integridade estrutural e aproveitamento de energia. $\mathrm{O}$ objetivo desta dissertação é desenvolver uma metodologia para projetar e otimizar filtros modais a partir de uma rede de sensores piezelétricos discretos. É de especial interesse a relação entre a topologia da rede de sensores e o desempenho dos filtros modais obtidos pela soma ponderada dos sinais de tensão elétrica medida por cada sensor. A modelagem estrutural, usando o método dos elementos finitos com acoplamento eletromecânico, considera uma placa retangular de alumínio com trinta e seis sensores piezelétricos, em forma de pequenas pastilhas, colados sobre uma de suas superfícies. As topologias de rede consideradas neste trabalho consistem das possíveis combinações de trinta e seis sensores tomados doze a doze. Esta estratégia permite um amplo processo de otimização topológica a partir de um único modelo de elementos finitos. Duas funções-objetivo definem os índices de desempenho de cada topologia de rede avaliada, objetivando projetar filtros modais capazes de isolar a resposta dos primeiros modos de vibrar que maximizem a faixa de frequência e minimizem o número de sensores necessários. Em uma primeira abordagem ao problema de otimização topológica combinatorial, é utilizado o método de busca extensiva em um espaço de soluções reduzido. Em seguida, o problema é codificado para o uso de um algoritmo genético. Os resultados mostram que aumentos de $25 \%$ a $50 \%$ na faixa de frequência dos filtros modais podem ser obtidos a partir da otimização topológica da rede de sensores.

Palavras chaves: Filtros modais. Sensores piezelétricos. Método dos elementos finitos. Otimização topológica, Algoritmo genético. 


\section{Abstract}

PAGANI JR., C.C. (2009). Design and optimization of modal filters using arrays of piezoelectric sensors. 153 p. Master's dissertation - São Carlos School of Engineering, University of São Paulo, São Carlos, 2009.

Modal filters allow identifying the contribution of each vibration mode to the dynamical response of a structure, which can simplify the design of dynamical systems in several applications, such as vibration control, shape control, structural health monitoring and energy harvesting. The aim of this dissertation is to develop a methodology to design and optimize modal filters by using a discrete array of piezoelectric sensors. The relationship between the sensors array topology and the performance of the modal filters, which are obtained by means of weighted sum of the voltage signs, draws special interest. The structural modeling through the finite element method with electromechanical coupling considers a retangular aluminum plate with thirty-six patch-shaped piezoelectric sensors bonded on one of its surfaces. The array topologies considered in this work consist of the possible combinations of thirty-six sensors taken twelve at a time. This strategy allows for a broad process of topological optimization by using only one finite element model. Two objective functions define the performance index associated with each evaluated array topology, aiming to design modal filters able to isolate the response of the first vibration modes that maximize the frequency band and minimize the number of sensors needed. As a first approach to the combinatorial topology optimization problem, the extensive search method is applied to a reduced solutions space. Next, the optimization problem is codified for using a genetic algorithm. The results show that an increase from $25 \%$ to $50 \%$ in the frequency band of the modal filters can be obtained from the topology optimization of the sensors array.

Keywords: Modal filters. Piezoelectric sensors. Finite element method. Topology optimization. Genetic algorithm. 


\section{Sumário}

Resumo

Abstract

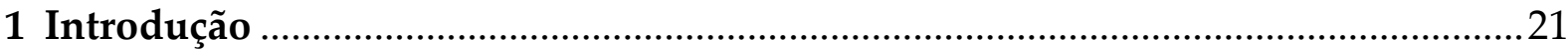

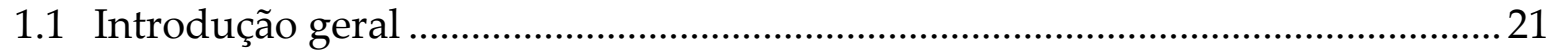

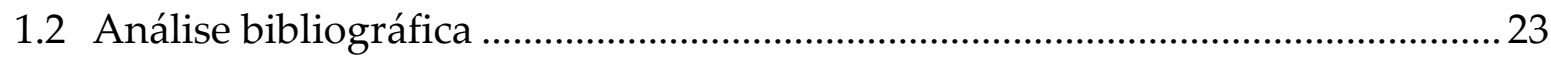

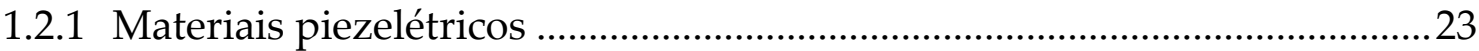

1.2.2 Modelagem de estruturas piezelétricas pelo método de elementos

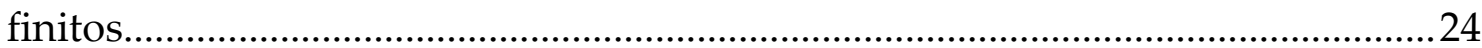

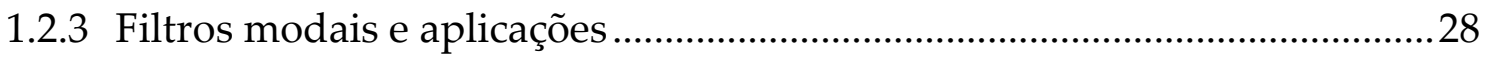

1.2.4 Otimização de estruturas inteligentes utilizando algoritmos genéticos...31

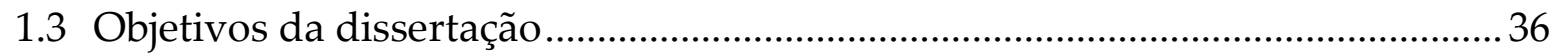

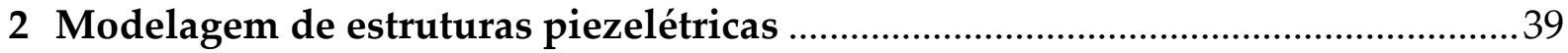

2.1 Revisão das leis de comportamento para materiais piezelétricos ......................39

2.1.1 Equações constitutivas para materiais elásticos..........................................39

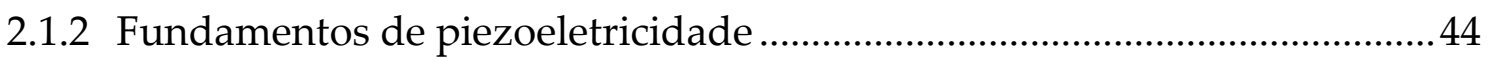

2.1.3 Equações constitutivas para materiais piezelétricos ..................................48

2.2 Modelagem da placa com pastilhas piezelétricas no ANSYS ............................5 52

2.2.1 Descrição da modelagem estrutural .............................................................52 
2.2.2 Condições de contorno elétricas ..................................................................... 57

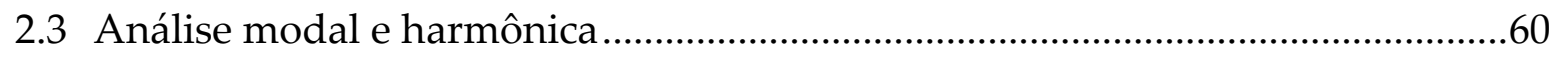

2.3.1 Revisão teórica de análise modal e harmônica................................................ 60

2.3.2 Análise modal de uma placa com pastilhas piezelétricas no ANSYS....... 66

2.3.3 Resposta a excitação harmônica de uma placa usando pastilhas piezelétricas como sensores......................................................................................71

3 Projeto de filtros modais usando redes de sensores …………………………….... 75

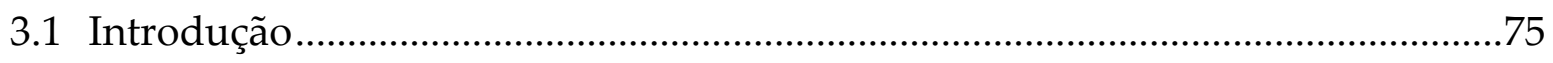

3.2 Projeto de filtros modais usando inversão da matriz de FRFs..............................77

3.3 Aplicação da técnica para uma placa com pastilhas piezelétricas.......................82

4 Otimização do projeto de filtros modais através da topologia de uma rede de

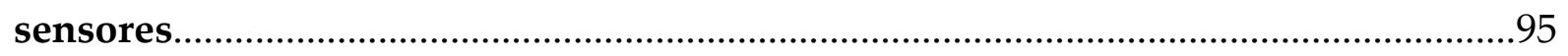

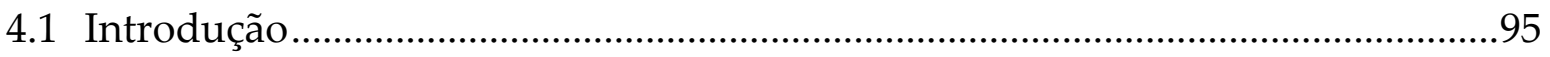

4.2 Descrição do problema de otimização ………………………………………….....95

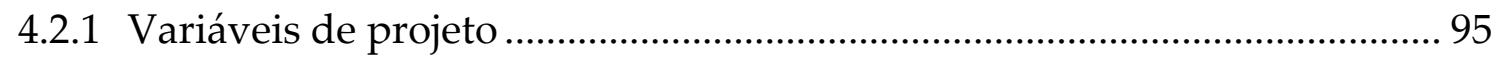

4.2.2 Funções objetivo......................................................................................... 99

4.2.2.1 Maximização da largura da banda residual .............................................. 99

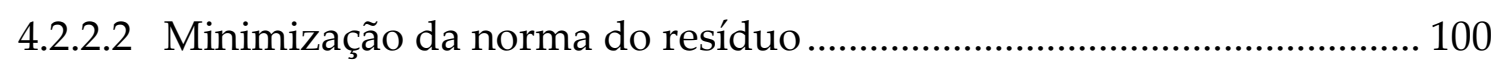

4.3 Otimização usando busca extensiva …………………………………………......103

4.3.1 Técnica de redução do espaço de busca (simetria) ……………………….... 103

4.3.2 Resultados da otimização por busca extensiva........................................... 108

4.4 Otimização usando algoritmos genéticos ............................................................113

4.4.1 Implementação do AG em MATLAB …………………………………...... 113

4.4.2 Otimização dos parâmetros quantitativos do AG ………………………... 120 
4.4.3 Resultados da otimização usando AG

4.5 Efeito da eliminação das pastilhas inativas....................................................... 132

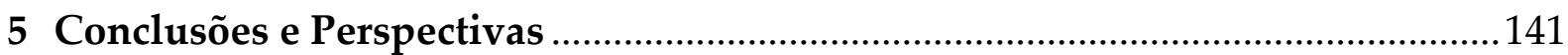

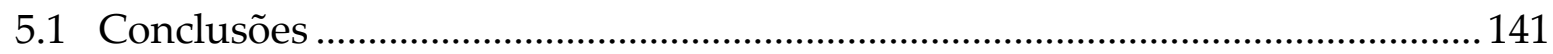

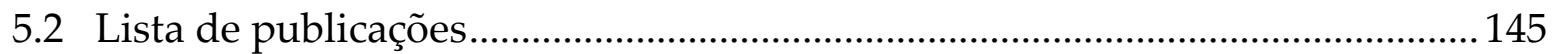

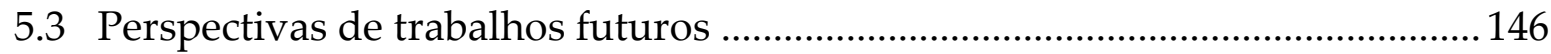




\section{Lista de Figuras}

Figura 2.1 Placa de alumínio $(320 \times 280 \times 3 \mathrm{~mm})$ com 36 sensores piezelétricos PZT5 H idênticos, em forma de pastilhas ( $25 \times 25 \times 0.5 \mathrm{~mm})$, colados sobre uma das superfícies da placa, de forma a compor uma rede de sensores regularmente distribuídos. 52

Figura 2.2 Representação do elemento SHELL99 e posição de nós, conforme convenção adotada pelo ANSYS. 53

Figura 2.3 Representação do elemento SOLID226 e posição de nós, conforme convenção adotada pelo ANSYS. 54

Figura 2.4 Vista frontal mostrando camadas de nós de uma pastilha piezelétrica alinhados verticalmente aos nós da placa. a) a operação de offset dos nós do elemento SHELL99 não é realizada e estes permanecem no seu plano médio (pontos em vermelho), deslocados verticalmente em relação à primeira camada de nós do SOLID226 (pontos em azul). b) os nós do elemento SHELL99 são deslocados ao topo pela operação de offset, sobrepondo-se à primeira camada de nós do SOLID226. 55

Figura 2.5 Vista frontal dos nós da malha de elementos finitos para o modelo de placa com sensores piezelétricos. 56

Figura 2.6 O aterramento dos nós da base de cada pastilha define um valor de referência para a leitura do potencial elétrico no topo das pastilhas.....59 
Figura 2.7 O acoplamento elétrico do grau de liberdade VOLT se dá pela implementação de uma rede de eletrodos distribuídos no topo de cada pastilha. O efeito da rede de eletrodos é uniformizar a tensão elétrica superficial e tornar inequívoca a leitura em cada sensor.

Figura 2.8 Formas modais e distribuição de voltagem nos sensores piezelétricos para os três primeiros modos de vibrar sem (esquerda) e com (direita) a implementação da condição de equipotencialidade.

Figura 2.9 Formas modais e distribuição de voltagem nos sensores piezelétricos para os modos de vibrar 4 a 6 sem (esquerda) e com (direita) a implementação da condição de equipotencialidade.

Figura 2.10 Amplitude da tensão elétrica induzida nos sensores indexados de 1 até 18, por unidade de força aplicada, no domínio da frequência. 72

Figura 2.11 Amplitude da tensão elétrica induzida nos sensores indexados de 19 até 36, por unidade de força aplicada, no domínio da frequência. 73

Figura 3.1 Amplitude normalizada das respostas dos quatro primeiros modos alvos (representação gráfica do vetor Gi para i de 1 até 4). 78

Figura 3.2 Média e intervalo de confiança da resposta do filtro modal projetado para isolar o primeiro modo de vibrar utilizando redes compostas por 12 sensores. 85

Figura 3.3 Média e intervalo de confiança da resposta do filtro modal projetado para isolar o segundo modo de vibrar utilizando redes compostas por 12 sensores. 85

Figura 3.4 Média e intervalo de confiança da resposta do filtro modal projetado para isolar o primeiro modo de vibrar utilizando redes compostas por 14 sensores. 85

Figura 3.5 Média e intervalo de confiança da resposta do filtro modal projetado para isolar o segundo modo de vibrar utilizando redes compostas por 14 sensores. 86 
Figura 3.6 Média e intervalo de confiança da resposta do filtro modal projetado para isolar o primeiro modo de vibrar utilizando redes compostas por 16 sensores. .86

Figura 3.7 Média e intervalo de confiança da resposta do filtro modal projetado para isolar o segundo modo de vibrar utilizando redes compostas por 16 sensores. .86

Figura 3.8 Média e intervalo de confiança da norma do erro residual em termos do número de modos na banda de frequência para diferentes números de sensores: (a). Relação entre o número de sensores e o número de modos para diferentes valores do erro residual: b) 0,4, c) 1,0, d) 1,6. 89

Figura 3.9 Topologia de rede retangular e filtros modais com desempenho esperado para o isolamento dos dois primeiros modos de vibrar até $800 \mathrm{~Hz}$. 91

Figura 3.10 Desempenho degenerado dos filtros modais derivados de uma topologia retangular para o isolamento dos dois primeiros modos de vibrar, quando a matriz de FRF é truncada em $1000 \mathrm{~Hz}$, de forma a incluir quatro modos residuais adicionais.

Figura 3.11 Topologia de sensores ativos e filtros modais para o isolamento dos dois primeiros modos de vibrar até $800 \mathrm{~Hz}$. O filtro para o segundo modo de vibrar apresenta baixo desempenho. .92

Figura 4.1 Ilustração da indexação dos sensores. Este critério de indexação foi concebido para a implementação da pesquisa com busca extensiva e mantido para a otimização com algoritmo genético. 104

Figura 4.2 Representação da pré-seleção de uma rede de 20 sensores para gerar uma rede de doze sensores: em cada quadrante, os sensores numerados representam uma das 126 possíveis combinações formadas por 9 sensores tomados 5 a 5 . Os 16 sensores encobertos formam o grupo de sensores descartados. 107 
Figura 4.3 Representação de uma topologia de 12 sensores selecionada para compor o espaço de soluções no processo de otimização topológica pelo método de busca extensiva: os sensores numerados representam apenas uma das 1.260.000 possíveis combinações formadas por 12 sensores, a partir do critério de seleção adotado. Todos os sensores encobertos estão descartados. 108

Figura 4.4 Topologia de rede e filtro otimizado para o isolamento do primeiro modo de vibrar. A frequência máxima alcançada é $1446 \mathrm{~Hz}$. 109

Figura 4.5 Topologia de rede e filtros otimizados para o isolamento dos dois primeiros modos de vibrar. A frequência máxima alcançada é $1188 \mathrm{~Hz}$.

Figura 4.6 Topologia de rede e filtros otimizados para o isolamento dos três primeiros modos de vibrar. A frequência máxima alcançada é $1113.5 \mathrm{~Hz}$.

Figura 4.7 Topologia de rede e filtros otimizados para o isolamento dos quatro primeiros modos de vibrar. A frequência máxima alcançada é $893 \mathrm{~Hz}$.

Figura 4.8 Topologia de rede e filtro otimizado para o isolamento do primeiro modo de vibrar. O filtro apresenta desempenho ótimo até aproximadamente $1.200 \mathrm{~Hz}$.

Figura 4.9 Topologia de rede e filtros otimizados para o isolamento dos dois primeiros modos de vibrar. Os modos residuais são filtrados até $1000 \mathrm{~Hz}$. Erros inferiores a 2\% são medidos na banda de frequência otimizada.

Figura 4.10 Topologia de rede e filtros otimizados para o isolamento dos três primeiros modos de vibrar. Os modos residuais são filtrados até $1000 \mathrm{~Hz}$. Erros inferiores a 3,5\% são medidos na banda de frequência otimizada. 111 
Figura 4.11 Topologia de rede e filtros otimizados para o isolamento dos quatro primeiros modos de vibrar. Os modos residuais são filtrados até $1000 \mathrm{~Hz}$. Erros inferiores a 6,5\% são medidos na banda de frequência otimizada.

Figura 4.12 Representação de uma combinação típica de sensores que define uma possível solução ótima para o problema de otimização topológica.....113

Figura 4.13 - Representação esquemática da operação de mutação: O sensor de índice 21 no indivíduo selecionado para mutação é substituído pelo sensor de índice 35 originalmente no conjunto de índices complementar, sendo ambos os índices escolhidos aleatoriamente. 114

Figura 4.14 Representação esquemática da operação de cruzamento: O dígito 1 no vetor binário está associado ao indivíduo (pai) da esquerda, enquanto que o dígito 0 está associado ao indivíduo da direta. $\mathrm{O}$ novo indivíduo (filho) é formado pelos genes de um pai correspondentes às posições do dígito 1 e pelos genes do outro pai correspondentes às posições do dígito 0 no vetor binário 115

Figura 4.15 Fluxograma básico para o processo de otimização topológica a partir de um algoritmo genético clássico. 119

Figura 4.16 Evolução do desempenho da média das frequências máximas em termos do tamanho da população, para diferentes taxas de cruzamento. 121

Figura 4.17 Evolução do desempenho do algoritmo em função do número de gerações forçadas.

Figura 4.18 Avaliação de desempenho e custo computacional do algoritmo genético para diferentes tamanhos de população. 123

Figura 4.19 Topologia de rede e filtro otimizado para o isolamento do primeiro modo de vibrar. A frequência máxima alcançada é $1890 \mathrm{~Hz}$. 124 
Figura 4.20 Topologia de rede e filtros otimizados para o isolamento dos dois primeiros modos de vibrar. A frequência máxima alcançada é $1262 \mathrm{~Hz}$.

Figura 4.21 Topologia de rede e filtros otimizados para o isolamento dos três primeiros modos de vibrar. A frequência máxima alcançada é $1147 \mathrm{~Hz}$.

Figura 4.22 Topologia de rede e filtros otimizados para o isolamento dos quatro primeiros modos de vibração. A frequência máxima alcançada é $980 \mathrm{~Hz}$ 125

Figura 4.23 Topologia de rede ótima e filtro modal projetado para isolar o primeiro modo de vibrar até $1000 \mathrm{~Hz}$, em escala linear. 126

Figura 4.24 Filtro modal projetado para isolar o primeiro modo de vibrar até $1000 \mathrm{~Hz}$, em escala logarítmica $(\mathrm{dB})$. 126

Figura 4.25 Topologia de rede ótima e filtro modal projetodo para isolar o segundo modo de vibrar até $1000 \mathrm{~Hz}$. 126

Figura 4.26 Topologia de rede ótima e filtro modal projetado para isolar o terceiro modo de vibrar até $1000 \mathrm{~Hz}$. 127

Figura 4.27 Topologia rede e filtros otimizados para o isolamento dos dois primeiros modos de vibrar. Os modos residuais são filtrados até 1000Hz. Erros inferiores a 1,5\% são medidos na banda de frequência otimizada. 127

Figura 4.28 Filtro para o primeiro modo de vibrar, obtido a partir da topologia de rede otimizada para isolar os dois primeiros modos de vibrar até $1000 \mathrm{~Hz}$, em escala logarítmica $(\mathrm{dB})$. 127

Figura 4.29 Filtro para o segundo modo de vibrar, obtido a partir da topologia de rede otimizada para isolar os dois primeiros modos de vibrar até $1000 \mathrm{~Hz}$, em escala logarítmica $(\mathrm{dB})$. 128 
Figura 4.30 Topologia de rede e filtros otimizados para o isolamento dos três primeiros modos de vibrar. Os modos residuais são filtrados até $1000 \mathrm{~Hz}$. Erros inferiores a $2 \%$ são medidos na banda de frequência otimizada. 128

Figura 4.31 Topologia de rede e filtros otimizados para o isolamento dos quatro primeiros modos de vibrar. Os modos residuais são filtrados até $1000 \mathrm{~Hz}$. Erros inferiores a 2,5\% são medidos na banda de frequência otimizada. 128

Figura 4.32 Topologia de rede e filtros otimizados para o isolamento dos cinco primeiros modos de vibrar. Os modos residuais são filtrados até $1000 \mathrm{~Hz}$. Erros inferiores a $4 \%$ são medidos na banda de frequência otimizada. .129

Figura 4.33 Topologia de rede e filtros otimizados para o isolamento dos dois primeiros modos de vibrar até a frequência máxima de $1200 \mathrm{~Hz}$. Erros residuais pouco superiores a 2,5\% são medidos na banda de frequência otimizada. .129

Figura 4.34 Topologia de rede e filtros otimizados para o isolamento dos três primeiros modos de vibrar até a frequência máxima de $1200 \mathrm{~Hz}$. O erro residual máximo na banda de frequência otimizada está em torno de $5 \%$.

Figura 4.35 Placa de alumínio remodelada a partir de diferentes topologias de rede otimizadas para diferentes conjuntos de filtros modais. .134

Figura 4.36 Comparação entre os filtros modais projetados para isolar o primeiro e o segundo modos de vibrar com (-) e sem (--) os vinte e quatro sensores sensores inativos. a) primeiro modo, b) segundo modo. 135

Figura 4.37 Comparação entre os filtros modais projetados para isolar o primeiro e o segundo modos de vibrar com (-) e sem (--) os vinte e quatro sensores sensores inativos. a) primeiro modo, b) segundo modo. 136 
Figura 4.38 Comparação entre os filtros modais projetados para isolar o primeiro, segundo e o tercerio modos de vibrar com (-) e sem (--) os vinte e quatro sensores sensores inativos. a) primeiro modo, b) segundo modo, c) terceiro modo. 137

Figura 4.39 Comparação entre os filtros modais projetados para isolar o primeiro, segundo, tercerio e o quarto modos de vibrar com (-) e sem (--) os vinte e quatro sensores sensores inativos. a) primeiro modo, b) segundo modo, c) terceiro modo e d) quarto modo. 138

Figura 4.40 Comparação entre os filtros modais projetados para isolar o primeiro, segundo, tercerio e o quarto modos de vibração com (-) e sem (--) os vinte e quatro sensores sensores inativos. Neste caso, a matriz de resposta em frequência é truncada em $1000 \mathrm{~Hz}$. a) primeiro modo, b) segundo modo. 140 


\section{Introdução}

\subsection{Introdução geral}

A modelagem de estruturas flexíveis e o desenvolvimento de técnicas de controle ativo e passivo aplicadas à estruturas reais têm sido alvo de intensas pesquisas. Trabalhos relevantes indicam que estratégias de controle e detecção de falhas estruturais podem ser substancialmente beneficiadas por uma redução na complexidade da resposta dinâmica do sistema cuja leitura, em geral, se dá pelo uso de sensores.

Filtros modais são projetados para reduzir a resposta dinâmica de um sistema à componentes fundamentais, correspondentes aos modos de vibrar. Um filtro eficiente preserva um conjunto seleto de modos de vibrar (modos alvos) e filtra todos os demais modos presentes em uma faixa prescrita de frequência (modos residuais).

O desenvolvimento de filtros modais requer o uso de sensores distribuídos ou redes de sensores. Isto tem sido viabilizado pelo desenvolvimento de sensores na forma de camadas ou pastilhas finas de materiais piezelétricos. De fato, materiais piezelétricos (particularmente piezocerâmicas) têm sido extensivamente estudados para fins de aplicações como sensores e atuadores, devido a possibilidade de construí-los como dispositivos leves e compactos, em formas geométricas variadas. Pastilhas cerâmicas finas têm sido fabricadas em escala industrial e podem ser adquiridas com custos relativamente baixos. 
O desempenho de um filtro modal derivado a partir de uma rede de sensores piezelétricos discretos, mediante a soma ponderada dos sinais de tensão medidos em cada sensor, pode ser maximizado pelo posicionamento ótimo dos sensores sobre a estrutura monitorada. A ponderação dos sinais de tensão dos sensores é por si só um problema de otimização, tradicionalmente tratado pelo método dos mínimos quadrados. Quando uma rede de sensores fixos é considerada, os principais parâmetros de otimização podem ser o tamanho e a forma geométrica dos sensores, além dos próprios coeficientes que ponderam os sinais de tensão a serem somados.

Não obstante, a inclusão da topologia da rede de sensores como uma variável de projeto para a construção de filtros modais de alto desempenho exige a definição de uma estratégia de otimização. No caso em que um número finito de topologias de rede serão avaliadas, o problema pode ser posto em termos de um processo de otimização combinatorial. Embora problemas envolvendo otimização combinatorial sejam de difícil formulação analítica, trabalhos recentes apontam para um bom desempenho das metaheurísticas na solução de tais problemas.

Uma das metodologias interessantes para este tipo de problema consiste nos algoritmos genéticos, que são ferramentas heurísticas baseadas em princípios evolutivos e podem ser implementados na forma de códigos computacionais simples.

Este trabalho se apresenta como um agregado de métodos e estratégias de otimização, nos quais são considerados, além do próprio desempenho dos filtros, os custos computacional e experimental inerentes à cada etapa do processo. Não obstante, as técnicas utilizadas para otimizar o desempenho de filtros modais obtidos a partir dos sinais de tensão de sensores piezelétricos podem ser aplicadas para redes de acelerômetros e demais tipos de sensores discretos. 


\subsection{Análise bibliográfica}

Esta seção apresenta uma revisão bibliográfica sobre os principais temas tratados neste trabalho, a saber: i) materiais piezelétricos, ii) modelagem de estruturas piezelétricas pelo método de elementos finitos, iii) filtros modais e aplicações, e iv) otimização de estruturas inteligentes utilizando algoritmos genéticos.

\subsubsection{Materiais piezelétricos}

Materiais piezelétricos integram uma seleta classe de materiais que apresentam propriedades funcionais especiais, denominados materiais inteligentes (Smart Materials). Materiais piezelétricos são particularmente difundidos devido à sua vasta aplicabilidade em projetos industriais e pesquisas científicas.

O efeito piezelétrico direto (efeito sensor) consiste na geração de um campo elétrico interno, devido a uma pressão mecânica exercida sobre o material. Sua descoberta é atribuída aos irmãos Pierre e Jacques Curie, no ano de 1880. No ano seguinte, por meio de análises termodinâmicas, Lippman previu a existência do efeito piezelétrico inverso (efeito atuador), que consiste em deformações elásticas induzidas pela ação de um campo elétrico externo. Segundo Anderson e Hagood (1994), materiais piezelétricos podem compor dispositivos integrados atuando simultaneamente como sensor e atuador.

A primeira aplicação tecnológica do efeito piezelétrico é atribuída a Paul Langevin, que desenvolveu um sonar baseado nas propriedades piezelétricas de cristais de quartzo (transdutor tipo langevin), durante a primeira grande guerra mundial, para gerar ultra-som na faixa de algumas dezenas de $\mathrm{kHz}$. 
Após a primeira guerra mundial, os esforços se concentraram no desenvolvimento de materiais piezelétricos sintéticos. Roberts (1947) descobriu que cerâmicas ferroelétricas de titanato de bário (BaTiO3) apresentavam propriedades piezelétricas quando polarizadas. Jaffe et al. (1954) estudaram soluções sólidas de $\mathrm{PbZrO3}-\mathrm{PbTiO} 3$, que resultaram na obtenção das cerâmicas de Titanato Zirconato de Chumbo. Estes trabalhos são considerados o ponto de partida para o desenvolvimento dos materiais piezocerâmicos sintéticos modernos.

O desenvolvimento das cerâmicas piezelétricas revolucionou a pesquisa básica e diversificou as áreas de aplicação dos materiais piezelétricos. Em relação aos cristais de quartzo, as cerâmicas apresentam melhores propriedades piezelétricas quando polarizadas.

Atualmente, há duas grandes frentes de pesquisa envolvendo materiais piezelétricos: i) caracterização das propriedades físicas dos materiais piezelétricos e desenvolvimento de novos materiais sintéticos altamente eficientes em aplicações industriais e ii) desenvolvimento de modelos matemáticos para a simulação de suas propriedades funcionais.

A caracterização de propriedades físicas é necessária para o desenvolvimento de modelos matemáticos confiáveis. Por conseguinte, modelos bem formulados podem ser empregados na modelagem e simulação funcional destes materiais.

\subsubsection{Modelagem de estruturas piezelétricas pelo método de elementos finitos}

O desenvolvimento de modelos matemáticos com um grau aceitável de precisão torna viável o uso de softwares comerciais em projetos envolvendo a simulação numérica de materiais e estruturas inteligentes. $\mathrm{O}$ uso destes softwares poupa ao pesquisador, ou ao engenheiro de projeto, o ônus inerente ao desenvolvimento de um modelo próprio de elementos finitos. Em muitos casos, os 
resultados podem ser obtidos a partir de análises rápidas e confiáveis, utilizando alguns dos principais softwares de elementos finitos disponíveis no mercado: ANSYS, NASTRAN, ABAQUS, entre outros.

No entanto, a maioria dos softwares de elementos finitos ainda apresentam uma modelagem restrita em relação aos materiais funcionais de maior interesse, o que limita a modelagem e a simulação das estruturas inteligentes. Atualmente, grande parte das pesquisas objetivam ampliar os elementos funcionais disponíveis nas bibliotecas dos softwares comerciais e desenvolver uma base sólida de conhecimento sobre o comportamento de sistemas inteligentes integrados.

Allik e Hughes (1970) desenvolveram um modelo numérico baseado em formulação variacional considerando um elemento piezelétrico tetraédrico com 16 graus de liberdade (12 graus de liberdade para deslocamentos e 4 graus de liberdade elétricos), para aplicações em problemas de vibração estrutural.

Segundo Tzou (1989), a partir de 1980, intensificaram-se os esforços para a modelagem de estruturas inteligentes pelo método dos elementos finitos. Em Tzou e Tseng (1990), um novo modelo de elementos finitos com grau de liberdade interno foi proposto para avaliar o desempenho de elementos do tipo placa ou casca com camadas de material piezelétrico integradas à estrutura. Os efeitos sensor e atuador do material piezelétrico permitiram concluir que a voltagem induzida em cada modo de vibrar de uma placa fina em regime de vibrações livre é determinada por deformações locais na estrutura.

Ha et al. (1992) apresentaram um modelo de elementos finitos para estudar o comportamento estático e dinâmico uma placa compósita com cerâmicas piezelétricas distribuídas, estando a estrutura sujeita a carregamentos mecânico e elétrico. $\mathrm{O}$ modelo foi derivado de princípios variacionais, considerando a energia total da estrutura e a energia potencial elétrica das piezocerâmicas.

Varadan et al. (1993) apresentaram uma versão modificada de um transdutor piezelétrico flexional axi-simétrico do tipo Langevin. Um modelo de elementos 
finitos considerando um grau de liberdade elétrico foi utilizado para avaliar os efeitos sensor e atuador do transdutor com perspectiva de aplicações em vibroacústica.

Benjeddou et al. (1997) modelaram vigas do tipo sanduíche compostas por materiais elásticos e piezelétricos. Dois mecanismos de atuação foram considerados: i) um núcleo elástico coberto por duas camadas piezelétricas transversalmente polarizadas; e ii) um núcleo piezelétrico axialmente polarizado coberto por duas camadas de material elástico. As camadas superficiais foram modeladas pela teoria de Euler-Bernoulli e o núcleo, pela teoria de Timoshenko.

Lam et al. (1997) desenvolveram um modelo de elementos finitos baseado na teoria clássica de placas laminadas, utilizando princípios variacionais, com objetivos de estudar o controle ativo de uma placa composta com sensores e atuadores piezelétricos distribuídos. Um algoritmo de controle por retroalimentação negativa de velocidade em malha fechada foi utilizado para acoplar os efeitos piezelétricos de sensor e atuador. Resultados numéricos validaram a eficácia do modelo para uso em projetos de controle ativo.

Lima (1999) considerou modelagens analítica e numérica de estruturas do tipo placas de Kirchhoff e Mindlin-Reissner e vigas de Euler-Bernoulli e Timoshenko em interação dinâmica com elementos piezelétricos integrados. Modelos numéricos baseados no método de elementos finitos foram desenvolvidos pela aplicação de princípios variacionais aos meios piezelétricos. Experimentos para a validação dos modelos e implementação de estratégias de controle ativo em uma estrutura do tipo viga foram realizados.

Hernandes et al. (2000) utilizaram um modelo de elementos finitos baseado na teoria de placa de Reissner-Mindlin para estudar a aplicação de atuadores piezelétricos para o enrijecimento ativo.

Trindade et al. (2001a) usaram um modelo de elementos finitos para estudar o amortecimento ativo-passivo em uma estrutura sanduíche, tipo viga, composta por 
um núcleo viscoelástico coberto por duas camadas de material elástico e piezelétrico. O modelo de elementos finitos considerou funções de forma lineares (Lagrange) para deslocamentos axiais e funções cúbicas (Hermite) para deflexões transversais. Em Trindade et al. (2001b), o modelo acima descrito foi validado para três diferentes vigas: i) viga composta por material elástico, adesivo e camada piezelétrica; ii) viga laminada e iii) viga sanduíche com atuadores piezelétricos.

Abreu et al. (2004) utilizaram a teoria de placa de Kirchhoff para a modelagem numérica e análise dos comportamentos estático e dinâmico de placas compósitas com camadas piezelétricas simetricamente coladas em ambas as superfícies. Um conjunto de simulações numéricas foi realizado e os resultados obtidos foram comparados aqueles obtidos a partir do modelo de elementos finitos do ANSYS e demais formulações analíticas encontradas na literatura.

Kögl e Bucalem (2005) propuseram um modelo de elementos finitos para estruturas do tipo placa e casca compostas por várias camadas de material piezelétrico atuando como sensores e atuadores. A nova abordagem consistiu no uso de elementos finitos livres de travamento por cisalhamento e membrana (MITC), e equações de vínculo adequadas para garantir uma perfeita colagem entre as camadas.

Costa et al. (2007) propuseram um modelo reduzido para estruturas do tipo placa compostas por camadas de materiais piezelétricas distintos, considerando os parâmetros mecânicos e elétricos parcialmente desacoplados. O efeito atuador é otimizado pela aplicação de um potencial elétrico que maximiza o deslocamento mecânico e minimiza o potencial elétrico induzido na placa (regiões de excitação), e o efeito sensor, pela aplicação de um carregamento mecânico que maximiza o potencial elétrico induzido na placa e minimiza as regiões de excitação.

Sylvain e Guillaume (2007) analisaram o desempenho dos softwares ANSYS e SDT (Structural Dynamic Toolbox) aplicados à modelagem de materiais piezelétricos pelo método de elementos finitos, objetivando o cálculo do fator de acoplamento 
eletromecânico (EMCC). Foram consideradas diferentes propriedades materiais e diferentes definições para o EMCC. Sylvain e Guillaume (2007) apresentaram aspectos técnicos relevantes para a construção do modelo estrutural e abordaram o efeito dos eletrodos de condução (condição de equipotencialidade) para a correta estimativa do EMCC.

Godoy (2008) modelou uma placa laminada com sensores piezelétricos integrados e conectados a um circuito tipo shunt resistivo-indutivo (RL), a partir de um modelo de elementos finitos implementado em MATLAB. Teorias de primeira e terceira ordem foram consideradas. Uma análise paramétrica foi utilizada para encontrar o posicionamento de pastilhas piezelétricas operando nos modos de extensão e cisalhamento que maximiza o coeficiente de acoplamento eletromecânico para os quatro primeiros modos de vibrar da estrutura.

Nas últimas duas décadas, um grande número de artigos dedicados à revisão do estado da arte e percepção de tendências na formulação e aplicação do método de elementos finitos à modelagem de elementos funcionais e estruturas adaptativas tem sido publicado. Uma extensa revisão bibliográfica sobre o assunto pode ser encontrada em (BENJEDDOU, 2000).

\subsubsection{Filtros modais e aplicações}

O desempenho de sistemas integrados aplicados ao controle de vibrações pode ser substancialmente beneficiado pelo uso de filtros modais de alta qualidade. Neste contexto, o desenvolvimento de técnicas para controle ativo usando sensores e atuadores modais integrados têm sido alvo de intensa pesquisa. Sensores e atuadores modais operando em malha fechada permitem a observabilidade e controlabilidade de modos específicos de vibração, de forma independente, reduzindo a aparente 
complexidade dinâmica do sistema e a energia envolvida no processo de controle, de forma a torná-lo mais estável.

Embora projetos pioneiros (LEE; MOON, 1990) tenham considerado o desenvolvimento de sensores e atuadores modais contínuos, a evolução das técnicas de filtragem modal e suas aplicações em sistemas integrados para controle ativo de vibrações indicam uma série de vantagens no uso de redes de sensores discretos (SHELLEY, 1991). Estas redes, em geral, são compostas por sensores na forma de pequenas pastilhas piezocerâmicas, enquanto que sensores modais contínuos são geometricamente projetados para garantir um eficaz acoplamento de forma entre o material sensitivo e as deformações elásticas da estrutura correspondentes aos modos de interesse.

A ponderação dos sinais de uma rede de sensores discretos é reconfigurável via software, de forma que os sinais de uma mesma rede possam ser utilizados em diferentes projetos de filtros modais. Daí a versatilidade do uso de uma rede de sensores discretos. Em geral, a otimização dos coeficientes de ponderação está condicionada ao conjunto de modos alvos e à banda de frequência na qual se busca um desempenho ótimo para o filtro.

Meirovitch e Baruh (1982) apresentaram uma estratégia de controle ótimo no espaço modal, aplicado a sistemas de parâmetros distribuídos, sem a necessidade de discretização espacial. O objetivo era desacoplar um conjunto de coordenadas modais e controlar os respectivos modos de vibrar de forma independente, modelando a resposta dinâmica do sistema com um conjunto de respostas de sistemas de segunda ordem em paralelo. $\mathrm{O}$ método de isolamento modal, que reduz o sistema a um conjunto equivalente de sistemas independentes de segunda ordem, foi chamado de filtro modal. O filtro modal proposto por Meirovitch e Baruh (1982) estima as coordenadas modais interpolando medidas físicas de deslocamento e velocidade, aquisitadas em pontos específicos de uma estrutura. Este trabalho 
seminal definiu as bases conceituais para a implementação de filtros modais em sistemas de parâmetros distribuídos.

Lee e Moon (1990) projetaram sensores e atuadores modais contínuos a partir da geometria de camadas finas de material piezelétrico (PVDF) depositado sobre as faces de uma placa metálica delgada e obtiveram bons resultados no isolamento dos dois primeiros modos de vibrar.

Sumaly e Cudney (1991) usaram dois acelerômetros fixos em uma viga engastada atuando como uma rede unidimensional de sensores e obtiveram um melhor desempenho experimental no isolamento de um modo alvo, em relação aquele obtido pelo uso de sensores contínuos.

Shelley (1991) estudou a robustez e o desempenho de filtros modais discretos para estruturas de parâmetros distribuídos, em termos do número e do posicionamento dos sensores. Resultados experimentais foram obtidos a partir de uma rede de acelerômetros distribuídos sobre uma estrutura do tipo treliça, em forma de cruz.

Fripp (2000) estudou técnicas para o desenvolvimento e implementação prática de filtros modais discretos de alto desempenho, utilizando como estrutura de teste um modelo reduzido de fuselagem de avião. $O$ filtro modal permitiu o controle ativo de uma estrutura de alta complexidade dinâmica, a partir de um algoritmo simples de controle. Diferentes métodos para calcular os coeficientes de ponderação conduzindo ao filtro ótimo foram implementadas e comparadas.

Preumont et al. (2003), em trabalho experimental, utilizaram uma rede composta por 32 sensores piezelétricos na forma de pequenas pastilhas distribuídas regularmente sobre uma placa de vidro engastada. Os coeficientes de ponderação para os sinais da rede foram calculados pelo método de mínimos quadrados baseado na pseudo-inversão, por decomposição em valores singulares, das matrizes complexas de resposta em frequência medidas no sensores (FRFs). Neste trabalho, Preumont et al. (2003) analisaram a distribuição de tensão induzida na rede de 
sensores em diferentes modos de vibrar e concluíram que o desempenho limitado dos filtros modais obtidos pela ponderação dos sinais de tensão ocorre devido ao fenômeno de Spatial Aliasing, sugerindo uma relação aproximada entre o número de sensores ativos na rede e o número de modos residuais que podem ser efetivamente filtrados.

Deraemaeker e Preumont (2005) apresentaram uma nova técnica para detecção de falhas estruturais a partir do uso de uma rede composta por um grande número de sensores discretos, para fins de filtragem modal. A detecção de falha é baseada nas características da FRF filtrada: falhas locais (variação local de rigidez) originam picos espúrios, enquanto que alterações térmicas na estrutura (variação global de rigidez) apenas deslocam os picos de ressonância, mantendo inalterada a sua forma. Foi considerada uma abordagem numérica para o caso de uma viga simplesmente apoiada.

Kailin e Friswell (2007) estudaram o desempenho de sensores modais distribuídos sobre uma placa retangular uniforme simplesmente apoiada. As formas modais da placa foram obtidas a partir de um modelo analítico e a geometria dos sensores foi otimizada de acordo com projetos específicos de filtros modais.

\subsubsection{Otimização de estruturas inteligentes utilizando algoritmos genéticos}

Processos de otimização topológica são comuns em projetos estruturais avançados e podem ter como objetivos concorrentes minimizar os custos e a quantidade de material utilizada, enquanto maximizar a resistência estrutural e o desempenho de dispositivos mecânicos agregados (BEGG; LIU, 2000).

Não obstante, inúmeros autores (FRECKER, 2003) têm reconhecido a importância da topologia da rede de sensores e atuadores integrados, com perspectivas de aplicações em projetos de controle modal e semi-modal. O problema 
de otimização topológica de uma rede de elementos discretos, em geral, pode ser reduzido a um problema de otimização combinatorial. A abordagem moderna aos problemas de otimização combinatorial, que em geral estão associados a modelos não lineares e espaços de soluções extensos e descontínuos, sugere o uso de métodos não determinísticos, tais como redes neurais, lógica nebulosa e algoritmos genéticos.

Segundo Langley (1999), a necessidade de se otimizar o desempenho funcional de sistemas inteligentes integrados tem impulsionado o desenvolvimento de metodologias formais de otimização aplicadas a projetos de estruturas inteligentes e ao posicionamento ótimo de sensores e atuadores.

Além disso, técnicas de otimização podem também ser utilizadas para o projeto de transdutores piezelétricos. Silva e Kikuchi (1997) propuseram uma metodologia para obter transdutores piezelétricos com alto índice de conversão de energia eletromecânica em modos de vibrar específicos. O trabalho considerou a otimização topológica de transdutores piezelétricos pelo método de elementos finitos e o uso de programação linear sequencial (SLP). O projeto de otimização topológica utilizado consiste em determinar a distribuição de material para a qual uma determinada função objetivo seja otimizada, de forma que o modelo do transdutor seja definido por regiões densas e vazias. Os resultados indicaram ser possível obter transdutores com melhor desempenho que aqueles obtidos por simples otimização geométrica.

Frecker (2003) fornece uma ampla revisão bibliográfica acerca dos avanços em processos de otimização em estruturas ativamente controladas, redes de sensores e atuadores e sistemas de acionamento eletrônico. Embora o foco principal recaia sobre projetos de otimização envolvendo atuadores piezocerâmicos, relevantes trabalhos abordando o uso de atuadores baseados em ligas de memória de forma e materiais magnetoestritivos estão relacionados.

Estudos relacionados à otimização do número e localização de elementos sensitivos definindo uma rede de sensores discretos têm se concentrado em três 
principais áreas de pesquisa: controle de estruturas flexíveis, identificação de parâmetros e detecção de falhas estruturais (STASZEWSKI et al. 2000).

Algoritmos genéticos (AG) foram inicialmente desenvolvidos por John Holland e colaboradores, na Universidade de Michigan (GOLDBERG, 1983). São métodos heurísticos baseados em princípios de genética evolutiva, representados por códigos computacionais simples aplicados a processos de busca e otimização funcional de sistemas dinâmicos. O uso de um algoritmo genético é possível mediante uma codificação apropriada do problema de otimização. Alguns conceitos básicos da teoria da evolução de Charles Darwin são redefinidos do ponto de vista da computação evolutiva.

Um indivíduo é um conjunto finito de parâmetros discretos (string), relacionados direta ou indiretamente à variável de projeto que se deseja otimizar. Cada parâmetro, por sua vez, define um gene do indivíduo. Os genes carregam as informações vitais sobre a capacidade de sobrevivência e adaptabilidade às adversidades do meio para se reproduzir (aptidão), ou seja, o potencial evolutivo de cada indivíduo. O conjunto de genes que compõe um indivíduo define o seu material genético. Cada indivíduo representa uma potencial solução para o problema de otimização em estudo.

Em sistemas artificiais, os mecanismos de seleção natural são desempenhados por um critério analítico, denominado função objetivo ou função custo (fitness). O propósito da função objetivo é classificar cada indivíduo de acordo com a sua aptidão ao critério de seleção adotado. A função objetivo define uma estratégia para se alcançar os objetivos de otimização.

Uma população é um conjunto finito de indivíduos, cada qual com um grau específico de aptidão. A população define o espaço de pesquisa onde se encontram as possíveis soluções para o problema de otimização. Uma população inicial é um qualquer subespaço do espaço de pesquisa, geralmente escolhido de forma 
estocástica. A população inicial é o ponto de partida para pesquisas de busca e otimização com algoritmos genéticos.

O algoritmo genético aplica operações básicas de reprodução (elitismo, cruzamento e mutação) sobre os indivíduos da população inicial com o propósito de gerar novas gerações de indivíduos e diversificar o material genético disponível para análise. Por meio desta estratégia, o algoritmo genético expande continuamente o seu espaço de pesquisa. As taxas de elitismo, cruzamento e mutação são ajustáveis e, em geral, variam de acordo com a aplicação do algorítimo genético. Uma descrição geral sobre a estrutura de um algoritmo genético e suas aplicações podem ser encontrada em (GOLDBERG, 1989; DE JONG, 2006; BEASLEY ET AL, 1993).

Worden et al. (1995) compararam o desempenho de algoritmos genéticos aplicados a problemas de otimização de posicionamento de sensores discretos para detecção de falha estrutural, utilizando codificações gênicas na forma de números binários e inteiros (cada gene indexa a posição de um sensor). $\mathrm{O}$ estudo apontou a maior eficácia no uso de codificação gênica em termos de números inteiros.

Han e Lee (1999) utilizaram um algoritmo genético para otimizar o posicionamento de sensores e atuadores sobre uma placa de material compósito, definindo uma função objetivo com base em critérios de observabilidade, controlabilidade e estabilidade no processo de controle integrado. Resultados experimentais indicaram o controle efetivo dos modos alvos, com pequeno efeito sobre os modos residuais, e a robustez do sistema em malha fechada à variação de parâmetros.

Sadri et al. (1999) modelaram estruturas do tipo viga incorporando atuadores piezelétricos. As equações dinâmicas do modelo, relacionando as deformações piezelétricas àquelas induzidas na estrutura, foram obtidas pelo método de RayleighRitz para uma placa isotrópica simplesmente apoiada. Critérios para a otimização da topologia dos atuadores piezelétricos baseados em controlabilidade modal e 
controlabilidade Gramiana foram considerados e avaliados pelo uso de um algoritmo genético.

Begg e Liu (2000) apontaram a eficiência dos algoritmos genéticos aplicados a projetos avançados de otimização topológica envolvendo componentes discretos em estruturas inteligentes.

Staszewski et al. (2000) combinaram redes neurais e algoritmo genético para otimizar o posicionamento de sensores piezelétricos discretos visando a detecção e de falhas induzidas por impactos superficiais em um painel compósito. O estudo experimental avaliou o desempenho do método de otimização combinatorial adotado, com base nos resultados de uma busca extensiva, e indicou a eficácia do método de otimização topológica com algoritmos genéticos aplicado a problemas de detecção de falhas em estruturas flexíveis.

Worden e Burrows (2001) desenvolveram uma estratégia para detecção e classificação de falhas estruturais utilizando otimização combinatorial e métodos gerais de computação evolutiva (lógica nebulosa, algoritmos genéticos e arrefecimento simulado) para encontrar o posicionamento ótimo (topologia) de um grupo de sensores piezelétricos discretos. Uma revisão sobre trabalhos relacionados ao posicionamento ótimo de sensores para detecção de falhas estruturais é apresentada.

Yang et al. (2006) desenvolveram um modelo de casca cilíndrica com sensores e atuadores piezelétricos integrados e aplicaram um algoritmo genético modificado para otimizar simultaneamente as variáveis de projeto consideradas: posição e tamanho dos sensores/atuadores (S/As) e fator de ganho no controlador integrado. $\mathrm{O}$ sistema de controle foi otimizado para (S/As) colocalizados, com base no método da dissipação de energia (LEE; CHEN, 1994) . Resultados numéricos indicaram que significativa supressão de vibração estrutural pode ser obtida pala otimização do posicionamento dos sensores e do ganho do controlador e sugerem o posicionamento de (S/As) piezelétricos em regiões separadas por linhas nodais. 
Trindade (2007) avaliou a influência da variação de parâmetros topológicos e geométricos sobre o desempenho de um mecanismo de controle híbrido aplicado a uma viga de alumínio bi-engastada. O sistema foi modelado pelo método dos elementos finitos, na forma de uma estrutura do tipo sanduíche, composta por uma camada de material viscoelástico (elemento passivo), duas camadas de alumínio e um conjunto de três atuadores piezelétricos na forma de pequenas pastilhas. Um algoritmo genético foi adotado para otimizar simultaneamente parâmetros geométricos (espessura das camadas na estrutura sanduíche) e topológicos (posição relativa entre as camadas e os atuadores piezelétricos), com base em uma função custo objetivando maximizar o amortecimento da estrutura e minimizar a massa adicionada.

Cicogna (2008) desenvolveu uma técnica para estimar funções de resposta em frequência angulares (FRFAs), baseada na relação direta entre curvaturas locais na estrutura e voltagem elétrica induzida em sensores bimorph. Este trabalho considerou estruturas do tipo viga engastada-livre e placa simplesmente apoiada. Um algoritmo genético foi desenvolvido para otimizar as dimensões e o posicionamento dos sensores bimorph. Um modelo em elementos finitos para a placa com sensores piezelétricos bimorph foi construído no software ANSYS e os resultados numéricos para a viga foram validados experimentalmente.

\subsection{Objetivos da dissertação}

O objetivo deste trabalho é estudar a influência da topologia de uma rede de sensores piezelétricos discretos sobre o comportamento de um conjunto de filtros modais obtidos pela soma ponderada de sinais de tensão e desenvolver uma estratégia robusta de otimização topológica para maximizar o desempenho dos filtros modais na banda de frequência. 
Uma vez definida as propriedades geométricas e materiais dos sensores, bem como o método utilizado para a ponderação dos sinais de tensão, o desempenho de um dado filtro modal será determinado pelo número de sensores ativos e pela topologia da rede. O comportamento médio de um conjunto de filtros modais obtidos a partir de um grande número de topologias de rede permite relacionar a frequência de validade dos filtros ao número de sensores ativos na rede.

Os resultados numéricos obtidos para o modelo placa-pastilhas considerado neste trabalho indicam que, em média, tendo-se como alvo os primeiros modos de vibrar, os filtros modais derivados a partir de redes compostas por doze sensores apresentam alto desempenho até $800 \mathrm{~Hz}$, enquanto que filtros modais derivados a partir de redes compostas por dezesseis sensores apresentam alto desempenho até $1000 \mathrm{~Hz}$. Este acréscimo de $200 \mathrm{~Hz}$ representa a inclusão de quatro modos residuais na banda de frequência, conforme previsto pelo modelo de elementos finitos.

O escopo da otimização topológica é selecionar topologias de rede compostas por doze sensores que garantam filtros modais de alto desempenho até $1000 \mathrm{~Hz}$, para os cinco primeiros modos de vibrar. Desta forma, é possível alcançar filtros de alto desempenho e minimizar a complexidade aparente da resposta dinâmica do sistema, a partir de um número reduzido de sensores. A redução do número de sensores necessários ao filtro otimiza os custos e as dificuldades técnicas inerentes à implementação do projeto.

Em particular, os resultados apresentados neste trabalho poderão servir como base para pesquisas envolvendo a aplicação de filtros modais ao controle integrado e monitoramento de falhas estruturais. 


\section{Modelagem de estruturas piezelétricas}

\subsection{Revisão das leis de comportamento para materiais piezelétricos}

\subsubsection{Equações constitutivas para materiais elásticos}

Um meio material elástico pode ser deformado pela ação de forças superficiais concentradas ou distribuídas, que definem um campo de tensão mecânica interno ao material. A equação constitutiva de um meio material quantifica a relação entre os tensores de tensão mecânica e deformação elástica, em um ponto específico, em termos de um conjunto de parâmetros estruturais característicos do material.

Materiais elásticos apresentam comportamento constitutivo dependente apenas do estado momentâneo dos campos de tensão e deformação. Um meio material é dito homogêneo se apresenta as mesmas propriedades materiais em todos os seus pontos.

O modelo constitutivo linear para deformações infinitesimais é denominado Lei de Hook Generalizada. A forma geral da equação constitutiva para um material em regime de deformação linear é:

$$
\sigma_{i j}=c_{i j k l} \varepsilon_{k l}+\sigma_{i j}^{0}, \quad i, j, k, l=1,2,3
$$

na qual $\sigma_{i j}$ e $\varepsilon_{k l}$ denotam, respectivamente, as componentes dos tensores de tensão e deformação. $c_{i j k l}$ é o tensor de rigidez elástica do material e, $\sigma_{i j}^{0}$, a componente 
residual de tensão, que supõe-se nula aqui. De acordo com a notação tensorial, a eq. (2.1) representa o somatório de termos com índices repetidos: $k, l$.

O tensor de rigidez $c_{i j k l}$ é de quarta ordem e apresenta 81 componentes escalares. Em geral, propriedades de simetria dos tensores $\sigma, \varepsilon$, e do próprio tensor $c$, restringem o número de componentes $c_{i j k l}$ que são independentes.

Na ausência de acoplamento material externo, os momentos aplicados estão em equilíbrio e o tensor de tensão é simétrico (MALVERN, 1969) de forma que:

$$
\sigma_{i j}=\sigma_{j i}
$$

Seja $\mathbf{u}=\mathrm{u}_{1} \widehat{\mathbf{x}}_{1}+\mathrm{u}_{2} \widehat{\mathbf{x}}_{2}+\mathrm{u}_{3} \hat{\mathbf{x}}_{3}$ o vetor de deslocamento infinitesimal de um ponto material em um meio elástico. $\mathrm{O}$ tensor deformação infinitesimal está relacionado ao vetor deslocamento pela equação:

$$
\varepsilon_{i j}=\frac{1}{2}\left(\frac{\partial \boldsymbol{u}}{\partial x_{i}} \cdot \widehat{\boldsymbol{x}}_{\boldsymbol{j}}+\frac{\partial \boldsymbol{u}}{\partial x_{j}} \cdot \widehat{\boldsymbol{x}}_{\boldsymbol{i}}\right), \quad i, j=1,2,3
$$

Como mostra a eq.(2.3), o tensor de deformação infinitesimal é simétrico:

$$
\varepsilon_{i j}=\varepsilon_{j i}
$$

Se $i=j$, as componentes na eq. (2.4) representam deformações normais, caso contrário, representam deformações por cisalhamento. As simetrias dos tensores de tensão e deformação induzem, respectivamente, as seguintes simetrias no tensor de rigidez elástica:

$$
c_{i j k l}=c_{j i k l} .
$$




$$
c_{i j k l}=c_{i j l k}
$$

As condições de simetria representadas pelas eqs. (2.5) e (2.6) reduzem o tensor de rigidez elástica a 36 componentes independentes. Desta forma, a eq. (2.1) pode ser escrita na forma compacta:

$$
\begin{gathered}
\sigma_{i}=c_{i j} \varepsilon_{j} . \quad i, j=1,2, \ldots, 6 \\
\sigma_{1} \equiv \sigma_{11}, \sigma_{2} \equiv \sigma_{22}, \quad \sigma_{3} \equiv \sigma_{33}, \quad \sigma_{4} \equiv \sigma_{23}, \quad \sigma_{5} \equiv \sigma_{13}, \quad \sigma_{6} \equiv \sigma_{12} \\
\varepsilon_{1} \equiv \varepsilon_{11,} \varepsilon_{2} \equiv \varepsilon_{22,} \quad \varepsilon_{3} \equiv \varepsilon_{33,} \quad \varepsilon_{4} \equiv 2 \varepsilon_{23}, \quad \varepsilon_{5} \equiv 2 \varepsilon_{13,}, \varepsilon_{6} \equiv 2 \varepsilon_{12}
\end{gathered}
$$

A eq. (2.8) representa as componentes dos tensores de tensão e deformação em termos de notação contraída, denominada notação de engenharia, ou de Voigt-Kelvin.

A função energia potencial de deformação elástica pode ser obtida pela aplicação do conceito de trabalho virtual a estruturas sob carregamento. Se um meio material elástico admite uma função energia potencial, é possível demonstrar que:

$$
c_{i j k l}=c_{k l i j}
$$

A partir das propriedades de simetria (2.5), (2.6) e (2.9), conclui-se que o tensor de rigidez elástica possui 21 parâmetros independentes. A equação constitutiva, na sua forma reduzida para materiais anisotrópicos, que não apresentam planos de simetria material, é:

$$
\left\{\begin{array}{l}
\sigma_{1} \\
\sigma_{2} \\
\sigma_{3} \\
\sigma_{4} \\
\sigma_{5} \\
\sigma_{6}
\end{array}\right\}=\left[\begin{array}{llllll}
c_{11} & c_{12} & c_{13} & c_{14} & c_{15} & c_{16} \\
c_{12} & c_{22} & c_{23} & c_{24} & c_{24} & c_{25} \\
c_{13} & c_{23} & c_{33} & c_{34} & c_{35} & c_{36} \\
c_{14} & c_{24} & c_{34} & c_{44} & c_{45} & c_{46} \\
c_{15} & c_{25} & c_{35} & c_{45} & c_{55} & c_{56} \\
c_{16} & c_{26} & c_{36} & c_{46} & c_{56} & c_{66}
\end{array}\right]\left\{\begin{array}{l}
\varepsilon_{1} \\
\varepsilon_{2} \\
\varepsilon_{3} \\
\varepsilon_{4} \\
\varepsilon_{5} \\
\varepsilon_{6}
\end{array}\right\}
$$


Em geral, o tensor de elasticidade e a resposta constitutiva de um material dependem da orientação do sistema de coordenadas adotado: tais materiais são classificados como anisotrópicos. Por outro lado, se o material é isotrópico, o tensor de rigidez elástica é invariante por rotações do sistema de coordenadas. O conjunto de transformações lineares que preserva invariante o comportamento constitutivo do material é chamado grupo de simetria do material.

Alguns corpos apresentam propriedades materiais invariantes em direções específicas, que definem eixos e planos de simetria no material. Uma redução adicional ao número de coeficientes de elasticidade independentes pode ser alcançada em materiais que apresentam planos de simetria.

Materiais ortotrópicos apresentam, em geral, diferentes propriedades materiais, que são simétricas em relação a três planos ortogonais de simetria elástica. Note-se que a existência de dois planos de simetria implica na existência do terceiro plano.

Em materiais naturais ou sintéticos, simetrias em níveis moleculares manifestam-se em escala macroscópica e definem as propriedades de simetria da resposta constitutiva do material. Aplicando o grupo de simetria característico ao material ortotrópico: $\left\{\boldsymbol{L}^{(1)}, \boldsymbol{L}^{(2)}, \boldsymbol{L}^{(3)}\right\}$, para o qual:

$$
\left[\boldsymbol{L}^{(1)}\right]=\left[\begin{array}{ccc}
1 & 0 & 0 \\
0 & 1 & 0 \\
0 & 0 & -1
\end{array}\right], \quad\left[\boldsymbol{L}^{(2)}\right]=\left[\begin{array}{ccc}
-1 & 0 & 0 \\
0 & 1 & 0 \\
0 & 0 & 1
\end{array}\right], \quad\left[\boldsymbol{L}^{(3)}\right]=\left[\begin{array}{ccc}
1 & 0 & 0 \\
0 & -1 & 0 \\
0 & 0 & 1
\end{array}\right]
$$

demonstra-se que o número de coeficientes independentes na matriz de rigidez, em relação ao sistema de eixos de ortotropia, é reduzido a nove.

$$
\left\{\begin{array}{l}
\sigma_{1} \\
\sigma_{2} \\
\sigma_{3} \\
\sigma_{4} \\
\sigma_{5} \\
\sigma_{6}
\end{array}\right\}=\left[\begin{array}{cccccc}
c_{11} & c_{12} & c_{13} & 0 & 0 & 0 \\
c_{12} & c_{22} & c_{23} & 0 & 0 & 0 \\
c_{13} & c_{23} & c_{33} & 0 & 0 & 0 \\
0 & 0 & 0 & c_{44} & 0 & 0 \\
0 & 0 & 0 & 0 & c_{55} & 0 \\
0 & 0 & 0 & 0 & 0 & c_{66}
\end{array}\right]\left\{\begin{array}{l}
\varepsilon_{1} \\
\varepsilon_{2} \\
\varepsilon_{3} \\
\varepsilon_{4} \\
\varepsilon_{5} \\
\varepsilon_{6}
\end{array}\right\}
$$


A prática experimental recomenda a caracterização das propriedades mecânicas do material pela aplicação de cargas ou tensões externas. A inversão da eq. (2.12) exige a definição da matriz de flexibilidade, como definida a seguir:

$$
[s]=[c]^{-1}
$$

A matriz de flexibilidade preserva todas as propriedades de simetria material deduzidas para a matriz de rigidez, e ambas são simétricas. As eqs. (2.14) até (2.18) representam as relações entre os coeficientes da matrizes de rigidez e flexibilidade.

$$
\begin{gathered}
c_{11}=\frac{s_{22} s_{33}-s_{23}^{2}}{D} \quad c_{12}=\frac{s_{13} s_{23}-s_{12} s_{33}}{D} \\
c_{22}=\frac{s_{33} s_{11}-s_{13}^{2}}{D} \quad c_{13}=\frac{s_{12} s_{23}-s_{13} s_{22}}{D} \\
c_{33}=\frac{s_{11} s_{22}-s_{12}^{2}}{D} \quad c_{23}=\frac{s_{12} s_{13}-s_{23} s_{11}}{D} \\
c_{44}=\frac{1}{s_{44}} \quad c_{55}=\frac{1}{s_{55}} \quad c_{66}=\frac{1}{s_{66}} \\
D=s_{11} s_{22} s_{33}-s_{11} s_{23}^{2}-s_{22} s_{13}^{2}-s_{33} s_{12}^{2}+2 s_{12} s_{23} s_{13}
\end{gathered}
$$

Como último passo, os coeficientes da matriz de flexibilidade são expressos em termos das chamadas constantes de engenharia: módulo de Young, $E$, coeficiente de Poisson, $v$, e módulo de cisalhamento, $G$. Tais constantes são obtidas diretamente a partir de ensaios mecânicos. 


$$
\left\{\begin{array}{l}
\varepsilon_{1} \\
\varepsilon_{2} \\
\varepsilon_{3} \\
\varepsilon_{4} \\
\varepsilon_{5} \\
\varepsilon_{6}
\end{array}\right\}=\left[\begin{array}{cccccc}
\frac{1}{E_{1}} & -\frac{v_{21}}{E_{2}} & -\frac{v_{31}}{E_{3}} & 0 & 0 & 0 \\
-\frac{v_{12}}{E_{1}} & \frac{1}{E_{2}} & -\frac{v_{32}}{E_{3}} & 0 & 0 & 0 \\
-\frac{v_{13}}{E_{1}} & -\frac{v_{23}}{E_{2}} & \frac{1}{E_{3}} & 0 & 0 & 0 \\
0 & 0 & 0 & \frac{1}{G_{23}} & 0 & 0 \\
0 & 0 & 0 & 0 & \frac{1}{G_{13}} & 0 \\
0 & 0 & 0 & 0 & 0 & \frac{1}{G_{12}}
\end{array}\right]\left\{\begin{array}{l}
\sigma_{1} \\
\sigma_{2} \\
\sigma_{3} \\
\sigma_{4} \\
\sigma_{5} \\
\sigma_{6}
\end{array}\right\} .
$$

A eq. (2.19) representa a equação constitutiva na forma matricial para um material ortotrópico. Os termos da matriz de flexibilidade são escritos em função das constantes de engenharia; $E_{1}, E_{2}$ e $E_{3}$ são, respectivamente, os módulos de Young do material nas direções $\mathbf{x}_{1}, \mathbf{x}_{2}$ e $\mathbf{x}_{3}$, o coeficiente de Poisson, $v_{i j}$, é definido pela razão entre a deformação da seção transversal orientada na direção $\mathbf{x}_{\mathbf{i}}$ e a deformação axial na direção $\mathbf{x}_{\mathbf{j}}$, quando o material é tensionado na direção $\mathbf{x}_{\mathbf{j}}$, e $G_{23}, G_{13}$ e $G_{12}$ denotam, respectivamente, os módulos de cisalhamento do material nos planos $\mathbf{x}_{\mathbf{2}}-\mathbf{x}_{\mathbf{3}}$, $\mathbf{x}_{1}-\mathbf{x}_{3}$ e $\mathbf{x}_{1}-\mathbf{x}_{2}$. Um estudo detalhado para a dedução das relações constitutivas a partir das constantes de engenharia e comportamento mecânico de estruturas do tipo placa e casca podem ser encontrados em (REDDY, 1997).

\subsubsection{Fundamentos de piezoeletricidade}

Alguns materiais apresentam acoplamento termo-mecânico ou eletro-mecânico, na medida em que suas respostas mecânicas estão, em algum grau, condicionadas à ação de campos térmicos ou elétricos. O acoplamento termo-elétrico também é possível. O acoplamento eletro-mecânico caracteriza os materiais piezelétricos e dá origem ao fenômeno conhecido como piezoeletricidade ( "piezo" $\rightarrow$ pressão). 
Materiais com propriedades piezelétricas, em geral, são dielétricos anisotrópicos. A anisotropia é definida pela ausência de centro de simetria nas moléculas dos materiais piezelétricos.

Um material dielétrico é dito polarizado quando momentos de dipolo são induzidos em moléculas apolares e alinhados na direção do campo elétrico polarizante, ou pelo simples alinhamento de moléculas polares.

O efeito piezelétrico é quantificado a partir do vetor polarização $\boldsymbol{P}$, que representa o momento de dipolo elétrico induzido por unidade de volume do dielétrico.

$$
\boldsymbol{P}=\lim _{\Delta v \rightarrow 0} \frac{\sum_{k=1}^{N} Q_{k} \boldsymbol{d}_{k}}{\Delta v}
$$

Na eq. (2.20), $\boldsymbol{d}$ é a distância entre as cargas do dipolo, $-Q$ e $+Q$, e $N$ é o número de dipolos em um elemento de volume $\Delta v$ do dielétrico. Note que $\boldsymbol{p}=Q \boldsymbol{d}$ é o momento de dipolo molecular.

Do ponto de vista elétrico, o efeito prático da polarização é o surgimento de uma densidade volumétrica de cargas $\rho_{v}$, e uma densidade superficial de cargas $\rho_{s}$, no material. Contudo, deve ser observado que a polarização mantém o material dielétrico eletricamente neutro; as cargas superficiais e volumétricas se cancelam.

Pela aplicação do teorema do divergente de Gauss ao volume do dielétrico, mostra-se que:

$$
D_{i}=\epsilon_{0} E_{i}+P_{i}
$$

na qual, $D_{i}$ é o deslocamento elétrico, $\epsilon_{0}$ é a permissividade elétrica do espaço livre (Farads/metro) e $E_{i}$ é o campo elétrico aplicado. 
O tensor polarização está relacionado ao campo elétrico interno pelo tensor adimensional de suscetibilidade elétrica do material $\chi_{e}$. Este tensor mede o quanto o material é suscetível (ou sensível) aos efeitos do campo elétrico polarizante.

$$
P_{i}=\epsilon_{0} \chi_{i j} E_{j}
$$

Em termos da eq. (2.22), a eq. (2.21) se escreve:

$$
D_{i}=\epsilon_{0}\left(1+\chi_{i j}\right) E_{j}
$$

Se os parâmetros $\epsilon_{0}$ e $\chi_{\mathrm{e}}$ são conhecidos, o tensor deslocamento elétrico é relacionado ao campo elétrico pela eq. (2.23). A constante dielétrica, ou permissividade relativa do material, é definida pelo do tensor suscetibilidade elétrica do material $\chi_{i j}$ :

$$
\epsilon_{i j}^{r}=\left(1+\chi_{i j}\right)
$$

Assim, a eq. (2.23) se escreve na seguinte forma:

$$
D_{i}=\epsilon_{i j} E_{j} \quad i, j=1,2,3
$$

na qual $\epsilon_{i j}=\epsilon_{i j}^{r} \epsilon_{0}$ é o tensor de permissividade dielétrica do material e $\epsilon_{r}$ é a permissividade do material relativa ao vácuo. A eq. (2.25) pode ser escrita na seguinte forma matricial.

$$
\left\{\begin{array}{l}
D_{1} \\
D_{2} \\
D_{3}
\end{array}\right\}=\left[\begin{array}{lll}
\epsilon_{11} & \epsilon_{12} & \epsilon_{13} \\
\epsilon_{21} & \epsilon_{22} & \epsilon_{23} \\
\epsilon_{31} & \epsilon_{32} & \epsilon_{33}
\end{array}\right]\left\{\begin{array}{l}
E_{1} \\
E_{2} \\
E_{3}
\end{array}\right\}
$$


Um material dielétrico é dito linear se $\epsilon$ não varia com o campo aplicado, homogêneo se $\epsilon$ não varia em termos das coordenadas materiais, e isotrópico se $\epsilon$ é invariante por rotação do sistema de coordenadas.

Em materiais piezelétricos, a polarização pode ser induzida pela aplicação de um campo elétrico, ou por deformações elásticas originadas por tensão mecânica (efeito piezelétrico direto). A equação constitutiva entre deslocamento elétrico e tensão mecânica é definida a partir do tensor de coeficientes, ou constantes piezelétricas $d_{k i j}$, em unidades (Coulomb/Newton).

$$
D_{K}=d_{k i j} \sigma_{i j} .
$$

A equação constitutiva relacionando o deslocamento elétrico à deformação do material é definida a partir do tensor de coeficientes piezelétricos $e_{k i j}$, em unidades $\left(\right.$ Coulomb $\left./ \mathrm{m}^{2}\right)$

$$
D_{K}=e_{k i j} \varepsilon_{i j}
$$

A deformação elástica ou a indução de tensões mecânicas no material pela aplicação de um campo elétrico, define o efeito piezelétrico inverso, tal que

$$
\begin{gathered}
\varepsilon_{i j}=d_{k i j} E_{k} . \\
\sigma_{i j}=-e_{k i j} E_{k} .
\end{gathered}
$$

As eqs. (2.29) e (2.30) representam as equações constitutivas relacionando, respectivamente, os campos de deformação e tensão mecânica no material ao campo elétrico polarizante, em termos dos coeficientes piezelétricos. Estes coeficientes são relacionados por 


$$
\boldsymbol{e}=\boldsymbol{d} \boldsymbol{c}^{E}
$$

A eq. (2.31) relaciona os tensores de coeficientes piezelétricos a partir da matriz de rigidez elástica. $\mathrm{O}$ sobrescrito ${ }^{E}$ denota propriedades elásticas a campo elétrico constante.

A descrição das equações constitutivas em termos dos vetores $\boldsymbol{E}$ e $\boldsymbol{D}$ é adequada, devido a facilidade prática para a medida do campo elétrico, relativo ao estado de polarização do material.

Para um material anisotrópico geral, os tensores de coeficientes piezelétricos são formados por 18 constantes independentes. Os coeficientes piezelétricos dependem das características cristalográficas do material, de forma que propriedades de simetrias podem contrair a notação tensorial e simplificar as equações constitutivas. A simetria dos tensores $\varepsilon_{i j}$ e $\sigma_{i j}$ tornam os tensores simétricos em relação aos índices $i, j$.

\subsubsection{Equações constitutivas para materiais piezelétricos}

As equações constitutivas são o ponto de partida para a modelagem e simulação de estruturas piezelétricas. A modelagem dinâmica de estruturas piezelétricas compósitas exige um conjunto de equações constitutivas, de acordo com as propriedades elásticas, elétricas e piezelétricas dos materiais envolvidos.

Equações constitutivas podem ser obtidas a partir de uma abordagem termodinâmica do efeito piezelétrico. Do ponto de vista físico, materiais piezelétricos constituem um sistema cujo comportamento dinâmico é descrito pelo acoplamento de dois sistemas independentes: o mecânico e o elétrico. 
A energia interna acumulada por um material piezelétrico pode ser representada em termos da primeira lei da termodinâmica. A eq. (2.34), é uma equação diferencial exata, na qual $d U$ representa uma variação infinitesimal na energia interna, devido ao trabalho $d W$ e à troca de calor $d Q$, ambos definidos pela interação do material com o meio externo.

$$
d U=d W+d Q
$$

A energia interna gerada pelo efeito piezelétrico define potenciais termodinâmicos específicos, em termos dos seguintes pares de variáveis independentes: $(\varepsilon, E) ;(\sigma, D)$ e $(\sigma, E)$ (IEEE, 1987).

$$
\begin{gathered}
H=U-E_{i} D_{i} \\
F=U-\sigma_{i j} \varepsilon_{i j} \\
G=U-\sigma_{i j} \varepsilon_{i j}-E_{i} D_{i}
\end{gathered}
$$

As eqs. (2.33), (2.34) e (2.35) representam potenciais termodinâmicos. Em analogia à teoria termodinâmica clássica; $H$ - entalpia, $F$ - energia livre de Helmholtz, e $G$ - energia livre de Gibbs. Estes potenciais relacionam-se pelo método matemático chamado transformação de Legendre (CALLEN, 1960). Dos potenciais termodinâmicos, derivam as equações constitutivas de um material piezelétrico.

Considerando desprezíveis as trocas de calor entre o material e o meio externo, a energia interna armazenada é a soma das energias devido aos trabalhos mecânico e elétrico que induzem deformações materiais. Em termos das variáveis independentes $(\sigma, E)$ : 


$$
d G(\sigma, E)=-D d E-\varepsilon d \sigma .
$$

A eq. (2.36) representa o balanço de energia interna para um material piezelétrico, na forma diferencial. A partir desta, podem ser obtidas as seguintes equações constitutivas para o material piezelétrico:

$$
\begin{gathered}
\varepsilon_{i j}(\sigma, E)=s_{i j k l}^{E} \sigma_{k l}+d_{k i j} E_{k} . \\
D_{i}(\sigma, E)=d_{i k l} \sigma_{k l}+\epsilon_{i k}^{\sigma} E_{k} .
\end{gathered}
$$

Nas eqs. (2.37) e (2.38), $\boldsymbol{s}^{E}$ é o tensor de flexibilidade a campo elétrico constante, $\boldsymbol{\epsilon}^{\sigma}$ é o tensor de constantes dielétricas à tensão constante. Estas equações podem ser reescritas de forma a representar os tensores $\boldsymbol{\varepsilon}$ e $\boldsymbol{E}$ como variáveis independentes.

$$
\begin{gathered}
\sigma_{i j}(\varepsilon, E)=c_{i j k l}^{E} \varepsilon_{k l}-e_{k i j} E_{k} . \\
D_{i}(\varepsilon, E)=e_{i k l} \varepsilon_{k l}+\epsilon_{i k}^{S} E_{k} .
\end{gathered}
$$

Nas eqs. (2.39) e (2.40), $\boldsymbol{c}^{E}$ é o tensor de rigidez elástica a campo elétrico constante, $\boldsymbol{\epsilon}^{S}$ é o tensor de constantes dielétricas à deformação constante. Em notação matricial, e usando notação contraída para $\boldsymbol{\sigma}$ e $\boldsymbol{\varepsilon}$, as eqs. (2.37) até (2.40) podem ser escritas:

$$
\begin{aligned}
& \sigma=c \varepsilon-e E \\
& D=e^{t} s+\epsilon E \\
& \varepsilon=s \sigma+d E
\end{aligned}
$$




$$
D=d^{t} \sigma+\epsilon E
$$

Nas eqs. (2.41) e (2.44), o subscrito ${ }^{t}$ denota o operador de transposição matricial. O último conjunto de equações representa as relações constitutivas para o acoplamento eletromecânico em materiais piezelétricos. Para materiais piezelétricos ortotrópicos polarizados na direção 3, tem-se:

$$
\left\{\begin{array}{l}
\varepsilon_{1} \\
\varepsilon_{2} \\
\varepsilon_{3} \\
\varepsilon_{4} \\
\varepsilon_{5} \\
\varepsilon_{6}
\end{array}\right\}=\left[\begin{array}{cccccc}
s_{11} & s_{12} & s_{13} & 0 & 0 & 0 \\
s_{12} & s_{22} & s_{23} & 0 & 0 & 0 \\
s_{13} & s_{23} & s_{33} & 0 & 0 & 0 \\
0 & 0 & 0 & s_{44} & 0 & 0 \\
0 & 0 & 0 & 0 & s_{55} & 0 \\
0 & 0 & 0 & 0 & 0 & s_{66}
\end{array}\right]\left\{\begin{array}{l}
\sigma_{1} \\
\sigma_{2} \\
\sigma_{3} \\
\sigma_{4} \\
\sigma_{5} \\
\sigma_{3}
\end{array}\right\}+\left[\begin{array}{ccc}
0 & 0 & d_{31} \\
0 & 0 & d_{32} \\
0 & 0 & d_{33} \\
0 & d_{24} & 0 \\
d_{15} & 0 & 0 \\
0 & 0 & 0
\end{array}\right]\left\{\begin{array}{l}
E_{1} \\
E_{2} \\
E_{3}
\end{array}\right\}
$$

A eq. (2.49) representa o efeito piezelétrico inverso (efeito atuador), na medida em que deformações elásticas resultam da ação conjunta de tensões mecânicas e campos elétricos.

$$
\left\{\begin{array}{l}
D_{1} \\
D_{2} \\
D_{3}
\end{array}\right\}=\left[\begin{array}{cccccc}
0 & 0 & 0 & 0 & d_{15} & 0 \\
0 & 0 & 0 & d_{24} & 0 & 0 \\
d_{31} & d_{32} & d_{33} & 0 & 0 & 0
\end{array}\right]\left\{\begin{array}{l}
\sigma_{1} \\
\sigma_{2} \\
\sigma_{3} \\
\sigma_{4} \\
\sigma_{5} \\
\sigma_{3}
\end{array}\right\}+\left[\begin{array}{ccc}
\epsilon_{11} & 0 & 0 \\
0 & \epsilon_{22} & 0 \\
0 & 0 & \epsilon_{33}
\end{array}\right]\left\{\begin{array}{l}
E_{1} \\
E_{2} \\
E_{3}
\end{array}\right\}
$$

A eq. (2.50) representa o efeito piezelétrico direto (efeito sensor), na medida em que cargas elétricas são geradas pela ação conjunta de tensões mecânicas e campos elétricos. 


\subsection{Modelagem da placa com pastilhas piezelétricas no ANSYS}

\subsubsection{Descrição da modelagem estrutural}

Esta seção descreve a modelagem estrutural, via método de elementos finitos, de uma placa retangular de alumínio com uma rede de 36 sensores piezelétricos (PZT-5H) superficialmente colados. A utilização de placas como protótipos para modelagem estrutural, análise dinâmica e implementação de técnicas de controle integrado representa a extensão natural de métodos e resultados obtidos em estudos com vigas. O modelo estrutural considerado foi concebido de acordo com a estratégia de otimização topológica adotada. A Fig. 2.1 representa o modelo e suas dimensões características.

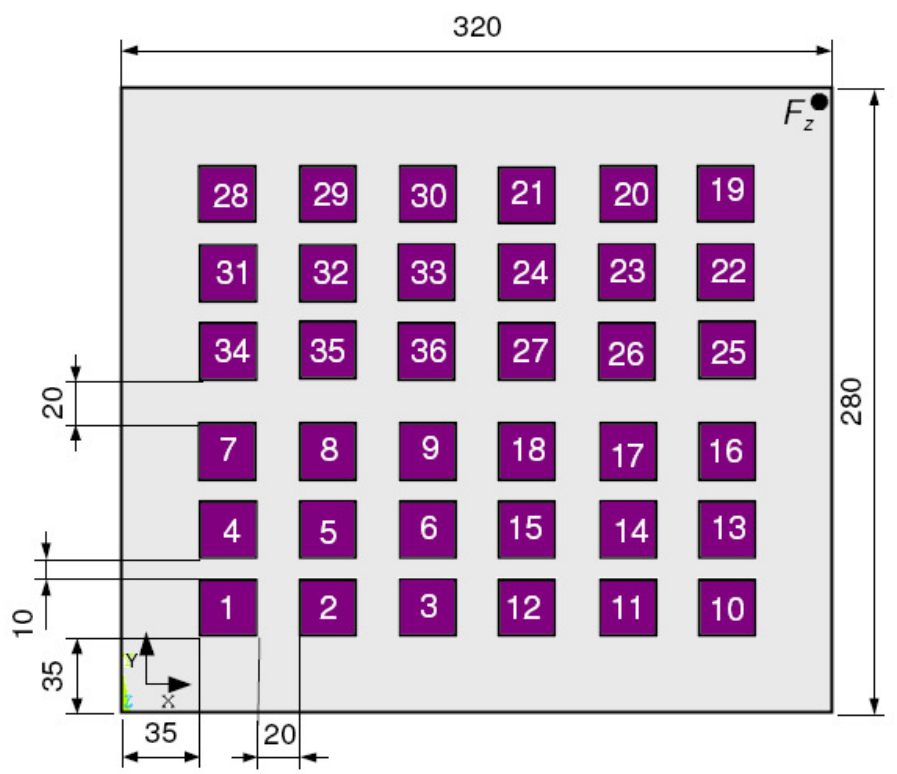

Figura 2.1 - Placa de alumínio $(320 \times 280 \times 3 \mathrm{~mm})$ com 36 sensores piezelétricos PZT-5H idênticos, em forma de pastilhas (25x25x0.5 mm), colados sobre uma das superfícies da placa, de forma a compor uma rede de sensores regularmente distribuídos. 
Para a construção da placa foi considerado o elemento de casca laminada SHELL99, modelado na forma quadrangular, em camada única. Este elemento, conforme descrito na Fig. 2.2, apresenta oito nós no seu plano médio e seis graus de liberdade por nó (deslocamentos e rotações nas direções $\mathrm{x}, \mathrm{y}, \mathrm{z}$ ).

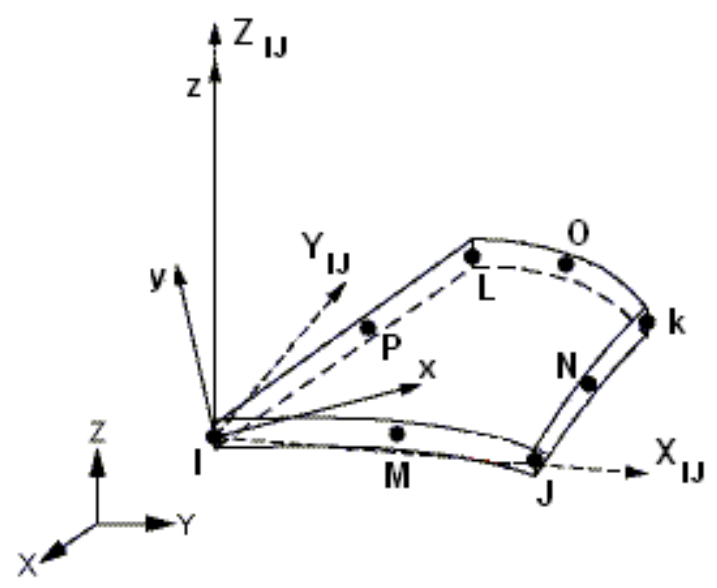

Figura 2.2 - Representação do elemento SHELL99 e posição de nós, conforme convenção adotada pelo ANSYS.

A formulação linear do elemento SHELL99 é adequada à modelagem proposta e reduz custos de simulação computacional. Além disto, os nós do plano médio do elemento SHELL99 podem ser deslocados às superfícies inferior ou superior do elemento, criando condições estruturais adequadas ao acoplamento mecânico.

O elemento SOLID226, representado na Fig. 2.3, foi considerado para modelar as pastilhas piezelétricas. Este elemento apresenta potencialidades de acoplamento estrutural-térmico, térmico-elétrico, estrutural-termoelétrico, térmico-piezelétrico ou puramente piezelétrico e piezoresistivo. Na forma cúbica, possui 20 nós, oito por face, com nós comuns nos vértices, e até cinco graus de liberdade por nó (deslocamentos em $\mathrm{x}, \mathrm{y}, \mathrm{z}$, tensão elétrica e temperatura). 


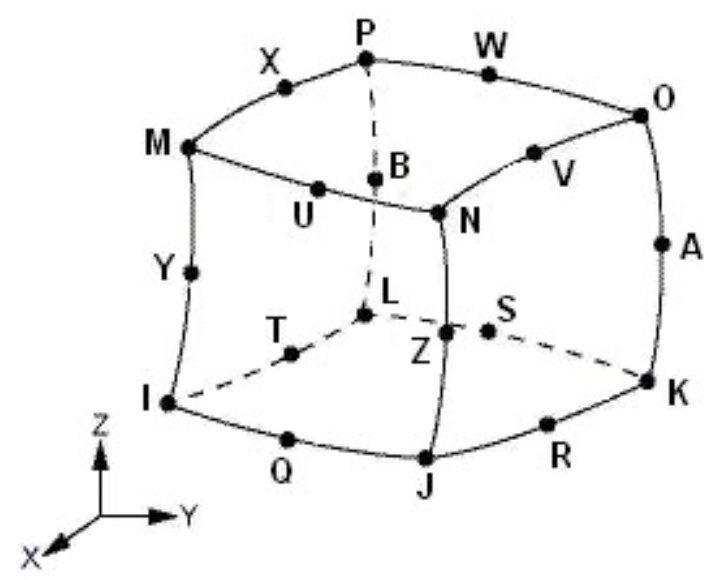

Figura 2.3 - Representação do elemento SOLID226 e posição de nós, conforme convenção adotada pelo ANSYS.

A construção de uma malha regular de elementos finitos é uma condição geométrica para o acoplamento eficaz entre elementos adjacentes, neste caso, placa e pastilhas. Nota-se que, no modelo considerado, ambos os elementos possuem oito nós coplanares. Se projetados ao topo, os nós do elemento SHELL99 estarão em um plano comum aos nós da base de cada pastilha em contato com a placa.

Posicionando as pastilhas de forma que seus nós estejam verticalmente alinhados aos nós da placa, o comando Merge é usado para acoplar mecanicamente cada nó do elemento SHELL99 ao nó mais próximo do elemento SOLID226.

A Fig. 2.4 ilustra o processo de acoplamento mecânico entre nós da placa e das pastilhas piezelétricas: inicialmente no plano médio do elemento SHELL99, os nós são deslocados para a sua superfície superior (offset dos nós), sobrepondo-se aos nós da base do elemento SOLID226. O comando Merge é então utilizado para a colagem dos elementos em contato, na medida em que cada par de nós coincidentes pela operação de offset são transformados em um único nó e os graus de liberdade comuns aos elementos são compartilhados. Neste caso, as translações nas direções x,y e z. 

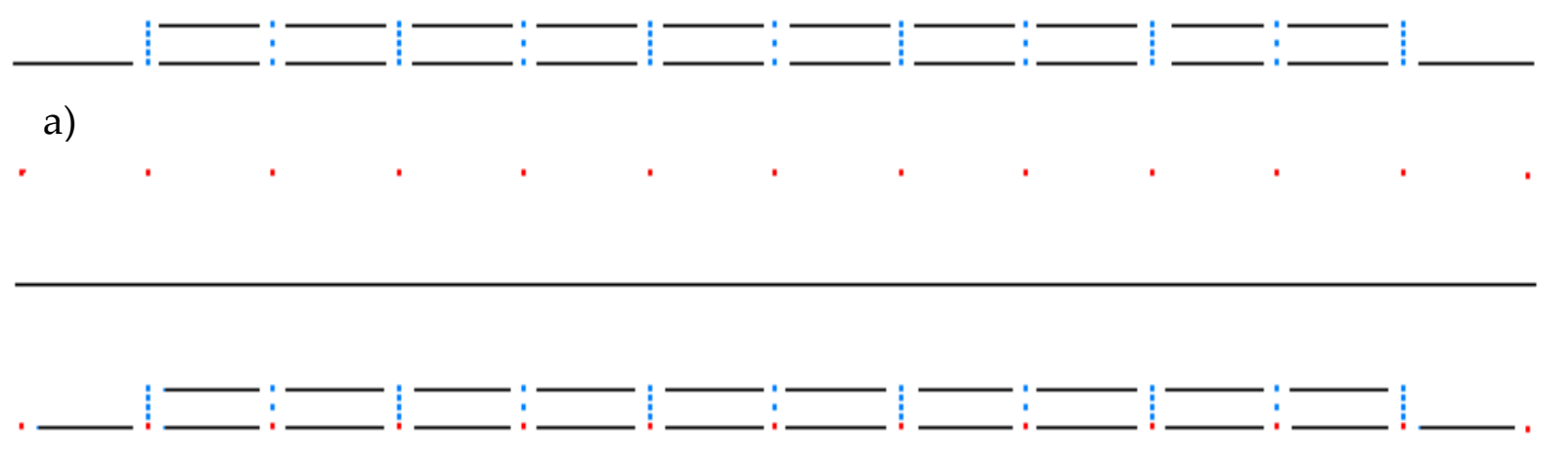

b)

Figura 2.4 - Vista frontal mostrando camadas de nós de uma pastilha piezoelétrica alinhados verticalmente aos nós da placa. a) a operação de offset dos nós do elemento SHELL99 não é realizada e estes permanecem no seu plano médio (pontos em vermelho), deslocados verticalmente em relação à primeira camada de nós do SOLID226 (pontos em azul). b) os nós do elemento SHELL99 são deslocados ao topo pela operação de offset, sobrepondo-se à primeira camada de nós do SOLID226.

A construção da malha é um processo de discretização de um meio contínuo, que consiste na subdivisão do volume original em pequenos elementos adjacentes, conectados por nós. No modelo considerado, a malha da placa define um reticulado uniforme de elementos SHELL99, com dimensões unitárias 5x5x3 mm, enquanto que a malha das pastilhas define um reticulado uniforme de elementos SOLID226, com dimensões $5 \times 5 \times 0,25 \mathrm{~mm}$. As pastilhas são discretizadas de forma que haja duas camadas de elemento piezelétrico sobrepostos na direção perpendicular à superfície da placa (direção de polarização do dielétrico). Foi observado que duas camadas de elementos sobrepostos consiste na mínima discretização necessária para a leitura da tensão elétrica induzida nas pastilhas com polarização transversal.

A Fig. 2.5 representa uma vista frontal dos nós que definem a malha em elementos finitos da placa de alumínio. Na construção do modelo foram utilizados dois tipos de elementos, que juntos perfazem um total de 5384 elementos finitos (3584 do tipo SHELL99 e 1800 do tipo SOLID262) e 23953 nós, dos quais 3456 acoplam graus de liberdade mecânicos entre a placa e as pastilhas. 


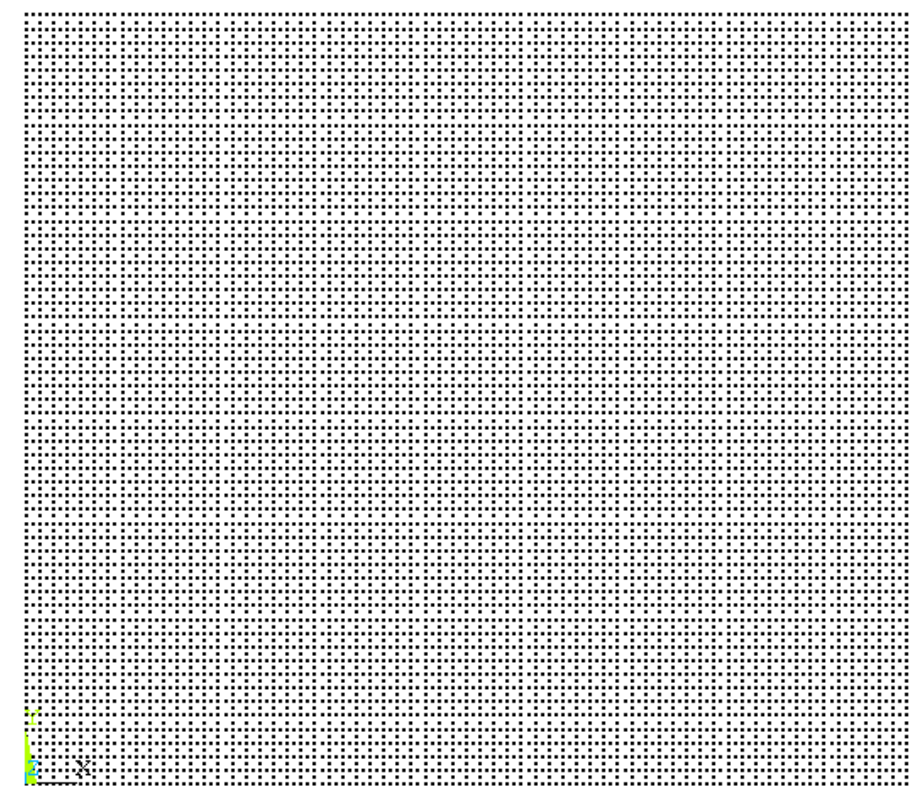

Figura 2.5 - Vista frontal dos nós da malha de elementos finitos para o modelo de placa com sensores piezelétricos.

À cada elemento considerado na modelagem estrutural correspondem propriedades materiais específicas. Ao elemento SHELL99, são atribuídas as propriedades materiais do alumínio - módulo de elasticidade $70 \mathrm{GPa}$, coeficiente de Poisson 0,33 , densidade $2700 \mathrm{~kg} / \mathrm{m}^{3}$. Ao elemento SOLID226, são atribuídas as propriedades materiais da cerâmica piezelétrica PZT-5H (Titanato Zirconato de Chumbo) - densidade $7500 \mathrm{~kg} / \mathrm{m}^{3}$, e matrizes de flexibilidade $\left(s_{E}\right)$, acoplamento piezelétrico $(d)$ e permissividade relativa $\left(\epsilon / \epsilon_{0}\right)$, conforme relacionadas abaixo.

$$
S_{E}=\left[\begin{array}{cccccc}
16.5 & -4.78 & -8.45 & 0 & 0 & 0 \\
-4.78 & 16.5 & -8.45 & 0 & 0 & 0 \\
-8.45 & -8.45 & 20.7 & 0 & 0 & 0 \\
0 & 0 & 0 & 43.5 & 0 & 0 \\
0 & 0 & 0 & 0 & 43.5 & 0 \\
0 & 0 & 0 & 0 & 0 & 42.6
\end{array}\right] \frac{p m^{2}}{N}
$$




$$
d=\left[\begin{array}{ccc}
0 & 0 & -274 \\
0 & 0 & -274 \\
0 & 0 & 593 \\
0 & 741 & 0 \\
741 & 0 & 0 \\
0 & 0 & 0
\end{array}\right] \frac{p C}{N}, \quad \epsilon_{r}=\left[\begin{array}{ccc}
3130 & 0 & 0 \\
0 & 3130 & 0 \\
0 & 0 & 3400
\end{array}\right]
$$

\subsubsection{Condições de contorno elétricas}

Uma vez assegurado o acoplamento mecânico entre placa e pastilhas, é necessário definir condições adequadas para a leitura do potencial elétrico nas pastilhas. Naturalmente, as propriedades dielétricas do PZT-5H impedem que o excesso de cargas elétricas induzidas localmente na superfície livre de cada pastilha se distribua uniformemente. A leitura do potencial elétrico em um nó específico da superfície livre dará informações locais sobre o valor da tensão elétrica induzida. Três condições de contorno elétricas podem ser consideradas:

i) pastilhas piezelétricas em circuito aberto. Para tal, os nós da base são aterrados e a superfície livre respeita a condição de equipotencialidade. As condições de contorno na superfície equipotencial são típicas de uma interface condutor-espaço livre.

ii) pastilhas piezelétricas em circuito fechado. Para tal, os nós da base e do topo são aterrados, de forma que os potenciais elétricos no topo e na base de cada pastilha sejam mantidos invariavelmente constantes. A pastilha comporta-se como um dispositivo em curto-circuito. Fisicamente, tudo se passa como se as cargas superficiais geradas escoassem para fora da pastilha, por meio de fios condutores, de forma à mantê-la descarregada.

iii) pastilhas piezelétricas sem eletrodos na superfície superior. Este caso é estudado apenas para demonstrar o efeito da condição de equipotencialidade nos estados de rigidez e resposta dinâmica da estrutura. Para tal, os nós da base são aterrados e a equipotencialidade no topo não é implementada. Desta forma, a 
ausência de eletrodos de condução impede a redistribuição uniforme das cargas superficiais, que mantêm sua configuração topológica original, definida principalmente por estados de deformações elásticas locais. $\mathrm{O}$ potencial elétrico em cada nó é, portanto, função das coordenadas $x, y$ e a superfície não se encontra em equilíbrio eletrostático; há gradiente de tensão elétrica e o campo elétrico superficial apresenta componentes normal e tangencial, ocasionando interação elétrica entre as cargas. A componente normal do vetor deslocamento elétrico é descontínua na interface. As condições de fronteira são típicas de uma interface dielétrico-dielétrico, sendo o espaço livre um caso particular de dielétrico.

O aterramento dos nós das superfícies das pastilhas coladas à placa é feito impondo-se que o potencial seja nulo em qualquer estado de deformação material. $\mathrm{O}$ objetivo do aterramento é definir um valor de referência em relação ao qual as tensões elétricas induzidas nos nós das superfícies livres serão medidas.

No software ANSYS, a condição de equipotencialidade é implementada pelo acoplamento do grau de liberdade VOLT nos nós da superfície livre de cada uma das pastilhas. Neste trabalho, as três condições de contorno elétricas descritas são implementadas e simuladas. A condição de circuito aberto torna inequívoca a leitura de tensão elétrica no topo das pastilhas, uma vez que uniformização da tensão elétrica torna equivalentes todos os nós superficiais, para efeito de leitura da tensão elétrica. As funções de resposta em frequência (medida de tensão elétrica nos sensores em termos da frequência de excitação) são invariavelmente obtidas a partir da condição de equipotencialidade na superfície dos sensores. A condição de circuito fechado é simulada para avaliar o coeficiente efetivo de acoplamento eletromecânico e a condição de ausência de eletrodos nas pastilhas é simulada para fins comparativos.

A implementação das condições de contorno elétricas requer a seleção cuidadosa dos nós condicionados à elas. Uma forma bastante prática para a aplicação das condições de contorno é a seleção geométrica (ou isolamento) dos nós, por 
especificação de suas coordenadas (localização de nós). O comando box permite a aplicação da condição de contorno escolhida a um conjunto de nós selecionados. A Fig. 2.6 representa o aterramento dos nós da base de uma pastilha piezelétrica, selecionados por critério de localização dos nós.

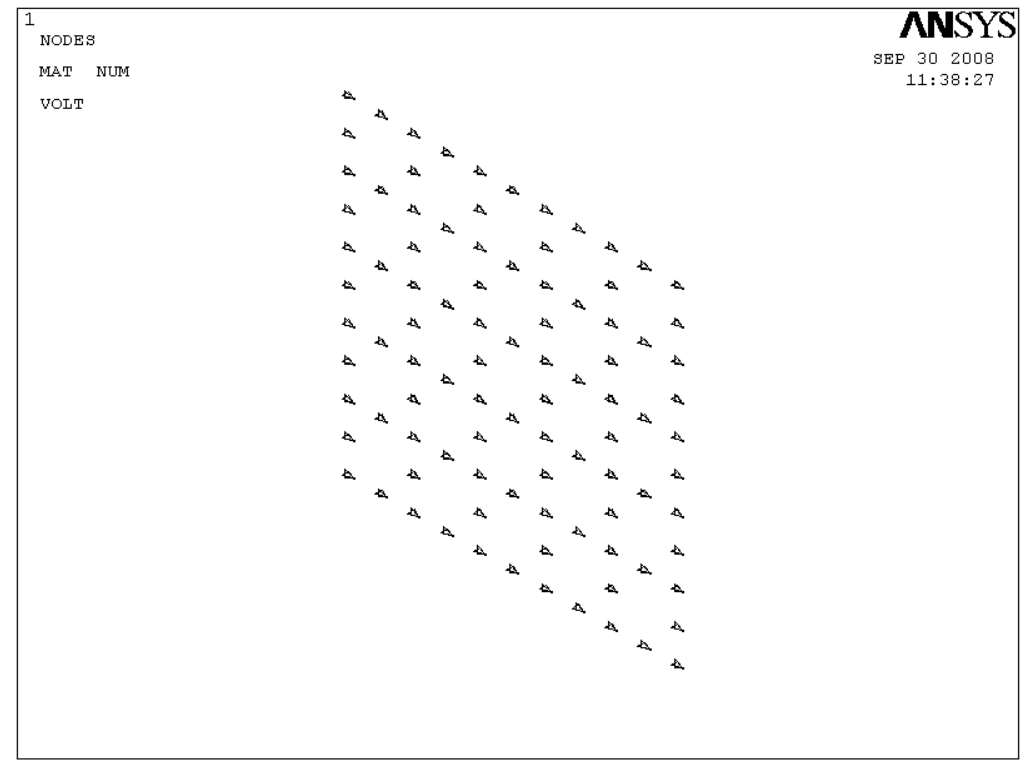

Figura 2.6 - O aterramento dos nós da base de cada pastilha define um valor de referência para a leitura do potencial elétrico no topo das pastilhas.

A Fig. 2.7 representa o acoplamento elétrico entre todos os nós da superfície superior de uma pastilha piezelétrica. Cada conjunto de nós acoplados deve receber uma numeração específica, ou seja, cada pastilha possui um acoplamento elétrico de nós independente das demais. 


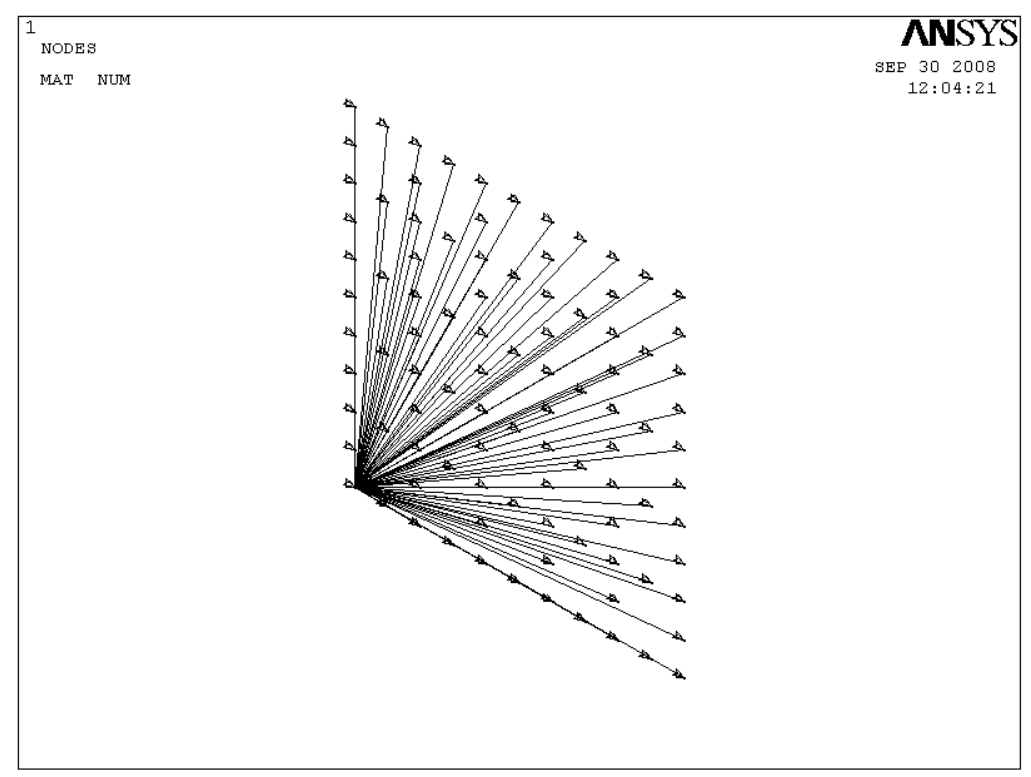

Figura 2.7 - O acoplamento elétrico do grau de liberdade VOLT se dá pela implementação de uma rede de eletrodos distribuídos no topo de cada pastilha. O efeito da rede de eletrodos é uniformizar a tensão elétrica superficial e tornar inequívoca a leitura em cada sensor.

Após a aplicação das condições de contorno elétricas, é necessária a re-seleção de todos os nós que compõem o modelo estrutural. Na sequência, a análise modal será usada para determinar as formas modais e as frequências de ressonância para cada uma das três condições de contorno elétricas consideradas. A análise harmônica usa uma base de vetores normais para desacoplar as equações de movimento e determinar a resposta da estrutura a uma excitação do tipo harmônica (força transversal concentrada).

\subsection{Análise modal e harmônica}

\subsubsection{Revisão teórica de análise modal e harmônica}

A modelagem de um sistema com acoplamento eletromecânico, pelo método dos elementos finitos, dá origem a um sistema de equações na forma: 


$$
\overline{\boldsymbol{M}} \ddot{\boldsymbol{q}}+\overline{\boldsymbol{K}} \boldsymbol{q}=\overline{\boldsymbol{F}},
$$

sendo $\overline{\boldsymbol{M}}$ a matriz da massa do sistema, $\overline{\boldsymbol{K}}$ a matriz de rigidez e $\overline{\boldsymbol{F}}$ o vetor de forças aplicadas ao sistema. No caso da existência de pastilhas piezelétricas, alguns dos graus de liberdade $\boldsymbol{q}$ representam quantidades mecânicas: $\boldsymbol{u}$ (deslocamentos nodais) e outros representam quantidades elétricas (tensões elétricas nodais presentes nas superfícies superior e inferior). Os graus de liberdade elétricos são divididas em dois grupos: $\boldsymbol{V}$ potencial elétrico nos nós superficiais de cada pastilha, e $\boldsymbol{\varphi}$, potencial elétrico nos nós internos de cada pastilha. Uma forma de escrever e evidenciar o acoplamento pode ser

$$
\left[\begin{array}{ccc}
\boldsymbol{M} & 0 & 0 \\
0 & 0 & 0 \\
0 & 0 & 0
\end{array}\right]\left[\begin{array}{c}
\ddot{\ddot{u}} \\
\ddot{\boldsymbol{\varphi}} \\
\ddot{\boldsymbol{\varphi}}
\end{array}\right]+\left[\begin{array}{ccc}
\boldsymbol{K}_{u u} & -\boldsymbol{K}_{u V} & -\boldsymbol{K}_{u \varphi} \\
-\boldsymbol{K}_{u V}{ }^{t} & \boldsymbol{K}_{V V} & \boldsymbol{K}_{V \varphi} \\
-\boldsymbol{K}_{u \varphi}{ }^{t} & \boldsymbol{K}_{V \varphi}{ }^{t} & \boldsymbol{K}_{\varphi \varphi}
\end{array}\right]\left[\begin{array}{l}
\boldsymbol{u} \\
\boldsymbol{V} \\
\boldsymbol{\varphi}
\end{array}\right]=\left[\begin{array}{l}
\boldsymbol{F} \\
\boldsymbol{Q} \\
\mathbf{0}
\end{array}\right],
$$

sendo $\boldsymbol{K}_{u u}, \boldsymbol{K}_{u V}$ e $\boldsymbol{K}_{u \varphi}, \boldsymbol{K}_{V V}, \boldsymbol{K}_{V \varphi}$ e $\boldsymbol{K}_{\varphi \varphi}$, as matrizes de rigidez mecânica (elástica), eletromecânica (piezelétrica) e elétrica (dielétrica), respectivamente, $\boldsymbol{F}$ o vetor de forças modais aplicadas e $\boldsymbol{Q}$ o vetor de cargas elétricas modais aplicadas. No caso de aplicação de condições de equipotencialidade nas pastilhas, um vetor de tensões elétricas nos eletrodos $\boldsymbol{V}_{p}$ pode ser construído através de equações de vínculo a partir das tensões elétricas nodais, tal que $\boldsymbol{V}=\boldsymbol{L}_{p} \boldsymbol{V}_{p}$, e as equações do movimento são reduzidas à seguinte forma:

$$
\left[\begin{array}{ccc}
\boldsymbol{M} & 0 & 0 \\
0 & 0 & 0 \\
0 & 0 & 0
\end{array}\right]\left[\begin{array}{c}
\ddot{\ddot{V}} \\
\ddot{\boldsymbol{\varphi}} \\
\ddot{\boldsymbol{\varphi}}
\end{array}\right]+\left[\begin{array}{ccc}
\boldsymbol{K}_{u u} & -\overline{\boldsymbol{K}}_{u V} & -\boldsymbol{K}_{u \varphi} \\
-\overline{\boldsymbol{K}}_{u V}{ }^{t} & \overline{\boldsymbol{K}}_{V V} & \overline{\boldsymbol{K}}_{V \varphi} \\
-\boldsymbol{K}_{u \varphi}{ }^{t} & \overline{\boldsymbol{K}}_{V \varphi}{ }^{t} & \boldsymbol{K}_{\varphi \varphi}
\end{array}\right]\left[\begin{array}{c}
\boldsymbol{u} \\
\boldsymbol{V}_{\boldsymbol{p}} \\
\boldsymbol{\varphi}
\end{array}\right]=\left[\begin{array}{c}
\boldsymbol{F} \\
\boldsymbol{Q}_{\boldsymbol{p}} \\
\mathbf{0}
\end{array}\right]
$$

$\operatorname{com} \overline{\boldsymbol{K}}_{u V}=\boldsymbol{K}_{u V} \boldsymbol{L}_{p} ; \overline{\boldsymbol{K}}_{V V}=\boldsymbol{L}_{p}^{t} \boldsymbol{K}_{V V} \boldsymbol{L}_{p} ; \overline{\boldsymbol{K}}_{V \varphi}=\boldsymbol{L}_{p}^{t} \boldsymbol{K}_{V \varphi} ; \boldsymbol{Q}_{p}=\boldsymbol{L}_{p}^{t} \boldsymbol{Q}$ 
As variáveis $\boldsymbol{\varphi}$, sendo internas, podem ser consideradas desconhecidas para quaisquer condições de contorno elétricas, mas podem ser encontradas resolvendo terceira equação de (2.53),

$$
-\boldsymbol{K}_{u \varphi}{ }^{t} \boldsymbol{u}+\overline{\boldsymbol{K}}_{V \varphi}{ }^{t} \boldsymbol{V}_{\boldsymbol{p}}+\boldsymbol{K}_{\varphi \varphi} \varphi=0
$$

A partir da eq.(2.54), obtêm-se explicitamente o potencial elétrico no nós internos do material piezoelétrico

$$
\boldsymbol{\varphi}=\boldsymbol{K}_{\varphi \varphi}{ }^{-1} \boldsymbol{K}_{u \varphi}{ }^{t} \boldsymbol{u}-\boldsymbol{K}_{\varphi \varphi}{ }^{-1} \overline{\boldsymbol{K}}_{V \varphi}{ }^{t} \boldsymbol{V}_{\boldsymbol{p}}
$$

O potencial elétrico $\boldsymbol{\varphi}$ assim obtido pode ser substituído na eq.(2.53), do que resulta

$$
\left[\begin{array}{cc}
\boldsymbol{M} & 0 \\
0 & 0
\end{array}\right]\left[\begin{array}{c}
\ddot{\boldsymbol{u}} \\
\ddot{\boldsymbol{V}}_{\boldsymbol{p}}
\end{array}\right]+\left[\begin{array}{cc}
\overline{\boldsymbol{K}}_{u u} & -\overline{\overline{\boldsymbol{K}}}_{u V} \\
-\overline{\overline{\boldsymbol{K}}}_{u V}{ }^{t} & \overline{\overline{\boldsymbol{K}}}_{V V}
\end{array}\right]\left[\begin{array}{c}
\boldsymbol{u} \\
\boldsymbol{V}_{\boldsymbol{p}}
\end{array}\right]=\left[\begin{array}{c}
\boldsymbol{F} \\
\boldsymbol{Q}_{\boldsymbol{p}}
\end{array}\right]
$$

sendo $\overline{\boldsymbol{K}}_{u u}=\boldsymbol{K}_{u u}-\boldsymbol{K}_{u \varphi} \boldsymbol{K}_{\varphi \varphi}{ }^{-1} \boldsymbol{K}_{u \varphi}{ }^{t}, \overline{\overline{\boldsymbol{K}}}_{u V}=\overline{\boldsymbol{K}}_{u V}-\boldsymbol{K}_{u \varphi} \boldsymbol{K}_{\varphi \varphi}{ }^{-1} \overline{\boldsymbol{K}}_{V \varphi}{ }^{t}$, e $\overline{\overline{\boldsymbol{K}}}_{V V}=\overline{\boldsymbol{K}}_{V V}-$ $\overline{\boldsymbol{K}}_{V \varphi} \boldsymbol{K}_{\varphi \varphi}{ }^{-1} \overline{\boldsymbol{K}}_{V \varphi}{ }^{t}$.

No caso de aterramento elétrico de nós, as linhas e colunas correspondentes das matrizes $\overline{\overline{\boldsymbol{K}}}_{u V}$ e $\overline{\overline{\boldsymbol{K}}}_{V V}$ podem ser eliminadas diretamente. No caso de curto-circuito de todas as pastilhas, naturalmente a eq. (2.56) se reduz ao caso puramente mecânico

$$
M \ddot{u}+\bar{K}_{u u} u=F
$$

No caso de circuito aberto, as variáveis $\boldsymbol{V}_{p}$ permanecem desconhecidas, porém podem ser calculadas estaticamente em função dos deslocamentos $\boldsymbol{u}$, através da equação 


$$
\boldsymbol{V}_{p}=\overline{\overline{\boldsymbol{K}}}_{V V}^{-1}{ }^{-1} \overline{\boldsymbol{K}}_{u V}^{t} \boldsymbol{u}+\overline{\overline{\boldsymbol{K}}}_{V V}^{-1} \boldsymbol{Q}_{\boldsymbol{p}}
$$

Reduzindo a eq. (2.56) ao seguinte problema mecânico equivalente:

$$
M \ddot{u}+K_{u u}^{o c} u=F+F_{V}
$$

com $\boldsymbol{K}_{u u}^{o c}=\overline{\boldsymbol{K}}_{u u}-\overline{\overline{\boldsymbol{K}}}_{u V} \overline{\overline{\boldsymbol{K}}}_{V V}{ }^{-1} \overline{\overline{\boldsymbol{K}}}_{u V}{ }^{t}$ sendo a matriz de rigidez elástica em condição de circuito aberto e $\boldsymbol{F}_{\boldsymbol{V}}=\overline{\overline{\boldsymbol{K}}}_{u V} \overline{\overline{\boldsymbol{K}}}_{V V}{ }^{-1} \boldsymbol{Q}_{\boldsymbol{p}}$. Para proceder à análise modal do sistema, devem-se ser aplicadas condições de contorno geométricas (mecânicas) e elétricas. Assim, os modos de vibrar $\boldsymbol{\phi}^{i}$ e frequências de vibração $\omega^{i}$ da estrutura são dados pela solução dos seguintes problemas de autovalores generalizados:

- pastilhas em curto-circuito

$$
\left(-\omega^{2} \boldsymbol{M}+\overline{\boldsymbol{K}}_{u u}\right) \boldsymbol{\phi}=0 \rightarrow \omega_{S C}^{i}, \boldsymbol{\phi}_{S C}^{i}
$$

- pastilhas em circuito aberto

$$
\left(-\omega^{2} \boldsymbol{M}+\boldsymbol{K}_{u u}^{o c}\right) \boldsymbol{\phi}=0 \rightarrow \omega_{O C}^{i}, \boldsymbol{\phi}_{O C}^{i}
$$

- pastilhas sem eletrodo na face superior

$$
\left(-\omega^{2} \boldsymbol{M}+\boldsymbol{K}_{u u}^{N E}\right) \boldsymbol{\phi}=0 \rightarrow \omega_{N E}^{i}, \boldsymbol{\phi}_{N E}^{i},
$$

onde $\boldsymbol{K}_{u u}^{N E}=\overline{\boldsymbol{K}}_{u u}+\boldsymbol{K}^{*}{ }_{u V} \boldsymbol{K}_{V V}^{*}{ }^{-1} \boldsymbol{K}^{*}{ }_{u V}{ }^{t}$ é a matriz de rigidez elástica na ausência de eletrodos, $\boldsymbol{K}_{u V}^{*}=\boldsymbol{K}_{u V}-\boldsymbol{K}_{u \varphi} \boldsymbol{K}_{\varphi \varphi}{ }^{-1} \boldsymbol{K}_{V \varphi}{ }^{t}$, e $\boldsymbol{K}_{V V}^{*}=\boldsymbol{K}_{V V}-\boldsymbol{K}_{V \varphi} \boldsymbol{K}_{\varphi \varphi}{ }^{-1} \boldsymbol{K}_{V \varphi}{ }^{t}$. 
Para o cálculo das funções de resposta em frequência, supondo-se excitação por meio de forças (mecânicas) e medição de tensões elétricas induzidas nas pastilhas, parte-se do seguinte problema

$$
\begin{gathered}
\boldsymbol{M} \ddot{\boldsymbol{u}}+\boldsymbol{D} \dot{\boldsymbol{u}}+\boldsymbol{K}_{u u}^{o c} \boldsymbol{u}=\boldsymbol{b} f \\
\boldsymbol{V}_{p}=\left(-\overline{\overline{\boldsymbol{K}}}_{V V}{ }^{-1} \overline{\overline{\boldsymbol{K}}}_{u V}{ }^{t}\right) \boldsymbol{u}
\end{gathered}
$$

no qual uma matriz de amortecimento modal ou proporcional $\boldsymbol{D}$ é adicionada ao sistema. O vetor $\boldsymbol{b}$ define o posicionamento da força de excitação.

Considerando-se uma excitação harmônica do tipo $f=\tilde{f} e^{j \omega t}$, tem-se:

$$
\left(-\omega^{2} \boldsymbol{M}+j \omega \boldsymbol{D}+\boldsymbol{K}_{u u}^{o c}\right) \widetilde{\boldsymbol{u}}=\boldsymbol{b} \tilde{f}
$$

$\operatorname{com} \widetilde{\boldsymbol{V}}_{p}=\left(-\overline{\overline{\boldsymbol{K}}}_{V V}{ }^{-1} \overline{\overline{\boldsymbol{K}}}_{u V}{ }^{t}\right) \widetilde{\boldsymbol{u}}$, pode-se escrever $\widetilde{\boldsymbol{V}}_{p}=\boldsymbol{H}(\omega) \tilde{f}$, tal que

$$
\boldsymbol{H}(\omega)=\boldsymbol{c}\left(-\omega^{2} \boldsymbol{M}+j \omega \boldsymbol{D}+\boldsymbol{K}_{u u}^{o c}\right)^{-1} \boldsymbol{b}
$$

sendo $\boldsymbol{H}(\omega)$ a função de resposta em frequência (FRF) e $\boldsymbol{c}=-\overline{\overline{\boldsymbol{K}}}_{V V}{ }^{-1} \overline{\overline{\boldsymbol{K}}}_{u V}{ }^{t}$.

Evidentemente, a inversão da matriz de rigidez dinâmica do sistema em (2.65) pode inviabilizar o cálculo para modelos com muitos graus de liberdade. Nestes casos, pode ser interessante partir das equações do movimento projetadas em uma base modal não-amortecida truncada. Para tal, considera-se a aproximação

$$
\boldsymbol{u} \cong \boldsymbol{\phi}_{R} \boldsymbol{\eta} ; \quad \boldsymbol{\phi}_{R}=\left[\boldsymbol{\phi}_{O C}^{1}, \ldots, \boldsymbol{\phi}_{O C}^{N}\right]
$$

na qual $\boldsymbol{\eta}$ denota um vetor de coordenadas modais e apenas as contribuições dos $N$ primeiros modos de vibrar são consideradas. A eq. (2.63) fica sendo 


$$
\begin{gathered}
\ddot{\boldsymbol{\eta}}+2 \xi \boldsymbol{\Omega}_{\mathrm{OC}} \dot{\boldsymbol{\eta}}+\boldsymbol{\Omega}_{O C}{ }^{2} \boldsymbol{\eta}=\boldsymbol{\phi}_{R}{ }^{t} \boldsymbol{b} f \\
\boldsymbol{V}_{p}=\boldsymbol{c} \boldsymbol{\phi}_{R} \boldsymbol{\eta}
\end{gathered}
$$

na qual $\boldsymbol{\Omega}_{O C}$ é uma matriz diagonal composta pelas frequências naturais da estrutura, para pastilhas em circuito aberto, e $\xi$ é o fator de amortecimento modal. Com $\boldsymbol{\phi}_{R}{ }^{t} \mathbf{M} \boldsymbol{\phi}_{R}=\boldsymbol{I}$, uma série de $N$ equações desacopladas podem ser escritas.

$$
\begin{gathered}
\ddot{\eta}_{i}+2 \xi \omega_{O C}^{i} \dot{\eta}_{i}+\left(\omega_{O C}^{i}\right)^{2} \eta_{i}=\boldsymbol{\phi}_{O C}^{i}{ }^{t} \boldsymbol{b} f ; i=1, \ldots, N \\
\boldsymbol{V}_{p}=\sum_{i} \boldsymbol{c} \boldsymbol{\phi}_{O C}^{i} \eta_{i}
\end{gathered}
$$

Desta forma, a FRF do sistema pode ser reescrita fazendo-se $f=\tilde{f} e^{j \omega t}$, tal que

$$
\begin{gathered}
\left(-\omega^{2}+2 \xi \omega \omega_{O C}^{i} j+\omega_{O C}^{i}{ }^{2}\right) \tilde{\eta}_{i}=\boldsymbol{\phi}_{O C}^{i}{ }^{t} \boldsymbol{b} \tilde{f} \\
\widetilde{\boldsymbol{V}}_{p}=\sum_{i} \boldsymbol{c} \boldsymbol{\phi}_{O C}^{i} \tilde{\eta}_{i}
\end{gathered}
$$

e assim,

$$
\begin{gathered}
\widetilde{\boldsymbol{V}}_{p}=\boldsymbol{H}(\omega) \tilde{f} \\
\boldsymbol{H}(\omega)=\sum_{i=1}^{N} \frac{\boldsymbol{c} \boldsymbol{\phi}_{O C}^{i} \boldsymbol{\phi}_{O C}^{i}{ }^{t} \boldsymbol{b}}{-\omega^{2}+2 \xi \omega \omega_{O C}^{i} j+\omega_{O C}{ }^{2}}
\end{gathered}
$$

Esta metodologia, chamada de superposição modal, viabiliza o cálculo da FRF do sistema, pois apenas $N$ escalares precisam ser invertidos para cada valor de 
frequência. $\mathrm{O}$ único custo adicional se deve ao cálculo das frequências naturais $\omega_{O C}^{i} \mathrm{e}$ aos modos de vibração $\phi_{O C}^{i}$. Esta técnica será utilizada no ANSYS, para o cálculo das respostas modais e harmônica de uma placa de alumínio com uma rede de pastilhas piezelétricas.

\subsubsection{Análise modal de uma placa com pastilhas piezelétricas no ANSYS}

O número de modos ressonantes e a sua distribuição no espectro de frequência são características à cada modelo estrutural. No caso da placa retangular de alumínio com trinta e seis pastilhas piezelétricas coladas, a análise modal encontrou 26 modos de vibrar no intervalo de frequência selecionado $[10,2000] \mathrm{Hz}$. As formas modais são próprias de uma placa livre-livre (sem engaste ou apoio). As três condições de contorno elétricas para as pastilhas piezelétricas foram consideradas em análises modais independentes. As análises modais para as pastilhas piezelétricas em curtocircuito $(S C)$, circuito aberto $(O C)$ e sem eletrodos $(N E)$ são consideradas equivalentes para a determinação das formas modais. No entanto, há uma mudança sutil nos valores das frequências de ressonância da estrutura quando diferentes condições de contorno elétricas são consideradas. Alterações nas frequências de ressonância da estrutura podem ser explicadas por alterações na rigidez mecânica das pastilhas sob diferentes condições de contorno elétricas. 

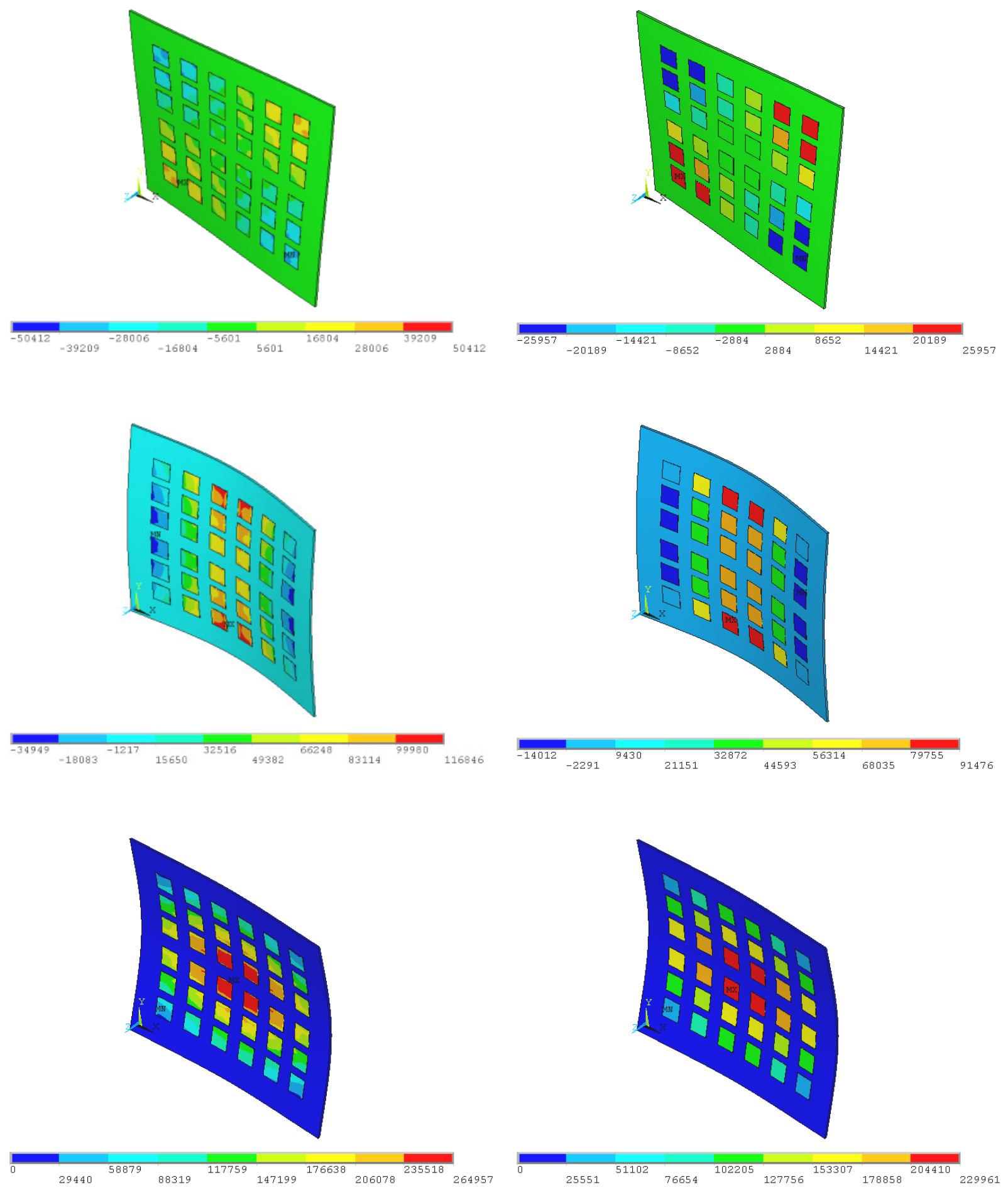

Figura 2.8 - Formas modais e distribuição de voltagem nos sensores piezelétricos para os três primeiros modos de vibrar sem (esquerda) e com (direita) a implementação da condição de equipotencialidade. 

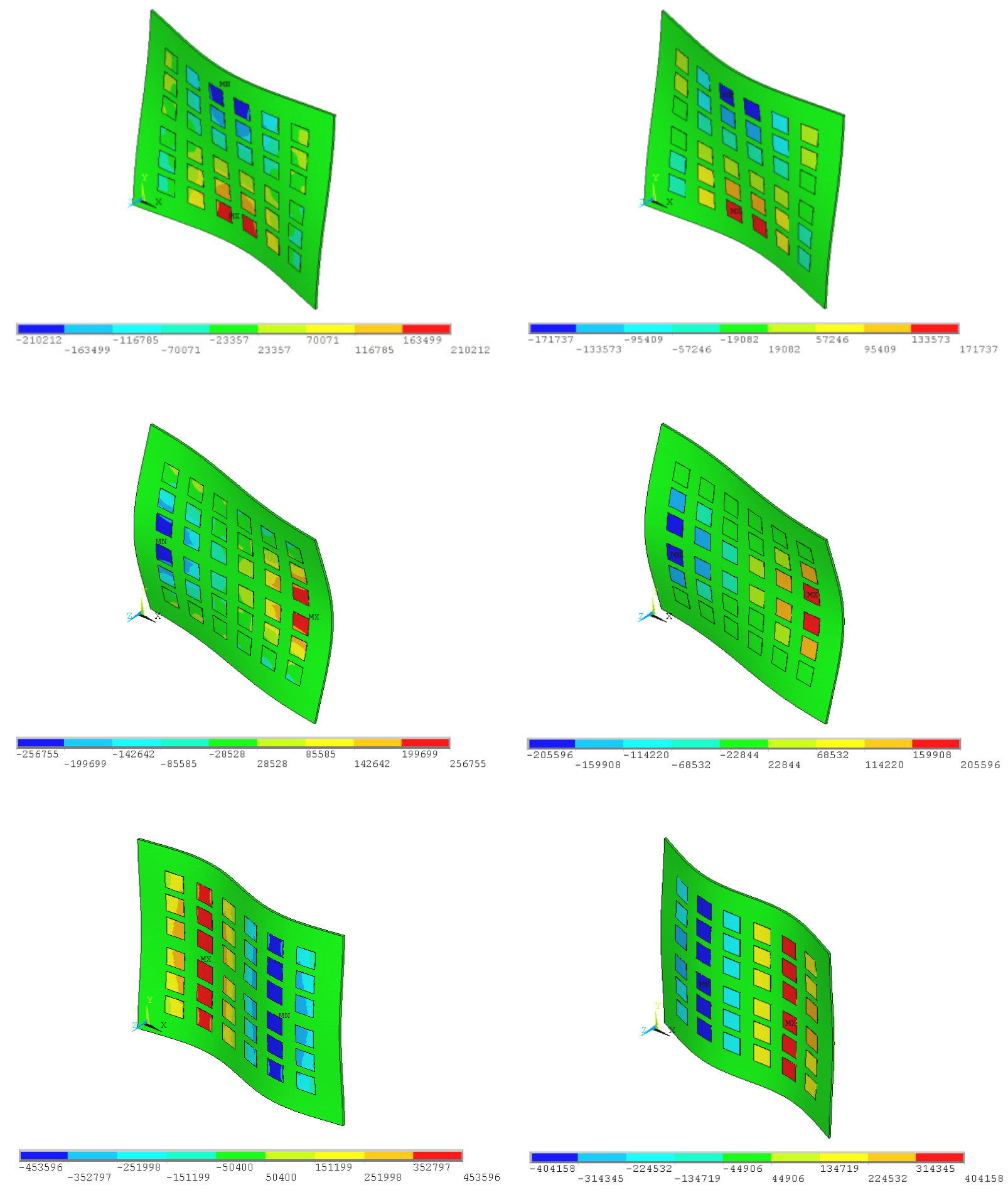

Figura 2.9 - Formas modais e distribuição de voltagem nos sensores piezelétricos para os modos de vibrar 4 a 6 sem (esquerda) e com (direita) a implementação da condição de equipotencialidade. 
Nas Figs. 2.8 e 2.9 são comparadas as distribuições de tensão elétrica superficiais nas pastilhas piezelétricas em circuito aberto $(O C)$ e sem eletrodos $(N E)$, induzidas por deformações elásticas correspondentes aos seis primeiros modos de vibrar. Note que os valores de tensão elétrica induzida nas pastilhas são irreais, pois decorrem da normalização dos modos. Porém, seus valores servem para uma análise comparativa entre as tensões geradas em diferentes pastilhas.

Pode-se observar, por inspeção visual, a descontinuidade de tensão elétrica no conjunto de nós superficiais na ausência da condição de equipotencialidade, ou eletrodos de condução. Na condição de curto-circuito $(S C)$, não há leitura de tensão nas pastilhas, uma vez que ela é nula por definição.

A partir das frequências naturais de vibração obtidas nas três condições de contorno elétricas, é possível calcular o coeficiente efetivo de acoplamento eletromecânico $(E M C C)$. O EMCC mede o potencial de conversibilidade entre as formas de energia mecânica e elétrica na estrutura. O EMCC modal de um sensor mede a sua sensibilidade a um modo específico, ou a fração de energia mecânica convertida em elétrica em um dado modo de vibrar. O EMCC modal pode ser definido pela diferença relativa entre as frequências de ressonância da estrutura em condições elétricas de circuitos aberto $\omega_{O C}$ e curto-circuito $\omega_{S C}$, conforme (TRINDADE; BENJEDDOU, 2007).

$$
E M C C=\frac{\omega_{O C}^{2}-\omega_{S C}^{2}}{\omega_{O C}^{2}}
$$

A Tabela 3.1 fornece as frequências de ressonância da estrutura para as três condições de contorno elétricas descritas na seção anterior, a saber, curto-circuito $(S C)$, circuito aberto $(O C)$ e sem eletrodos $(N E)$, assim como o EMCC modal para os vinte e seis primeiros modos de vibrar da estrutura. Cada uma das condições de contorno discutidas aplica-se indistintamente a todas as pastilhas. Conforme pode 
ser observado na Tabela 3.1, as frequências em SC e OC são muito próximas, resultando em valores relativamente baixos do $E M C C$, o que indica uma pequena variação na rigidez da estrutura em função da mudança na condição de contorno elétrica do material piezelétrico.

Tabela 3.1 - Frequências naturais da placa sob diferentes condições de contorno elétricas.

\begin{tabular}{cccccccccc}
\hline & $\omega_{S C}$ & $\omega_{N E}$ & $\omega_{O C}$ & $E M C C(\%)$ & & $\omega_{S C}$ & $\omega_{N E}$ & $\omega_{O C}$ & $E M C C(\%)$ \\
\hline 1 & 113,06 & 113,11 & 113,10 & 0,07 & 14 & 985,46 & 992,03 & 991,72 & 1,26 \\
2 & 155,24 & 155,68 & 155,67 & 0,55 & 15 & 1145,2 & 1154,4 & 1153,9 & 1,50 \\
3 & 220,99 & 223,28 & 223,26 & 2,02 & 16 & 1217,6 & 1124,7 & 1224,2 & 1,08 \\
4 & 278,08 & 278,62 & 278,60 & 0,37 & 17 & 1267,6 & 1274,1 & 1273,6 & 0,94 \\
5 & 307,56 & 308,23 & 308,20 & 0,41 & 18 & 1281,8 & 1288,0 & 1287,5 & 0,88 \\
6 & 451,02 & 454,70 & 454,61 & 1,57 & 19 & 1444,8 & 1456,6 & 1455,9 & 1,52 \\
7 & 534,26 & 535,76 & 535,69 & 0,53 & 20 & 1468,7 & 1478,0 & 1477,3 & 1,16 \\
8 & 550,67 & 551,99 & 551,91 & 0,45 & 21 & 1531,7 & 1540,3 & 1539,7 & 1,04 \\
9 & 589,51 & 594,85 & 594,72 & 1,74 & 22 & 1725,0 & 1734,8 & 1733,8 & 1,01 \\
10 & 679,99 & 685,05 & 684,90 & 1,43 & 23 & 1814,4 & 1823,8 & 1822,8 & 0,92 \\
11 & 850,83 & 853,84 & 853,64 & 0,66 & 24 & 1864,9 & 1876,8 & 1875,5 & 1,13 \\
12 & 874,45 & 880,94 & 880,65 & 1,40 & 25 & 1882,6 & 1899,2 & 1897,9 & 1,61 \\
13 & 906,91 & 910,55 & 910,31 & 0,75 & 26 & 1950,0 & 1963,8 & 1962,7 & 1,29 \\
\hline
\end{tabular}

A condição de contorno elétrica $O C$ é a condição definitiva para a modelagem estrutural e obtenção das matrizes de resposta em frequência (FRFs) a partir das análises modal e harmônica, que serão utilizadas na construção dos filtros modais. 


\subsubsection{Resposta a excitação harmônica de uma placa usando pastilhas piezelétricas como sensores}

O modelo dinâmico (placa com pastilhas piezelétricas) considerado neste trabalho apresenta resposta linear em regime estacionário a entradas senoidais. A resposta de um sistema linear invariante no tempo para uma excitação do tipo harmônica é uma função harmônica proporcional à excitação, de forma que a amplitude de vibração na coordenada de aquisição é proporcional à amplitude do excitação na coordenada de atuação. A entrada harmônica considerada é uma força senoidal transversal de amplitude 100N concentrada em um nó localizado na extremidade superior direita da placa. A frequência da força senoidal é discretizada no intervalo $[10,2000] \mathrm{Hz}$, em passos de $0,5 \mathrm{~Hz}$, assumindo 3980 valores reais.

Para cada frequência de excitação há uma configuração característica de deformação elástica na estrutura e, consequentemente, uma distribuição uniforme de tensão elétrica induzida na superfície equipotencial de cada sensor. $\mathrm{O}$ valor absoluto da tensão elétrica induzida em cada sensor depende do grau de deformação elástica ao qual o mesmo está submetido. Em geral, as máximas amplitudes de tensão elétrica em cada sensor estão associadas a deformações causadas por alguns modos de vibrar da estrutura, o que ocorre para frequências de excitação suficientemente próximas às respectivas frequências de ressonância.

O método de superposição modal empregado na análise harmônica usa as frequências naturais e as formas modais obtidas a partir da análise modal para caracterizar a resposta da estrutura para excitações do tipo transiente ou harmônica estacionária. A opção pelo método de superposição modal, que neste trabalho é implementada de forma a excluir os modos do corpo rígido da placa, é apropriada para este tipo de análise e reduz consideravelmente os custos computacionais envolvidos. Um amortecimento viscoso modal de $1 \%$ foi considerado para cada modo de vibrar na análise harmônica. 

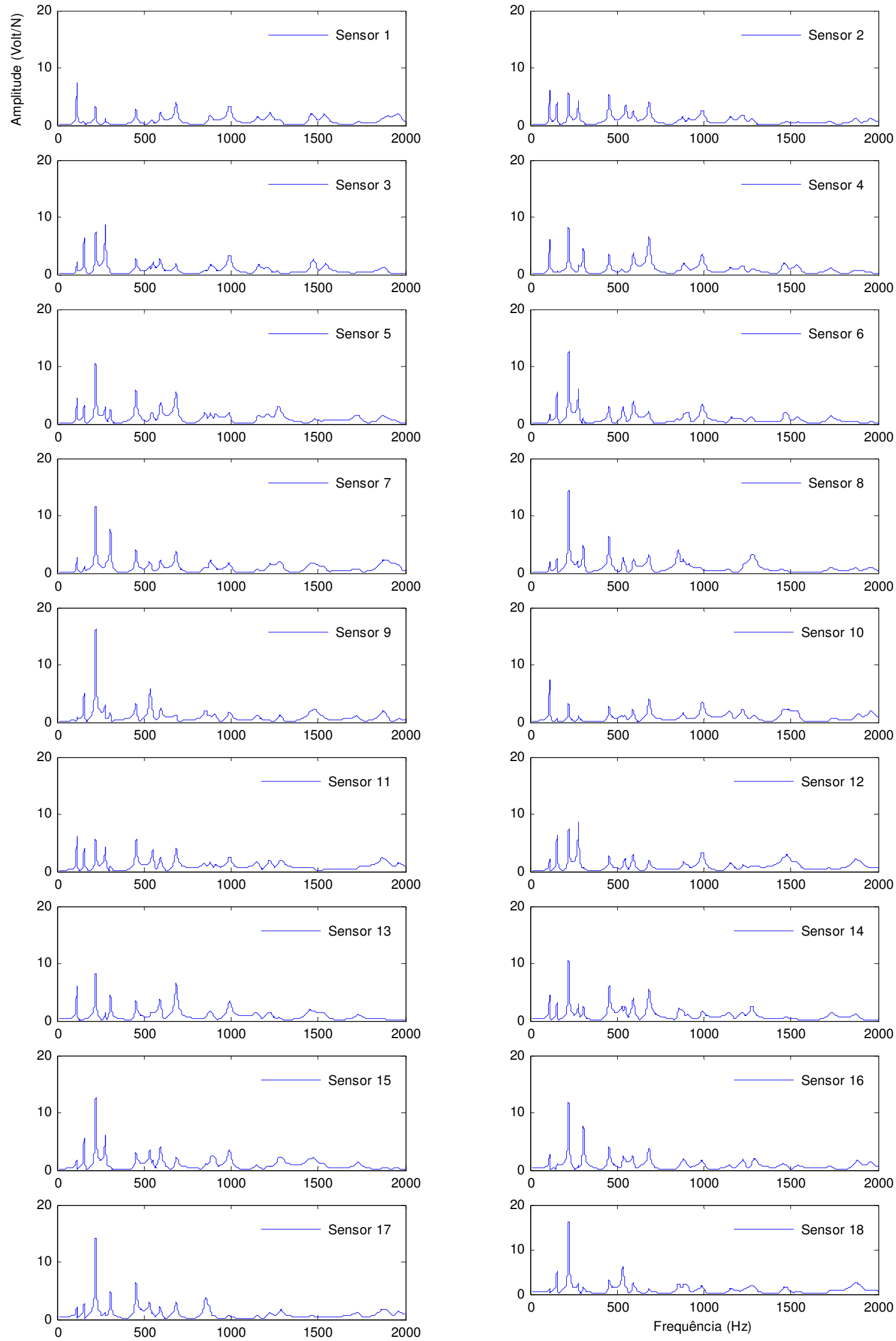

Figura 2.10 - Amplitude da tensão elétrica induzida nos sensores indexados de 1 até 18, por unidade de força aplicada, no domínio da frequência. 

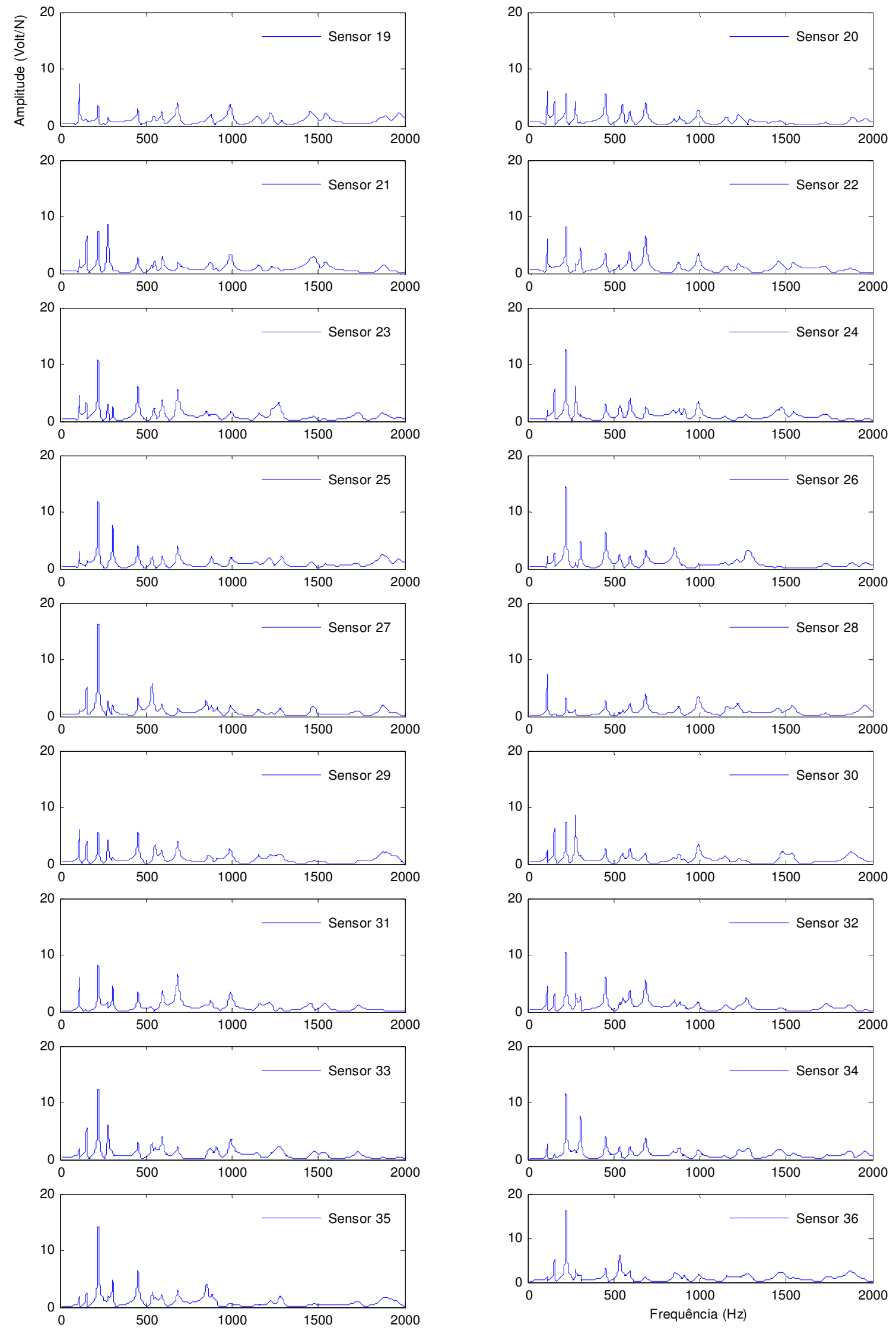

Figura 2.11 - Amplitude da tensão elétrica induzida nos sensores indexados de 19 até 36, por unidade de força aplicada, no domínio da frequência. 
A análise harmônica no software ANSYS requer a especificação do tipo de carregamento. A discretização no domínio de frequência exige a especificação dos limites e sub-passos que deverão estar representados no arquivo de resposta em frequência. As matrizes de resposta em frequência podem ser apresentadas na forma amplitude e fase ou real e imaginário.

As Figs. 2.10 e 2.11 representam a resposta harmônica de cada um dos trinta e seis sensores piezelétricos colados sobre a placa, como resposta à excitação senoidal aplicada. Como pode ser observado, cada sensor apresenta uma distribuição característica de tensão elétrica no domínio de frequência. De fato, o estado de tensão induzida em cada frequência de excitação depende do posicionamento do sensor sobre a estrutura. As medidas de tensão são um indicativo da sensibilidade dos sensores relativa a cada modo de vibrar, ou da qualidade do EMCC dos sensores. 


\section{Projeto de filtros modais usando redes de sensores}

\subsection{Introdução}

Um filtro modal é uma transformação espacial que fornece as coordenadas modais de um sistema a partir de sua resposta dinâmica. Filtros modais discretos derivam do processamento da resposta medida em pontos específicos de um sistema de parâmetros distribuídos (sistema contínuo), nos domínios do tempo ou frequência. Em geral, trabalha-se com a matriz função de resposta em frequência (FRF), obtida a partir de dados experimentais ou numéricos. O uso de FRFs experimentais dispensa a modelagem analítica do sistema.

Neste trabalho, usa-se uma rede de sensores piezelétricos para medir a resposta dinâmica em regiões específicas da superfície de uma placa metálica e construir filtros modais discretos de alto desempenho a partir de técnicas de ponderação dos sinais de tensão elétrica e otimização topológica.

Na prática, é de interesse analisar o comportamento dinâmico de um sistema mecânico em uma faixa limitada de frequência, na qual um número restrito de modos de vibrar são excitados. O truncamento na banda de frequência define uma resposta dinâmica reduzida. O objetivo de um filtro modal é processar a resposta reduzida e extrair as coordenadas modais de um conjunto seleto de modos de vibrar.

A filtragem modal a partir de uma rede de sensores discretos é alcançada pela soma ponderada dos sinais de tensão disponíveis. O cálculo dos coeficientes de 
ponderação dos sinais de tensão é otimizado de forma que a sensibilidade da rede de sensores seja maximizada em relação aos modos alvos (que se deseja medir) e minimizada em relação aos modos residuais (que se deseja filtrar).

Há basicamente três técnicas de ponderação de sinais para o projeto de filtros modais baseadas na utilização de uma rede de sensores discretos (FRIPP; ATALLA, 2001): i) ponderação dos sinais de tensão pela forma dos modos alvos, ii) ponderação baseada na definição de uma função objetivo de otimização, e iii) ponderação pela pseudo-inversão da matriz complexa de resposta em frequência.

Este trabalho utiliza o método de pseudo-inversão da matriz de FRF. Em geral, este método otimiza os coeficientes de ponderação a partir de medidas experimentais da resposta dinâmica da estrutura, descrevendo o estado real da estrutura, o que minimiza erros devido à variações de parâmetros do modelo. Não obstante, é possível monitorar a variação de parâmetros estruturais em tempo real, o que encontra grandes aplicações em monitoramento e detecção de falhas estruturais. Uma outra característica desejável deste método é a possibilidade de sua implementação a partir de circuitos analógicos simples.

As principais limitações do método de pseudo-inversão matricial são basicamente duas: i) o uso de uma rede de sensores e atuadores integrados gera uma matriz de transferência tridimensional, para a qual a pseudo-inversa não está definida e ii) não é possível exercer um ajuste controlado sobre o desempenho do filtro na banda de frequência. É conveniente ressaltar que este método pode também ser suscetível a erros numéricos.

No caso geral, a ponderação dos sinais de redes de sensores, ou sensores e atuadores integrados, é reconfigurável via software, de forma que uma única rede admite ponderações para o isolamento de diferentes modos alvos. Em cada caso, a otimização dos coeficientes de ponderação leva em conta o conjunto de modos alvos e a banda de frequência considerada no processo de filtragem. 
Embora diversos trabalhos tenham relacionado o número de modos efetivamente isolados pelas técnicas de ponderação dos sinais de tensão ao número de sensores ativos na rede, o desempenho limitado dos filtros modais abre perspectivas para o estudo de processos de otimização complementares. Desta forma, o estudo da otimização topológica de uma rede de sensores surge como uma etapa natural em projetos de filtros modais de alto desempenho.

\subsection{Projeto de filtros modais usando inversão da matriz de FRFs}

As coordenadas modais no domínio da frequência, ou FRFs modais, definem sistemas de um único grau de liberdade. A forma da FRF de um sistema de um grau de liberdade, com frequência natural $\omega_{i}$ e fator de amortecimento modal $\xi_{i}$, pode ser construída a partir da equação (PREUMONT ET AL, 2003)

$$
g_{i}(\omega)=\frac{2 \xi_{i} \omega_{i}^{2}}{\omega_{i}^{2}-\omega^{2}+2 j \xi_{i} \omega_{i} \omega}
$$

A amplitude de vibração em um ponto da estrutura pode ser aproximada pela soma ponderada das amplitudes de cada modo excitado. Entretanto, se os modos são pouco amortecidos e relativamente bem espaçados, o pico de amplitude em cada frequência de ressonância é bem definido pelas coordenadas do modo ressonante. Nestas condições, a eq. (3.1) representa uma construção realista de um modo de vibrar.

A Fig. 3.1 mostra as coordenadas modais isoladas a partir do uso da eq. (3.1), para os quatro primeiros modos de vibrar, nas respectivas frequências de ressonância da placa considerada neste trabalho. 


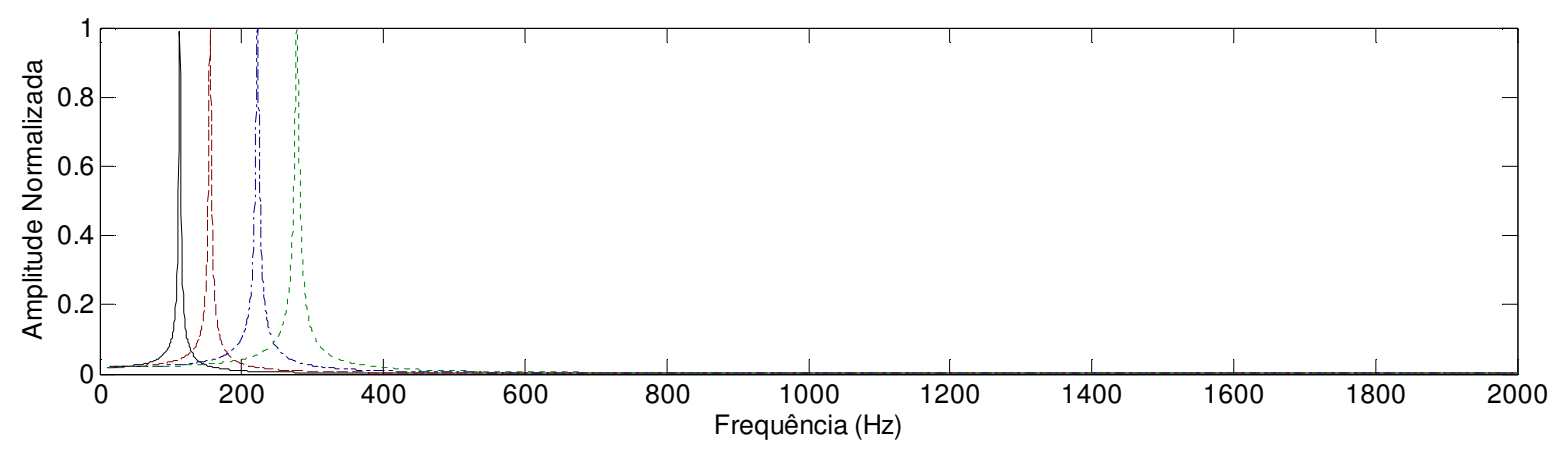

Figura 3.1 - Amplitude normalizada das respostas dos quatro primeiros modos alvos (representação gráfica do vetor $\boldsymbol{G}_{\boldsymbol{i}}$ para $\boldsymbol{i}$ de 1 até 4 ).

Seja $\boldsymbol{Y}$ a matriz complexa de respostas em tensão dos sensores no domínio de frequência $\left[\omega_{1}, \ldots, \omega_{m}\right]$, sendo que cada uma de suas $n$ colunas representa a resposta de um único sensor da rede. Seja $\boldsymbol{G}_{i}=\left[g_{i}\left(\omega_{1}\right), \ldots, g_{i}\left(\omega_{m}\right)\right]$ o vetor que representa a discretização da eq. (3.1) no domínio da frequência

$$
\left[\begin{array}{ccc}
Y_{1}\left(\omega_{1}\right) & \cdots & Y_{n}\left(\omega_{1}\right) \\
\vdots & \ddots & \vdots \\
Y_{1}\left(\omega_{m}\right) & \cdots & Y_{n}\left(\omega_{m}\right)
\end{array}\right]\left\{\begin{array}{c}
\alpha_{i 1} \\
\vdots \\
\alpha_{i n}
\end{array}\right\}=\left\{\begin{array}{c}
g_{i}\left(\omega_{1}\right) \\
\vdots \\
g_{i}\left(\omega_{m}\right)
\end{array}\right\}
$$

Na eq. (3.2), o vetor de variáveis $\boldsymbol{\alpha}_{\mathrm{i}}$ agrupa os coeficientes de ponderação que tornam a soma ponderada das FRFs dos sensores idêntica à resposta de um sistema de um único grau de liberdade, representada pelo vetor $\boldsymbol{G}_{i}$.

Em geral, o sistema linear definido pela eq. (3.2) não admite solução exata. A solução $\boldsymbol{\alpha}_{i}^{\dagger}$ representa a melhor solução do sistema obtida pelo método de mínimos quadrados. A eq. (3.2) representa um processo analítico para a construção de filtros modais a partir de sinais numéricos ou experimentais, nos quais deseja-se isolar o modo de vibrar representado, na sua forma discreta, pelo vetor $\boldsymbol{G}_{i}$.

Se vários modos alvos são considerados na eq. (3.2), o vetor $\boldsymbol{G}_{\boldsymbol{i}}$ deverá ser substituído pela matriz $\boldsymbol{G}$, que define as respostas (FRFs modais) de um conjunto de sistemas com um grau de liberdade. Se $p$ modos alvos são considerados, a matriz $\boldsymbol{G}$ terá dimensão $m \times \mathrm{p}$. 
Conseqüentemente, a solução da eq. (3.2), que denota-se $\boldsymbol{\alpha}^{\dagger}$, será uma matriz de dimensão $n \times p$, na qual cada coluna é o vetor de coeficientes de ponderação que melhor isola as coordenadas modais associadas à cada coluna da matriz $\boldsymbol{G}$. Em notação compacta, a eq. (3.2) se escreve:

$$
Y \boldsymbol{\alpha}^{\dagger}=\boldsymbol{G}
$$

$\mathrm{Na}$ medida em que apenas soluções aproximadas são possíveis, $\boldsymbol{Y} \boldsymbol{\alpha}^{\dagger}$ é a melhor aproximação para $\boldsymbol{G}^{\dagger}$; a matriz cujas colunas são as projeções ortogonais dos vetores de coordenadas modais sobre o espaço gerado pelas colunas da matriz de resposta em frequência $\boldsymbol{Y}$. Multiplicando a eq. (3.3) por $\boldsymbol{Y}^{H}$, onde o símbolo $H$ denota hermitiano, tem-se:

$$
\boldsymbol{Y}^{H} \boldsymbol{Y} \boldsymbol{\alpha}^{\dagger}=\boldsymbol{Y}^{H} \boldsymbol{G}
$$

A partir da eq. (3.4), calcula-se a matriz de soluções aproximadas $\boldsymbol{\alpha}^{\dagger}$ :

$$
\boldsymbol{\alpha}^{\dagger}=\left(\boldsymbol{Y}^{H} \boldsymbol{Y}\right)^{-1} \boldsymbol{Y}^{H} \boldsymbol{G},
$$

pela ação da pseudo-inversa da matriz de resposta em frequência, $\boldsymbol{Y}^{\dagger}=\left(\boldsymbol{Y}^{H} \boldsymbol{Y}\right)^{-1} \boldsymbol{Y}^{H}$, sobre a matriz $\boldsymbol{G}$. A condição para a existência da solução aproximada recai sobre a não singularidade da matriz $\left(\boldsymbol{Y}^{H} \boldsymbol{Y}\right)^{-1}$. Em geral, a melhor solução aproximada é aquela que minimiza a norma euclidiana do resíduo. Em termos das matrizes $\boldsymbol{Y}, \boldsymbol{G}$ e $\boldsymbol{\alpha}$, a norma do resíduo é definida pela equação

$$
\|\boldsymbol{G}-\boldsymbol{Y} \boldsymbol{\alpha}\|_{2}^{2}=(\boldsymbol{G}-\boldsymbol{Y} \boldsymbol{\alpha})^{H}(\boldsymbol{G}-\boldsymbol{Y} \boldsymbol{\alpha})=\boldsymbol{\alpha}^{H} \boldsymbol{Y}^{H} \boldsymbol{Y} \boldsymbol{\alpha}-2 \boldsymbol{\alpha}^{H} \boldsymbol{Y}^{H} \boldsymbol{G}+\boldsymbol{G}^{H} \boldsymbol{G} .
$$


Define-se a função $\Phi(\alpha)=\boldsymbol{\alpha}^{H} \boldsymbol{Y}^{H} \boldsymbol{Y} \boldsymbol{\alpha}-2 \boldsymbol{\alpha}^{H} \boldsymbol{Y}^{H} \boldsymbol{G}+\boldsymbol{G}^{H} \boldsymbol{G}$, cujo gradiente tem a forma:

$$
\nabla[\Phi(\alpha)]=2 \boldsymbol{Y}^{H} \boldsymbol{Y} \boldsymbol{\alpha}-2 \boldsymbol{Y}^{H} \boldsymbol{G} .
$$

A solução de mínimos quadrados, que denota-se $\boldsymbol{\alpha}^{*}$, é aquela que minimiza a função $\Phi\left(\alpha^{*}\right)$, tornando nulo o seu gradiente:

$$
\nabla\left[\Phi\left(\alpha^{*}\right)\right]=0
$$

A eq. (3.7) pode ser escrita na seguinte forma:

$$
2 \boldsymbol{Y}^{H} \boldsymbol{Y} \boldsymbol{\alpha}^{*}-2 \boldsymbol{Y}^{H} \boldsymbol{G}=0 .
$$

Resolvendo a eq. (3.9) em termos de $\boldsymbol{\alpha}^{*}$, tem-se:

$$
\boldsymbol{\alpha}^{*}=\left(\boldsymbol{Y}^{H} \boldsymbol{Y}\right)^{-1} \boldsymbol{Y}^{H} \boldsymbol{G} .
$$

Comparando a eq. (3.10) à eq. (3.5), vê-se que a solução da eq. (3.3) pelo método de pseudo-inversão da matriz $\boldsymbol{Y}$ provê a solução de mínimos quadrados. Se o objetivo da otimização é minimizar a norma euclidiana do resíduo pelo método de pseudo-inversão, uma discussão crítica sobre a forma apropriada para a decomposição da matriz $\boldsymbol{Y}$ é necessária. Tal discussão se justifica pelo fato de que o custo computacional envolvido na solução de um sistema de equações lineares sobreposto está intrinsecamente relacionado aos métodos numéricos empregados.

O método mais geral de fatoração matricial se baseia na decomposição por valores singulares (SVD). No caso em estudo, a solução pelo método de mínimos quadrados baseada em SVD será adequada ao caso em que a matriz $\boldsymbol{Y}$ apresentar 
posto deficiente, ou deficiência de posto. De outra forma, se a matriz $\boldsymbol{Y}$ tem posto completo, a solução de mínimos quadrados desejada $\boldsymbol{\alpha}^{*}$, pode ser encontrada a partir da decomposição QR da matriz $\boldsymbol{Y}$ :

$$
\boldsymbol{Y}=\boldsymbol{Q} \boldsymbol{R}
$$

Na eq. (3.11), a matriz $\boldsymbol{Y}$ é decomposta em uma matriz ortogonal $\boldsymbol{Q}(m x m)$ e uma matriz triangular superior $\boldsymbol{R}(m \times n)$. Em termos da decomposição QR da matriz $\boldsymbol{Y}$, a solução de mínimos quadrados se escreve:

$$
\begin{gathered}
\boldsymbol{\alpha}^{*}=\left[(\boldsymbol{Q} \boldsymbol{R})^{H} \boldsymbol{Q} \boldsymbol{R}\right]^{-1}(\boldsymbol{Q} \boldsymbol{R})^{H} \boldsymbol{G} \\
\boldsymbol{\alpha}^{*}=\left[\boldsymbol{R}^{H}\left(\boldsymbol{Q}^{H} \boldsymbol{Q}\right) \boldsymbol{R}\right]^{-1} \boldsymbol{R}^{H} \boldsymbol{Q}^{H} \boldsymbol{G} \\
\boldsymbol{\alpha}^{*}=\boldsymbol{R}^{-1}\left(\boldsymbol{R}^{H}\right)^{-1} \boldsymbol{R}^{H} \boldsymbol{Q}^{H} \boldsymbol{G} \\
\boldsymbol{\alpha}^{*}=\boldsymbol{R}^{-1} \boldsymbol{Q}^{H} \boldsymbol{G}
\end{gathered}
$$

Na prática, a inversão de $\boldsymbol{R}$ é desnecessária. Ao invés disto, o sistema triângular superior $\boldsymbol{R} \boldsymbol{\alpha}^{*}=\boldsymbol{Q}^{H} \boldsymbol{G}$ é resolvido por métodos numéricos elementares, o que reduz o custo computacional. Uma descrição mais detalhada sobre métodos de mínimos quadrados baseados em decomposições SVD e QR pode ser encontrada em (STRANG, 1993).

As colunas da matriz $\boldsymbol{Y}$ são vetores de respostas em frequência medidas por sensores discretos, em regiões específicas da estrutura, e suas linhas representam as tensões elétricas na rede de sensores, medidas em cada ponto do espectro discreto de frequência definido para a análise. Em geral, o número de aquisições é muito maior que o número de sensores na rede. Daí, o sistema linear representado pela eq. (3.2) 
ser sobreposto e o posto da matriz $\boldsymbol{Y}$ ser definido pelo número de colunas linearmente independentes.

Simulações numéricas mostram que a matriz composta pela resposta dos trinta e seis sensores distribuídos sobre a placa de alumínio sempre possui posto completo. Isto significa que as respostas dos trinta e seis sensores são linearmente independentes, e qualquer combinação destas respostas também o será.

Este resultado justifica o uso da decomposição QR da matriz $\boldsymbol{Y}$ na solução do particular problema de mínimos quadrados. Há dois fatores que podem condicionar o posto da matriz $\boldsymbol{Y}$ : a topologia da rede de sensores e a faixa de frequência em análise. Se estes fatores forem definidos de forma que a matriz $\boldsymbol{Y}$ apresente deficiência de posto (colunas linearmente dependentes), então as respostas de alguns sensores da rede serão equivalentes entre si. Para efeitos práticos, a rede será composta por um menor número de sensores e apresentará um desempenho menos robusto em projetos de filtros modais.

Conseqüentemente, espera-se que os filtros modais de mais alto desempenho sejam obtidos a partir de respostas linearmente independentes, para as quais a decomposição QR da matriz completa de respostas em frequência é apropriada.

Na prática, a matriz $\boldsymbol{Y}$ é definida sobre uma banda limitada de frequência. Do ponto de vista da análise modal experimental, este fato limita o cálculo dos parâmetros modais ao referido intervalo de frequência. Embora, em teoria, infinitos modos sejam necessários para a descrição exata da resposta dinâmica de um sistema, vários autores argumentam que a resposta pode ser modelada de forma precisa a partir de um número finito de modos de vibrar. Tais argumentos se justificam pelo fato de que modos em alta frequência, em geral, são pouco excitáveis e apresentam alto amortecimento modal. Não obstante, as medições de resposta em frequência são condicionadas pela capacidade limitada de aquisição e processamento de dados e pela limitação funcional de sensores e atuadores. 
Em aplicações numéricas, os modos em frequências mais altas podem ser eliminados pelo simples truncamento da matriz de resposta em frequência. Todos os resultados aqui deduzidos para a matriz FRF completa são igualmente aplicáveis à matriz truncada.

Conforme os resultados apresentados na seção 3.3, o índice de desempenho de um conjunto de filtros modais está relacionado aos números de sensores ativos na rede e modos excitados na matriz FRF. Em termos numéricos, cada vetor de ponderação calculado pelo método de mínimos quadrados, ou coluna da matriz $\boldsymbol{\alpha}^{\dagger}$, é função implícita do número de pontos aquisitados na FRF. Desta forma:

$$
\boldsymbol{\alpha}^{\dagger}=\boldsymbol{\alpha}^{\dagger}\left(\omega_{m}\right)
$$

Denota-se por $\boldsymbol{Y}_{t}$ e $\boldsymbol{G}_{t}$ as matrizes $\boldsymbol{Y}$ e $\boldsymbol{G}$ truncadas na frequência $\omega_{t},\left(\omega_{1}<\omega_{t}<\right.$ $\left.\omega_{m}\right)$, e $\overline{\boldsymbol{\alpha}}^{\dagger}$ a matriz de coeficientes que representa a solução aproximada da equação $\boldsymbol{Y}_{t}=\overline{\boldsymbol{\alpha}}^{\dagger} \boldsymbol{G}_{t}$, pelo método de mínimos quadrados. Seja $\omega_{l}$ a frequência limite até a qual todos os modos alvos são efetivamente filtrados, e a partir da qual o filtro apresenta uma súbita perda de qualidade. $\mathrm{O}$ intervalo $\left[\omega_{1}, \omega_{l}\right]$ define a extensão da banda de frequência na qual o filtro é eficiente no isolamento de um conjunto específico de coordenadas modais. Dois casos de otimização, em termos da banda de frequência efetiva no processo de filtragem modal, são considerados:

i) Se $\omega_{t} \leq \omega_{l}$, é possível encontrar um número mínimo de sensores que torne o filtro modal topologicamente robusto no intervalo $\left[\omega_{1}, \omega_{t}\right]$, na medida em que este apresenta alto desempenho para uma grande variedade de topologias de rede. Neste caso, o filtro modal é projetado para um desempenho ótimo na faixa $\left[\omega_{1}, \omega_{t}\right]$ e a otimização topológica seleciona a rede com melhor desempenho na faixa $\left[\omega_{t}, \omega_{m}\right]$.

ii) De outra forma, se $\omega_{t} \geq \omega_{l}$, o filtro não é topologicamente robusto. Em geral, o ganho conseguido na faixa $\left[\omega_{l}, \omega_{t}\right]$ se dá às custas de um pior desempenho dos filtros em toda a faixa de truncamento. Sendo o filtro modal projetado para um 
desempenho ótimo na faixa $\left[\omega_{1}, \omega_{t}\right]$, a otimização topológica seleciona a rede com melhor desempenho na faixa de projeto do filtro e ignora o desempenho da rede na faixa $\left[\omega_{t}, \omega_{m}\right]$.

Este trabalho considera um espectro de frequência discreto com 3980 pontos uniformemente espaçados $0.5 \mathrm{~Hz}$.

\subsection{Aplicação da técnica para uma placa com pastilhas piezelétricas}

Nesta seção é apresentada um visão geral sobre a possibilidade de derivar filtros modais de alto desempenho a partir uma rede de sensores discretos. São apresentados alguns resultados que relacionam o desempenho dos filtros modais ao número de sensores na rede e à quantidade de modos na banda de frequência truncada.

A primeira análise consiste em determinar o número mínimo de sensores necessários para isolar os dois primeiros modos de vibrar até $1000 \mathrm{~Hz}$, utilizando a média e o intervalo de confiança da norma do erro residual para 10.000 filtros modais derivados de topologias de rede geradas aleatoriamente como índices de desempenho. Para cada topologia, a norma do erro residual é calculada usando

$$
E_{r}=\left\|\left|\boldsymbol{G}_{t}\right|-\left|\boldsymbol{Y}_{t} \boldsymbol{\alpha}^{\dagger}\right|\right\|_{2}
$$

As Figs. 3.2 até 3.7 mostram a média, linha traço-ponto em azul, e o intervalo de confiança da saída normalizada dos filtros modais, área em amarelo, projetados para isolar os dois primeiros modos de vibrar até $1000 \mathrm{~Hz}$, cada qual obtido pela soma ponderada dos sinais de tensão de doze, quatorze e dezesseis sensores, respectivamente. Em todos os casos, os filtros são calculados a partir de uma amostragem de 10.000 topologias de rede selecionadas aleatoriamente. 


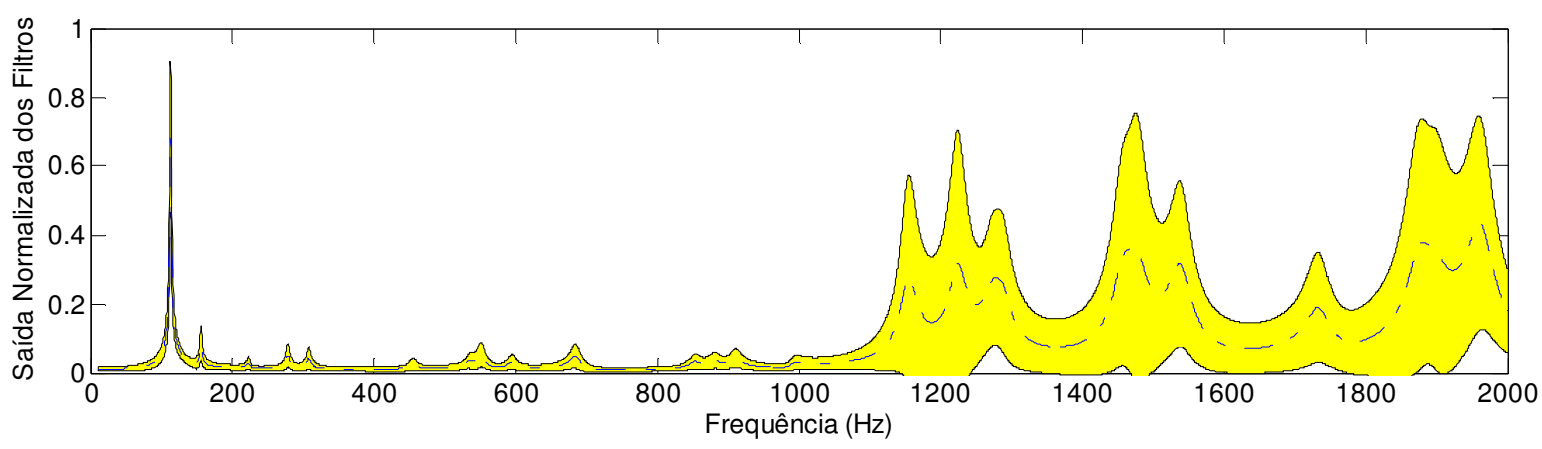

Figura 3.2 - Média e intervalo de confiança da resposta do filtro modal projetado para isolar o primeiro modo de vibrar utilizando redes compostas por 12 sensores.

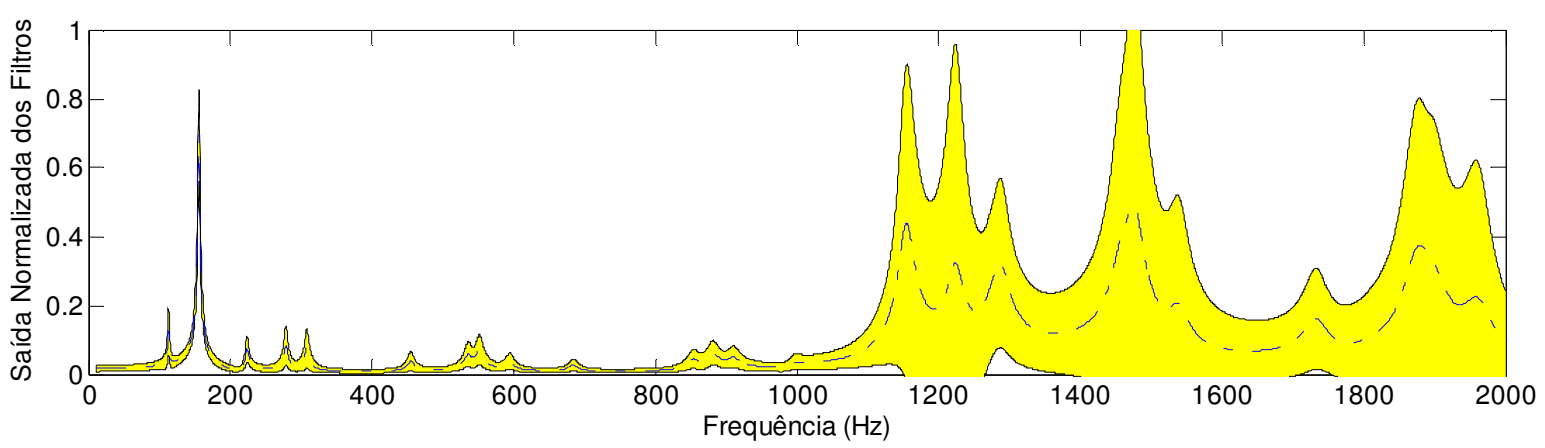

Figura 3.3 - Média e intervalo de confiança da resposta do filtro modal projetado para isolar o segundo modo de vibrar utilizando redes compostas por 12 sensores.

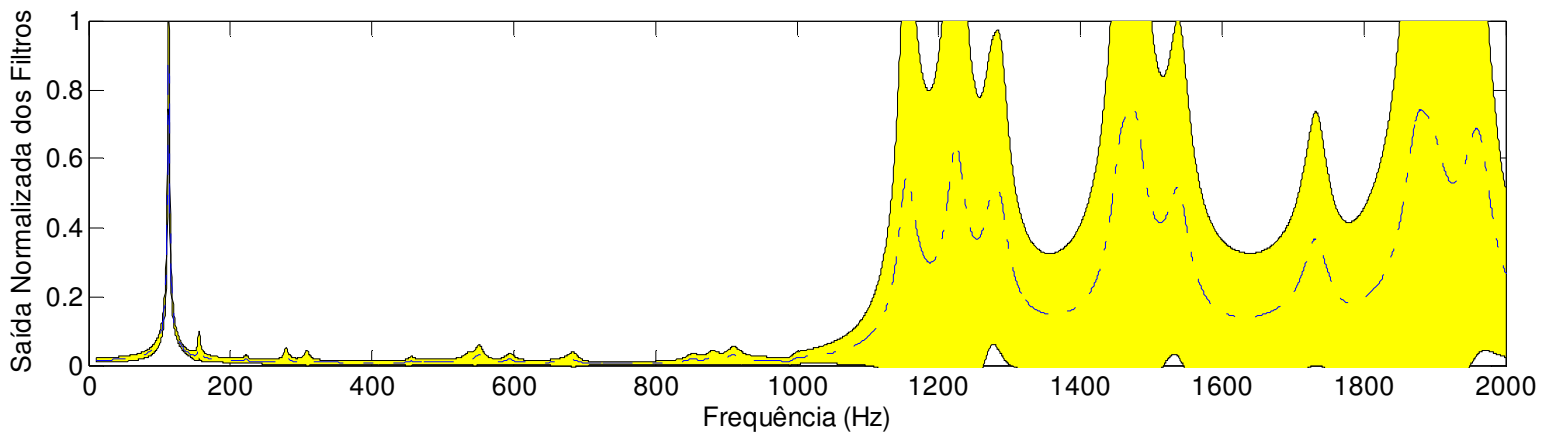

Figura 3.4 - Média e intervalo de confiança da resposta do filtro modal projetado para isolar o primeiro modo de vibrar utilizando redes compostas por 14 sensores. 


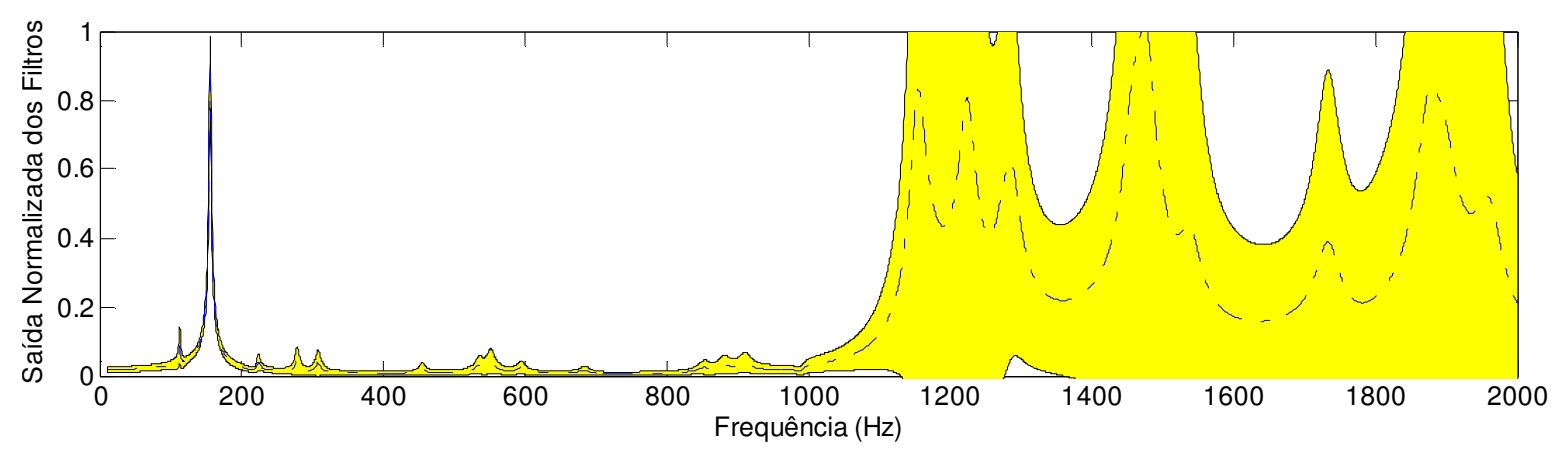

Figura 3.5 - Média e intervalo de confiança da resposta do filtro modal projetado para isolar o segundo modo de vibrar utilizando redes compostas por 14 sensores.

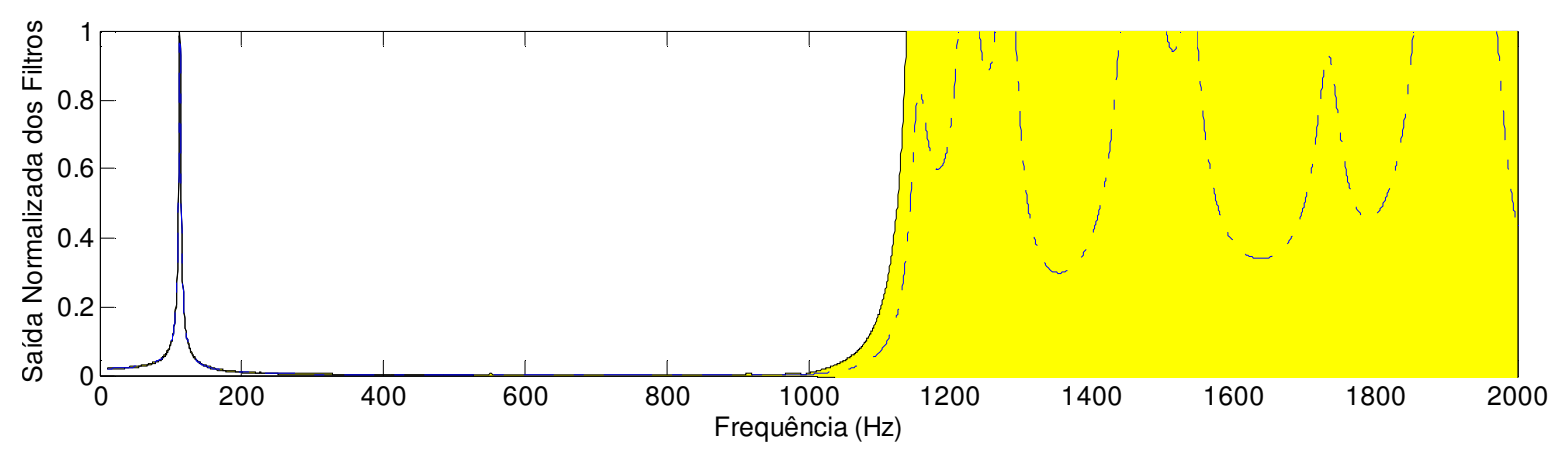

Figura 3.6 - Média e intervalo de confiança da resposta do filtro modal projetado para isolar o primeiro modo de vibrar utilizando redes compostas por 16 sensores.

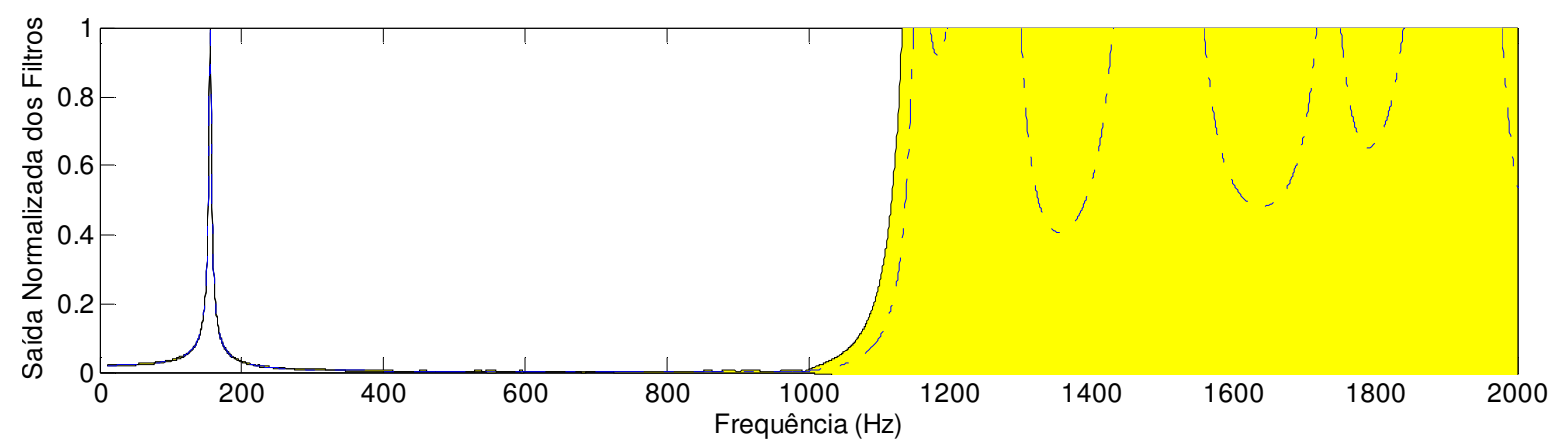

Figura 3.7 - Média e intervalo de confiança da resposta do filtro modal projetado para isolar o segundo modo de vibrar utilizando redes compostas por 16 sensores.

Na análise estatística apresentada nas Figuras acima, vale ressaltar os seguintes parâmetros: $\mathrm{ns}=$ número de sensores ativos na rede, e nm = número de modos de vibrar na banda de frequência. Neste caso, $(n s=\{12,14,16\})$ e $(n m=14)$. Há dois modos alvos e doze modos residuais na banda de frequência. 
Os filtros mostrados nas Figs. 3.2 e 3.3 foram obtidos a partir da seguinte relação paramétrica: $n s=n m-2$. Os filtros modais derivados a partir desta relação apresentaram desempenho médio insatisfatório na faixa de projeto e um desvio padrão relativamente alto. Os filtros derivados a partir da relação $n s=n m$, conforme as Figs. 3.4 e 3.5, apresentam melhor comportamento médio na faixa de projeto e uma perceptível redução do desvio padrão, sendo mais sensíveis aos dois modos alvos. Por sua vez, os filtros derivados a partir da relação $n s=n m+2$, conforme as Figs. 3.6 e 3.7, apresentaram o comportamento médio desejável na faixa de projeto e um desvio padrão praticamente nulo.

O desvio padrão praticamente nulo obtido na análise estatística de 10.000 amostragem de topologias sugere que os filtros modais derivados da relação $n s=n m+2$ são topologicamente robustos, na medida em que o desempenho é pouco sensível ao posicionamento dos sensores (ou à topologia).

Por outro lado, pode-se aferir que filtros derivados a partir de relações ( $n s \in$ $\mathbb{N}: n s<n m+2)$ são topologicamente menos robustos. Esta margem de variância na robustez dos filtros modais justifica o emprego de otimização topológica como forma de encontrar a topologia da rede de sensores associada ao valor ótimo no intervalo de confiança, que pode ser encontrado no conjunto total de amostras.

Esta análise mostra que o desempenho dos filtros modais em uma banda prescrita de frequência está fortemente relacionado ao número de sensores ativos na rede. É importante notar que o número de amostras consideradas nesta análise é bastante reduzida face o número total de combinações de 36 sensores tomadas 12 a 12 , ou 14 a 14 .

A seguir, uma análise paramétrica é usada para tentar generalizar a relação entre o índice de desempenho dos filtros modais, o número de sensores ativos na rede e o número de modos na banda de frequência truncada. São avaliados os desempenhos de um conjunto de filtros projetados para isolar os dois primeiros modos de vibrar, em função dos seguintes parâmetros: número de sensores ativos na 
rede $n s=\{4,8,12,16,20\}$ e número de modos na banda de frequência $n m \in \mathbb{N}: 1 \leq$ $n m \leq 26$.

Para cada elemento do conjunto ns, um algoritmo gera aleatoriamente 10.000 topologias de rede, cujos índices de desempenho no isolamento dos dois primeiros modos de vibrar são avaliados com base na eq. (3.17). As FRFs que representam as respostas dos sensores selecionados para formar cada topologia de rede são truncadas na frequência $\omega_{t}$, tal que:

$$
\omega_{t}(j)=\frac{\omega_{j}+\omega_{j+1}}{2}, \quad 3 \leq \mathrm{j} \leq 26
$$

sendo $\omega_{j}$ a j-ésima frequência de ressonância de estrutura.

A eq. (3.18) mostra que as FRFs são truncadas em pontos da frequência discretos que são intermediários entre duas ressonância residuais consecutivas a partir do terceiro modo, havendo dois modos alvos e no máximo vinte e quatro modos residuais. A inclusão de cada modo residual na FRF requer uma análise independente, na medida em que a decomposição QR é efetuada a partir das matrizes truncadas.

A Fig. 3.8(a) mostra a média e o intervalo de confiança da norma do erro residual na filtragem dos dois primeiros modos de vibrar devido ao truncamento da FRF nas frequências $\omega_{t}$, para cada valor do parâmetro ns. 

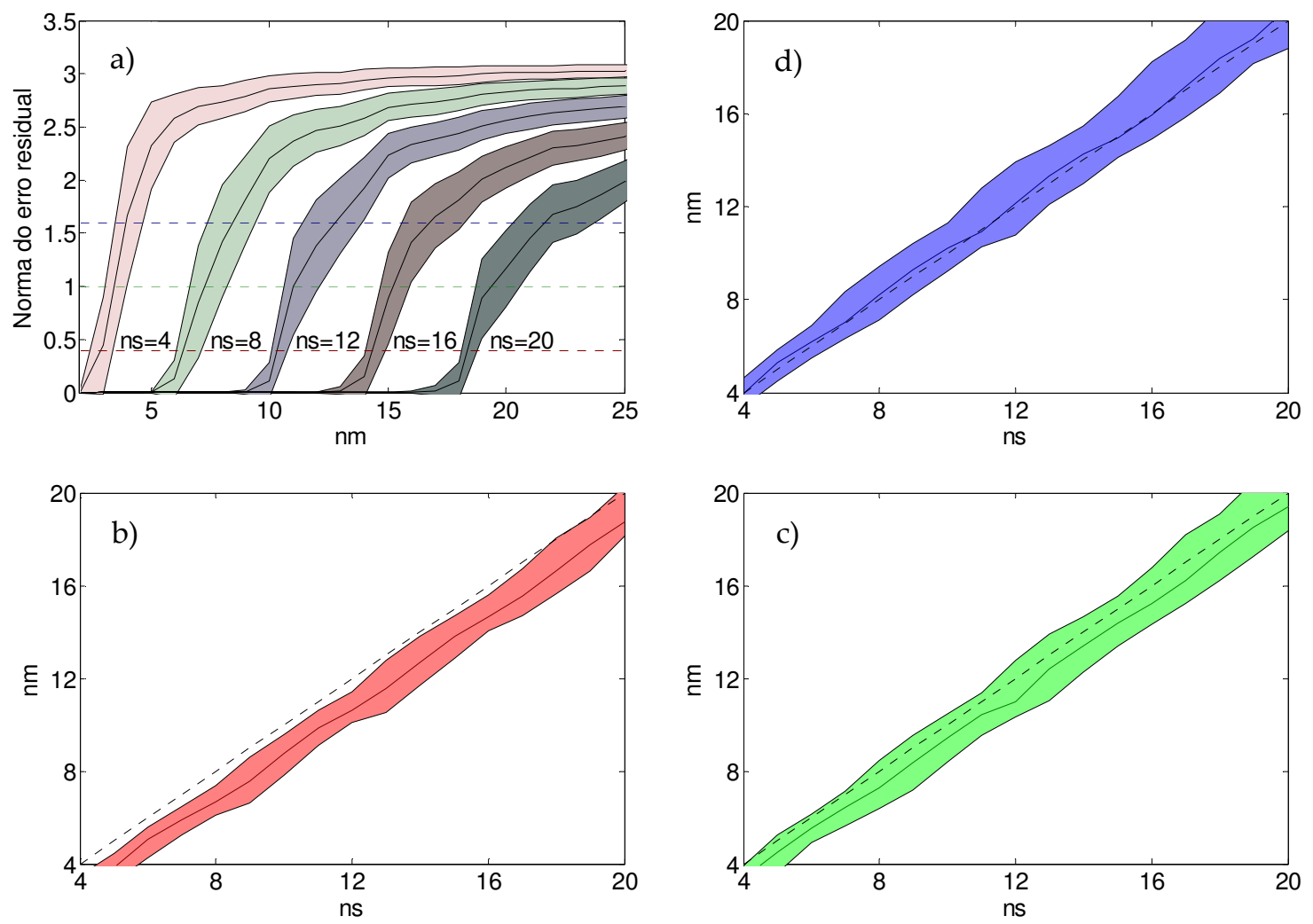

Figura 3.8 - Média e intervalo de confiança da norma do erro residual em termos do número de modos na banda de frequência para diferentes números de sensores: (a). Relação entre o número de sensores e o número de modos para diferentes valores do erro residual: b) $0,4, c) 1,0, d) 1,6$.

Estes resultados mostram, de forma mais geral, que o desempenho ótimo dos filtros modais na banda de frequência é limitado pelo número de sinais de tensão ponderados, ou sensores ativos na rede.

A partir destes limites, a inclusão de um único modo residual na FRF invariavelmente eleva o índice de erro, até então situado em um patamar de valor mínimo, que tende a aumentar à medida que novos modos residuais são incluídos. A partir desta análise é possível estimar o desempenho esperado de um filtro modal em termos dos números de sensores ativos e de modos na banda de frequência truncada, para uma dada estrutura.

Relações diretas entre os parâmetros nm e ns podem ser obtidas a partir dos dados apresentados na Fig. 3.8a, desde que seja fixado um valor de referência para a norma do erro residual. As Figs. 3.8b, 3.8c e 3.8d mostram os valores médios dos 
parâmetros nm e ns e os respectivos intervalos de confiança para diferentes valores do erro residual, respectivamente $0,4,1,0$ e 1,6. Fixando o valor de referência para o erro residual em 0,4 é possível verificar a seguinte relação aproximada ( $n s \in \mathbb{N}: n m-$ $2 \leq n s \leq n m$ ), o que significa, por exemplo, que é possível filtrar 8,9 ou 10 modos residuais utilizando uma rede de doze sensores para isolar os dois primeiros modos de vibrar. De fato, como sugerem os filtos representados nas Figs. 3.6 e 3.7, a relação $n s=n m+2$ é esperada para um erro residual abaixo de 0,4.

A Fig. $3.8 \mathrm{c}$ mostra que uma relação $n s=n m$ encontra-se próxima à média dos valores amostrados e poderia ser esperada para um erro residual de 1,0. A Fig. 3.8d mostra que é possível alcançar, na média, a relação aproximada $n s=n m$ a partir de um erro residual de 1,6.

Os resultados mostram que, para o conjunto de topologias amostradas, a relação $n s=n m-2$ é obtida somente a partir de valores de erros residuais altos o suficiente para invalidar a aplicação dos filtros modais em controle integrado ou monitoramento de integridade estrutural para a detecção de falhas. No entanto, a análise indica que seria possível usar otimização topológica para alcançar a relação $n s=n m-2$ a partir de um valor aceitável para a norma do erro residual e validar a viabilidade da aplicação dos filtros modais obtidos a partir de um número reduzido de sensores.

Em seguida, uma perspectiva complementar sobre o uso de topologias de rede com número fixo de sensores para filtragem modal é apresentada. A Fig. 3.9 mostra uma topologia de forma retangular, com doze sensores ativos (em vermelho), e os filtros para os dois primeiros modos de vibração derivados pela soma ponderada dos sinais de tensão dos sensores ativos. A matriz de FRF foi truncada em $800 \mathrm{~Hz}$, de forma a filtrar os oito primeiros modos residuais. 


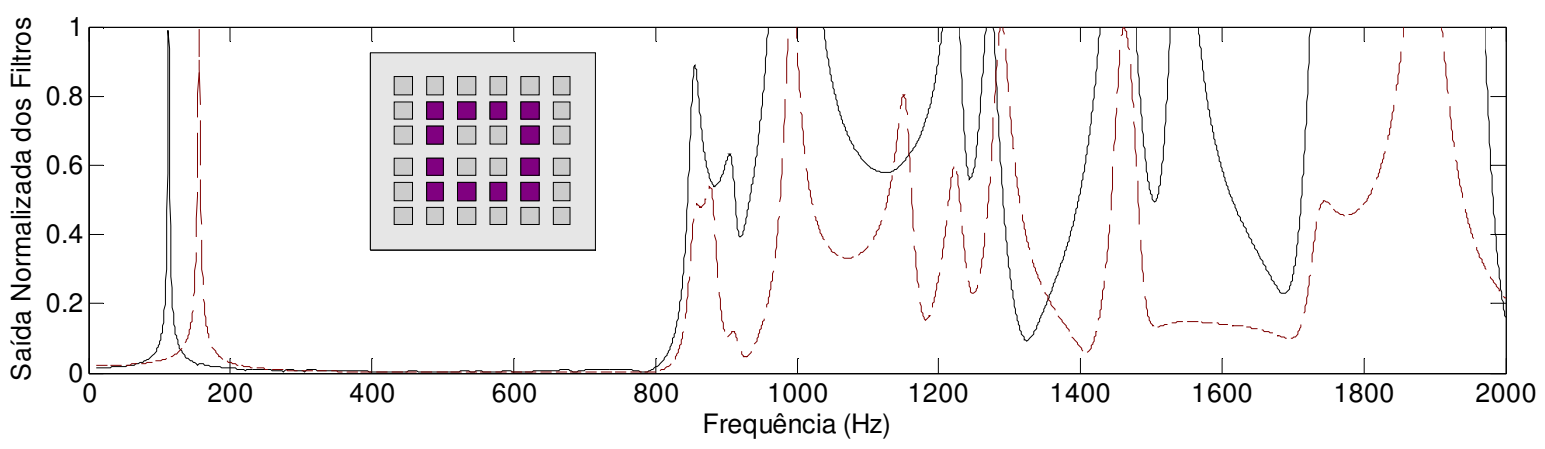

Figura 3.9 - Topologia de rede retangular e filtros modais com desempenho esperado para o isolamento dos dois primeiros modos de vibrar até $800 \mathrm{~Hz}$.

Como pode ser observado na Fig. 3.9, os filtros apresentaram ótimo desempenho na faixa de projeto, sem a necessidade de otimização topológica.

A Fig. 3.10 mostra os filtros para os dois primeiros modos de vibrar derivados da mesma topologia de rede retangular, com a matriz de FRF truncada em $1000 \mathrm{~Hz}$, objetivando filtrar os doze primeiros modos residuais (quatro modos adicionais).

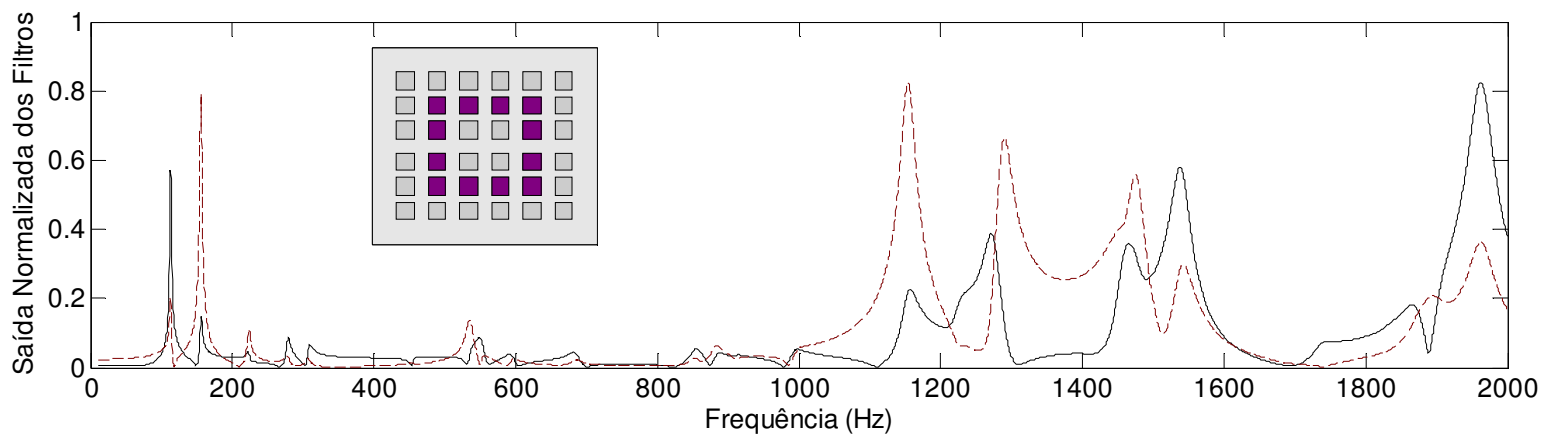

Figura 3.10 - Desempenho degenerado dos filtros modais derivados de uma topologia retangular para o isolamento dos dois primeiros modos de vibrar, quando a matriz de FRF é truncada em $1000 \mathrm{~Hz}$, de forma a incluir quatro modos residuais adicionais.

Neste caso, o que se consegue é filtrar parcialmente os modos residuais com uma baixa sensibilidade aos modos alvos. A tentativa de filtrar os modos residuais na banda de frequência $[800,1000] \mathrm{Hz}$ degradou o desempenho global dos filtros. Este resultado exemplifica o limite de desempenho dos filtros modais derivados de uma topologia de rede arbitrária e coloca a necessidade de otimização topológica 
para assegurar filtros modais de alto desempenho na banda de frequência $[10,1000] \mathrm{Hz}$, a partir de uma rede de doze sensores.

A Fig. 3.11 ilustra o caso de uma topologia de rede particular que dá origem a um filtro modal de baixo desempenho para isolar o segundo modo. Este fato está associado ao fenômeno de Spatial Aliasing, que consiste em padrões similares de tensão elétrica na rede de sensores ativos, quando a estrutura vibra em diferentes frequências naturais. Neste caso, em especial, o baixo desempenho do filtro ocorre devido à forte similaridade nos padrões de tensão correspondentes ao segundo e o sétimo modos de vibrar.

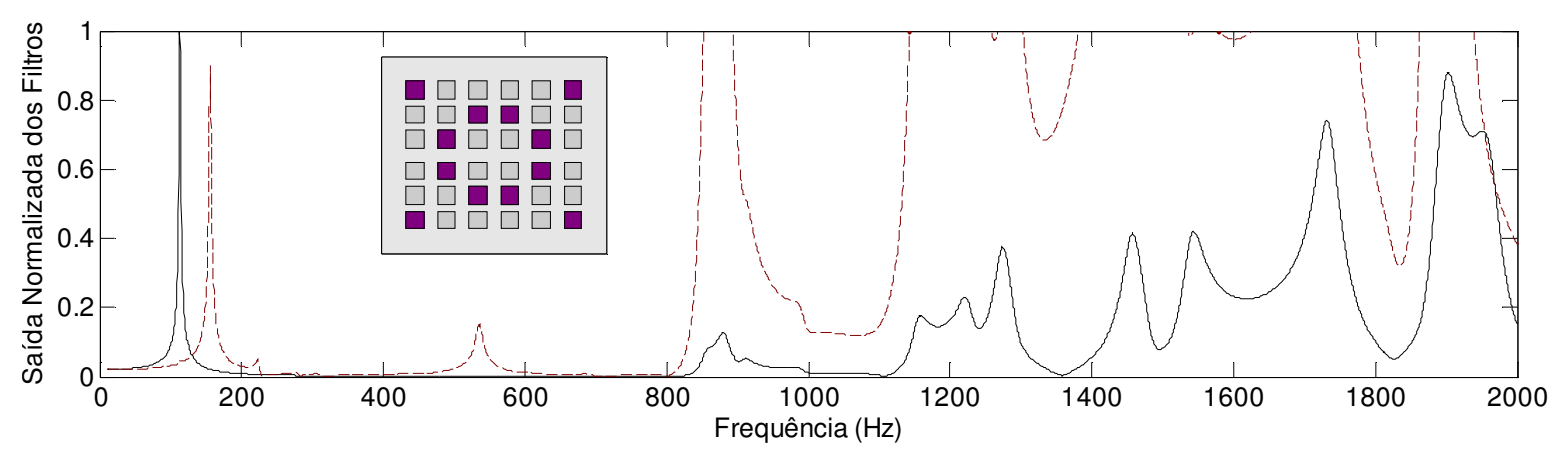

Figura 3.11 - Topologia de sensores ativos e filtros modais para o isolamento dos dois primeiros modos de vibrar até $800 \mathrm{~Hz}$. O filtro para o segundo modo de vibrar apresenta baixo desempenho.

Embora a intensidade do fenômeno de Spatial Aliasing esteja relacionado à topologia da rede de sensores e às condições de contorno da estrutura, a incidência deste fenômeno pode ser prevista para uma rede retangular de sensores monitorando uma estrutura em condições específicas de engaste.

Uma topologia de rede similar àquela representada na Fig. 3.11, que posiciona sensores nas partes central e periférica da placa, é intuitivamente adequada para a leitura simultânea de modos de flexão e torção em baixas frequências e poderia ser naturalmente escolhida na prática.

Os resultados apresentados nesta seção têm por objetivo prover ao leitor uma visão geral sobre a influência da topologia de uma rede de sensores discretos para fins de filtragem modal. Uma pequena amostragem do espaço de soluções foi 
analisada para evidenciar a influência dos parâmetros ns e nm sobre o desempenho médio e o intervalo de confiança dos filtros modais derivados para o isolamento dos dois primeiros modos de vibrar.

No próximo capítulo, serão descritos métodos gerais de otimização topológica com o objetivo de derivar filtros modais de alto desempenho a partir de redes compostas por doze sensores na banda de frequência $[10,1000] \mathrm{Hz}$. 


\section{Otimização do projeto de filtros modais através da topologia de uma rede de sensores}

\subsection{Introdução}

As análises do capítulo anterior mostraram a influência da topologia de uma rede de sensores no desempenho de filtros modais. Assim sendo, ferramentas de otimização topológica podem ser aplicadas a este problema, como forma de maximizar a relação desempenho/número de sensores.

A otimização topológica de um conjunto de elementos discretos, em geral, envolve um problema de otimização combinatorial, para os quais metodologias baseadas em algoritmos genéticos (AG) e redes neurais têm se mostrado bastante promissoras.

\subsection{Descrição do problema de otimização}

\subsubsection{Variáveis de projeto}

A proposta de otimização topológica apresentada neste trabalho foi desenvolvida com base em simulações numéricas pelo método de elementos finitos (ANSYS). Uma estratégia natural a ser seguida seria construir diversos modelos de 
placa com pastilhas piezelétricas, cada qual definindo uma topologia de rede em particular, e avaliar o desempenho dos filtros modais derivados de cada uma delas, com base em algum critério objetivo. Esta estratégia, embora seja a mais geral, exige um modelo de elementos fintios e análises modal e harmônica para cada topologia de rede avaliada, o que implica em alto custo computacional.

Uma estratégia alternativa para se obter resultados a partir de um menor custo computacional foi adotada: constrói-se um modelo em elementos finitos da estrutura placa-sensores com uma rede de 36 pastilhas piezelétricas coladas superficialmente. Os sinais de tensão nos sensores são então calculados, de forma que apenas os sinais de subgrupos dos sensores da rede são efetivamente ponderados para a filtragem modal.

Cada subgrupo de sensores selecionados define uma topologia de rede. As topologias são classificadas de acordo com critérios objetivos de desempenho dos filtros no isolamento de um conjunto seleto de modos de vibrar. Desta forma, um grande número de topologias de rede de sensores são geradas e avaliadas a partir de um único modelo estrutural e uma única análise modal-harmônica.

A relação entre o número total de sensores colados sobre a placa e o número de sensores ativos decorre de uma escolha arbitrária. $\mathrm{O}$ fato relevante é que o número de sensores efetivamente ativados definirá índices de desempenho para os filtros modais em uma banda prescrita de frequência.

Além da redução do custo computacional no processo de otimização topológica, esta metodologia facilita o pós-processamento dos resultados do modelo estrutural. A principal limitação reside no fato de as topologias disponíveis estarem condicionadas às posições dos trinta e seis sensores que definem a rede inicial. Naturalmente, espera-se que o ótimo alcançado seja um sub-ótimo do caso geral, para o qual não há restrições ao posicionamento dos sensores sobre a placa.

Outro fato importante é que a colagem de sensores e/ou atuadores modifica a rigidez global e desloca as frequências naturais de vibração da estrutura. $\mathrm{O}$ objetivo 
deste trabalho é ampliar a faixa de frequência na qual um conjunto de filtros modais apresenta alto desempenho, o que significa filtrar um maior número de modos ressonantes. Do ponto de vista prático, deseja-se um filtro modal de alto desempenho a partir do número mínimo de sensores necessários para garantir tal desempenho. A redução do número de sensores e/ou atuadores torna mais leve a estrutura e reduz os custos e o aparato experimental necessário para a implementação de qualquer projeto baseado em transdutores modais.

Naturalmente, uma vez encontrada a topologia da rede de sensores que maximiza o desempenho de um conjunto de filtros modais, deseja-se utilizar apenas a topologia de rede otimizada para a construção dos filtros. Para validar a metodologia de otimização, é necessário simular a resposta dinâmica da estrutura remodelada com a topologia ótima de sensores, isto é, eliminando-se os sensores inativos, e reavaliar o desempenho dos filtros modais derivados.

Para dimensionar o espaço de soluções associado ao problema de otimização topológica, considere as possíveis combinações de 36 sensores tomados 12 a 12, cada qual definindo uma topologia de rede. O número total de combinações é:

$$
C_{36,12}=\frac{36 !}{12 !(36-12) !}=1,2517 \times 10^{9}
$$

Neste caso, o espaço de soluções é extenso e descontínuo. Métodos determinísticos exploram o espaço de pesquisa ponto a ponto. A função objetivo é avaliada sequêncialmente pela iteração de valores em pontos adjacentes e a busca é direcionada de acordo com o gradiente da função objetivo em cada ponto. Se o espaço de pesquisa for descontínuo, ou as restrições impostas às variáveis de projeto definirem um espaço factível não convexo, o método determinístico poderá não alcançar o máximo global em várias tentativas de alocação do ponto de partida. Se a função objetivo tem caráter multimodal para máximos e mínimos (apresenta máximos e mínimos locais), o método baseado no cálculo do gradiente da função 
objetivo não distinguirá entre pontos de extremo local e global, pois ambos satisfazem o critério de busca pelo ótimo. Desta forma, vê-se que métodos determinísticos são altamente sensíveis ao ponto inicial da pesquisa.

Métodos analíticos, em geral, são muito eficientes na otimização de funções unimodais (um único ponto de máximo ou mínimo), mas apresentam um desempenho limitado na otimização de funções multimodais. Quando aplicáveis, métodos baseados no cálculo de um gradiente podem apresentar alta eficiência computacional em problemas específicos de otimização, que apresentam funções objetivo diferenciáveis e restrições ao espaço de pesquisa não muito severas. São, por isto, também conhecidos como métodos especializados.

A natureza discreta do espaço de soluções define um problema de otimização combinatorial e sugere o uso de métodos heurísticos e busca extensiva. Métodos heurísticos analisam, em cada etapa do processo de otimização, um conjunto de pontos estocasticamente distribuídos, o que permite o mapeamento eficiente do espaço de pesquisa. Algoritmos genéticos apresentam um processo de busca evolutivo, de forma que mesmo quando ótimos locais são atingidos, a pesquisa possa ainda convergir para o ótimo global. A pesquisa evolutiva a partir de pontos mapeados permite a otimização de funções multimodais, descontínuas ou definidas em espaços de contorno irregular, sujeitos a várias condições restritivas.

Neste trabalho, como primeira abordagem ao problema de otimização topológica combinatorial, usa-se o método de busca extensiva para pesquisar um subespaço do espaço de soluções. Em seguida, o problema é codificado para o uso de um algoritimo genético, como forma de expandir o domínio do espaço de pesquisa e criar condições para que a otimização convirja para o ótimo global. 


\subsubsection{Funções objetivo}

Neste trabalho, dois processos de otimização são utilizados em série para maximizar o desempenho de um conjunto de filtros modais: i) os coeficientes de ponderação dos sinais de tensão são otimizados pelo método de mínimos quadrados; e ii) otimização topológica é empregada para selecionar a rede de sensores cujos sinais ponderados maximizam o desempenho dos filtros.

A otimização topológica é baseada em critérios objetivos de desempenho, aos quais chamamos de funções objetivo. Cada função objetivo é considerada um critério independente para quantificar o desempenho dos filtros modais. Consoante ao desempenho dos respectivos filtros, as topologias de rede são classificadas.

\subsubsection{Maximização da largura da banda residual}

A função objetivo $J_{1}$ é usada para maximizar a frequência de validade $\omega_{v}$ para a qual as respostas residuais dos filtros não ultrapassam um valor pré-definido.

$$
J_{1}=\frac{1}{\omega_{v}}
$$

Se o objetivo é isolar vários modos alvos, a função objetivo $J_{1}$ procura maximizar os valores de $\omega_{v}$ até os quais $\left|\boldsymbol{G}_{t}-\boldsymbol{Y}_{t} \boldsymbol{\alpha}^{\dagger}\right| \leq E r$. À cada filtro está associado um valor $\omega_{v}$, de forma que o menor destes valores define o desempenho de um conjunto de filtros projetados simultaneamente. Conforme especificado neste trabalho, a topologia de rede ótima é aquela que maximiza a frequência $\omega_{v}$, até a qual todas as respostas residuais dos filtros se mantêm abaixo de $10 \%$ do valor absoluto das respostas dos filtros nas frequências de ressonância $\left(A_{p}\right)$. Neste caso, $\operatorname{Er}=$ $10 \% A_{p}$. 


\subsubsection{Minimização da norma do resíduo}

Neste caso, os filtros modais são projetados e avaliados na faixa de frequência $[10,1000] \mathrm{Hz}$. Ambas as otimizações pelo método de mínimos quadrados e topológica têm o objetivo comum de maximizar o desempenho dos filtros modais na banda de frequência. A função objetivo $J_{2}$ é definida como:

$$
J_{2}=\left\|\left|\boldsymbol{G}_{t}\right|-\left|\boldsymbol{Y}_{t} \boldsymbol{\alpha}^{\dagger}\right|\right\|_{2} .
$$

Os filtros modais projetados para filtrar modos ressonantes além do décimo modo podem apresentar baixo desempenho global, na medida em que altos níveis de ruído podem ser detectados em toda a faixa de projeto. O objetivo é a filtragem eficaz dos modos ressonantes na faixa [800,1000], de forma a preservar o desempenho ótimo de cada filtro individual na faixa $[10,800]$. Duas definições de norma foram consideradas para a implementação da otimização topológica baseada na função objetivo $J_{2}:$ i) Norma Frobenius; e ii) Norma Euclidiana.

A Norma Frobenius, para o resíduo $\mathcal{R}$, aqui $\mathcal{R}=\boldsymbol{G}_{t}-\boldsymbol{Y}_{t} \boldsymbol{\alpha}^{\dagger}$, é definida como:

$$
\|\mathcal{R}\|_{F}=\sqrt{\sum_{i=1}^{m} \sum_{j=1}^{n}\left(\mathfrak{r}_{i j}\right)^{2}}=\operatorname{tr}\left(\mathcal{R}^{T} \mathcal{R}\right),
$$

sendo $\mathfrak{r}_{\mathrm{ij}}$ um elemento genérico de $\mathcal{R} \mathrm{e} \operatorname{tr}\left(\boldsymbol{\mathcal { R }}^{\mathrm{T}} \boldsymbol{\mathcal { R }}\right)$ o traço da matriz $\boldsymbol{\mathcal { R }}^{\mathrm{T}} \boldsymbol{\mathcal { R }}$.

A norma Euclidiana é uma classe das normas subordinadas à norma vetorial $\|\cdot\|$, de ordem $p, 1 \leq p \leq \infty$ :

$$
\|\mathcal{R}\|_{p}=\operatorname{Sup} \frac{\|\mathcal{R} \boldsymbol{x}\|_{p}}{\|\boldsymbol{x}\|_{p}}, \quad\|\boldsymbol{x}\|_{p}=1
$$


Assim, a norma subordinada é definida como sendo o vetor de maior comprimento no espaço imagem $\{\mathcal{R} x\}$ pela transformação $\boldsymbol{x} \rightarrow \mathcal{R} \boldsymbol{x}$. Em especial, estamos interessados na norma de ordem 2, $(p=2)$, também conhecida como norma Euclidiana ou norma espectral:

$$
\|\mathcal{R}\|_{2}=\operatorname{Sup}\|\mathcal{R} x\|_{2} .
$$

Para uma melhor compreensão acerca do processo operacional envolvido no cálculo da norma espectral, seja a decomposição em valores singulares da matriz $\mathcal{R}$ :

$$
\mathcal{R}=\boldsymbol{U} \boldsymbol{\Sigma} \boldsymbol{V}^{H},
$$

de forma que

$$
\|\mathcal{R}\|_{2}=\operatorname{Sup}\left\|\boldsymbol{U} \boldsymbol{\Sigma} \boldsymbol{V}^{H} \boldsymbol{x}\right\|_{2}
$$

Considera-se também a relação:

$$
\left\|\boldsymbol{U} \boldsymbol{\Sigma} \boldsymbol{V}^{H} \boldsymbol{x}\right\|_{2}^{2}=\left\|\left(\boldsymbol{U} \boldsymbol{\Sigma} \boldsymbol{V}^{H} \boldsymbol{x}\right)^{H}\left(\boldsymbol{U} \boldsymbol{\Sigma} \boldsymbol{V}^{H} \boldsymbol{x}\right)\right\|_{2},
$$

Por construção da SVD, as colunas da matriz $\boldsymbol{V}$ definem um conjunto de vetores ortonormais e $\boldsymbol{x}$ é o vetor que satisfaz a condição $\boldsymbol{V}^{T} \boldsymbol{x}=1$, de forma que a eq. (4.9) se escreve:

$$
\|\mathcal{R}\|_{2}^{2}=(\boldsymbol{U} \boldsymbol{\Sigma})^{H}(\boldsymbol{U} \boldsymbol{\Sigma})=\boldsymbol{\Sigma}^{H}\left(\boldsymbol{U}^{H} \boldsymbol{U}\right) \boldsymbol{\Sigma} .
$$

Note que $\left(\boldsymbol{U}^{H} \boldsymbol{U}\right)=\boldsymbol{I}$. Deste resultado decorre que: 


$$
\|\mathcal{R}\|_{2}=\sqrt{\left\|\boldsymbol{\Sigma}^{H} \boldsymbol{\Sigma}\right\|_{2}}
$$

Aplicando a definição (4.6) à norma da matriz $\boldsymbol{\Sigma}^{H} \boldsymbol{\Sigma}$, para o vetor $\boldsymbol{x}=\{1,0, \ldots, 0\}$, vê-se que o vetor de maior comprimento no espaço imagem $\{\boldsymbol{R} \boldsymbol{x}\}$ é dado pela transformação $\boldsymbol{x} \rightarrow \sigma_{m} \boldsymbol{x}$, sendo $\sigma_{m}$ o máximo valor singular da matriz $\mathcal{R}$. Portanto, a norma $\|\mathcal{R}\|_{2}$ é definida pelo máximo valor singular da matriz $\mathcal{R}$. No entanto, esta pode ser definida em termos dos autovalores da matriz $\mathcal{R}^{\mathrm{H}} \mathcal{R}$. Para tal, seja o desenvolvimento

$$
\begin{gathered}
\mathcal{R}^{H} \mathcal{R}=\left(\boldsymbol{U} \boldsymbol{\Sigma} \boldsymbol{V}^{H}\right)^{H} \boldsymbol{U} \boldsymbol{\Sigma} \boldsymbol{V}^{H} . \\
\mathcal{R}^{H} \boldsymbol{R}=\boldsymbol{V} \boldsymbol{\Sigma} \boldsymbol{U}^{H} \boldsymbol{U} \boldsymbol{\Sigma} \boldsymbol{V}^{H}=\boldsymbol{V}\left(\boldsymbol{\Sigma}^{H} \boldsymbol{\Sigma}\right) \boldsymbol{V}^{H} .
\end{gathered}
$$

Portanto, $\boldsymbol{\Sigma}^{\mathrm{H}} \boldsymbol{\Sigma}$ é a matriz de autovalores da matriz $\mathcal{R}^{\mathrm{H}} \mathcal{R}$. A eq. (4.11) se escreve:

$$
\|\mathcal{R}\|_{2}=\sqrt{\text { máximo autovalor de }\left(\mathcal{R}^{H} \mathcal{R}\right)} .
$$

De acordo com a decomposição em valores singulares, se a matriz $\mathcal{R}$ possui posto $p$, então, seus autovalores verificam a relação:

$$
\sigma_{1} \geq \sigma_{2} \geq \cdots \geq \sigma_{p}
$$

de forma que:

$$
\|\mathcal{R}\|_{2}=\sigma_{1}
$$

Para uma matriz geral $\boldsymbol{A}_{m x n}$, verifica-se a relação: 


$$
\|\boldsymbol{A}\|_{2} \leq\|\boldsymbol{A}\|_{F} \leq \sqrt{n}\|\boldsymbol{A}\|_{2}
$$

Embora as normas $(p=1$ e $p=\infty)$ sejam computacionalmente mais baratas que a norma $(p=2)$, a minimização da norma do resíduo por decomposição QR da matriz $\boldsymbol{Y}$ exige o uso da norma $(p=2)$, pois esta é a única norma em $C^{n}$ que é invariante por transformações unitárias. As simulações numéricas mostraram que ambas as normas Frobenius e Euclidiana provêem filtros modais de alto desempenho, porém derivados de topologias de rede distintas. Este resultado indica que a topologia de rede ótima para um dado conjunto filtros modais não é única. Os resultados apresentados na sequência deste trabalho foram obtidos com o uso da norma Euclidiana na função objetivo $J_{2}$.

\subsection{Otimização usando busca extensiva}

\subsubsection{Técnica de redução do espaço de busca (simetria)}

A Fig. 4.1 representa a convenção de índices para uma rede composta por trinta e seis sensores. Esta convenção foi concebida de acordo com a estratégia de busca extensiva adotada neste trabalho. 


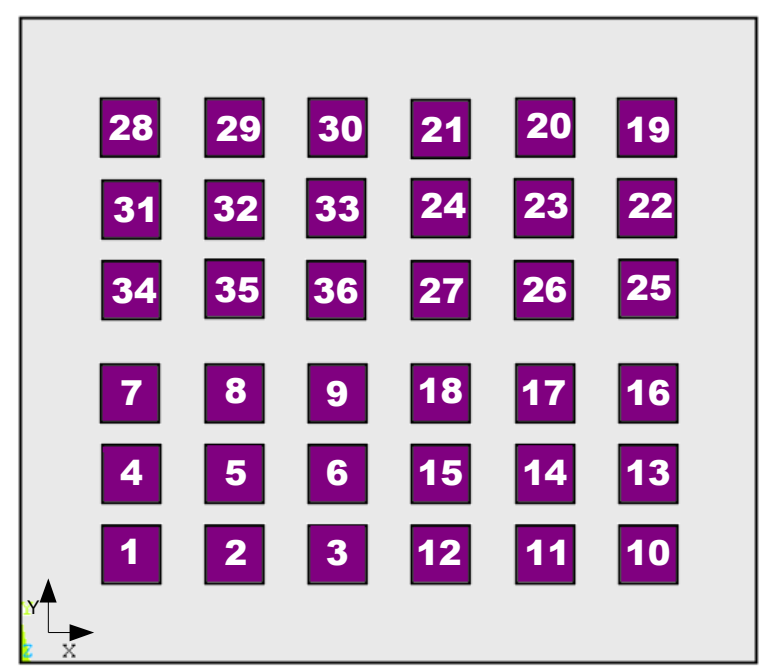

Figura 4.1 - Ilustração da indexação dos sensores. Este critério de indexação foi concebido para a implementação da pesquisa com busca extensiva e mantido para a otimização com algoritmo genético.

Uma busca extensiva completa requer a análise de todas as possíveis combinações de trinta e seis sensores tomados doze a doze, cujo número é dado pela eq. (4.1). Não é difícil concluir que tal análise demanda alto custo computacional, e pode ser inviável para fins de projeto. A fim de tornar o método de busca extensiva factível do ponto de vista de custo computacional, é adotada uma estratégia para reduzir o espaço de busca pela seleção de topologias de rede, partindo-se de um critério de simetria.

Para tal, considera-se como referência o quadrante da placa contendo os sensores de 1 até 9 . O número de combinações de nove sensores tomados cinco a cinco é dado pela eq. (4.17).

$$
C_{9,5}=\frac{9 !}{5 !(9-5) !}=126
$$

Cada uma destas 126 combinações selecionadas é definida por cinco sensores, cada qual indexado exclusivamente por um número entre 1 e 9. Em seguida, aos índices dos sensores que compõem cada uma das 126 combinações originais é somado o dígito 9. Desta forma, define-se um segundo grupo de cinco sensores, 
indexados com números entre 10 e 18. Aos índices dos sensores deste segundo grupo é somado o dígito 9, de forma a definir um terceiro grupo de sensores, cujos índices variam entre 19 e 27. Finalmente, aos índices destes últimos é novamente somado o dígito 9, de forma a definir um quarto conjunto de sensores, cujos índices estão no intervalo entre 28 e 36 .

Desta forma, são criadas 126 combinações representando topologias de redes formadas por 20 sensores, cada qual definida pela reunião de quatro grupos de cinco sensores situados em quadrantes distintos da placa. A operação de soma do dígito nove aos índices do primeiro grupo de sensores equivale à reflexão de cada sensor em relação ao semi-eixo y inferior. A soma do dígito nove aos índices do segundo grupo de sensores equivale à reflexão de cada sensor em relação ao semi-eixo $x$ positivo, e assim por diante, de acordo com a convenção de índices representada na Fig. 4.1. Este processo define um do espaço de busca reduzido e gera 126 topologias de rede formadas por 20 sensores, todas simétricas em relação ao sistema de eixos $(\mathrm{x}, \mathrm{y})$ com origem no centro da placa.

Em seguida, considere o número de combinações de cinco sensores tomados três a três, representado pela eq. (4.18).

$$
C_{5,3}=\frac{5 !}{3 !(5-3) !}=10
$$

Para cada uma das 126 topologias que agrupam combinações de 20 sensores, os cinco sensores em cada quadrante são combinados três a três, gerando dez combinações de três sensores por quadrante. Então, haverá:

$$
10 \times 10 \times 10 \times 10=10.000 \text {, }
$$


diferentes formas de se combinar grupos de três sensores para gerar topologias de rede definidas por doze sensores no conjunto de quadrantes. O número total combinações, ou topologias de rede formadas por doze sensores, será:

$$
126 \times C_{5,3}=1.260 .000 .
$$

As combinações entre os grupos de três sensores desconsideram restrições de simetria, mas mantêm os sensores equidistribuídos nos quadrantes. As topologias de rede assim definidas, que representam uma ínfima porção do espaço de soluções (aproximadamente $0,00000008 \%$ ), são avaliadas com base no desempenho de cada filtro modal associado, de acordo com as funções objetivos $J_{1}$ e $J_{2}$.

Em suma, a metodologia de busca extensiva adotada define combinações de doze sensores (simétricas e assimétricas) a partir de uma base simétrica de vinte sensores, e assegura redes com três sensores por quadrante. Estas restrições serão eliminadas na otimização topológica com algoritmo genético.

Naturalmente, uma infinidade de outras metodologias para a seleção de topologias de rede são possíveis. A otimização topológica por busca extensiva é implementada no software MATLAB. As funções de resposta em frequências referentes aos trinta e seis sensores da rede, identificadas pelos índices dos sensores, estão disponíveis em arquivos com extensão txt.

As Figs. 4.2 e 4.3 exemplificam o procedimento descrito em forma de texto. A Fig. 4.2 representa o critério de seleção para os vinte primeiros sensores, que permanecem indexados. A rede composta pelos sensores ímpares no quadrante inferior à esquerda representa uma das possíveis combinações de nove sensores tomados cinco a cinco. A soma do dígito nove aos índices ímpares condiciona a escolha dos sensores pares no quadrante adjacente à direita, e assim por diante. Como resultado, a rede composta pelos vinte sensores selecionados é simétrica em relação aos eixos de simetria e ao centro da placa. 


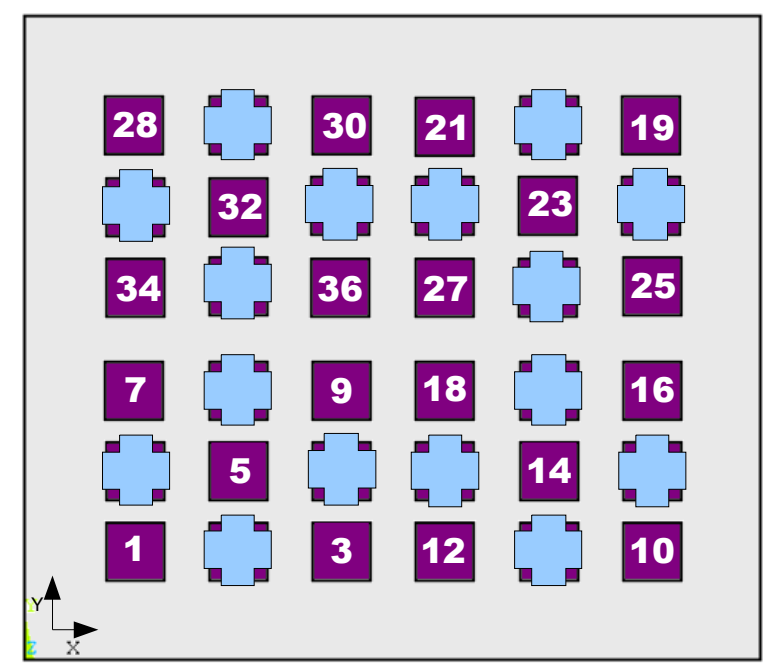

Figura 4.2 - Representação da pré-seleção de uma rede de 20 sensores para gerar uma rede de doze sensores: em cada quadrante, os sensores numerados representam uma das 126 possíveis combinações formadas por 9 sensores tomados 5 a 5 . Os 16 sensores encobertos formam o grupo de sensores descartados.

A Fig. 4.3 representa a seleção de doze dentre aqueles vinte sensores previamente selecionados. A topologia da rede final não possui simetria, mas mantem seus sensores equidistribuídos nos quadrantes.

À cada sensor está associado um vetor de resposta em frequência complexa $\boldsymbol{Y}_{\boldsymbol{j}}$, representando a tensão elétrica induzida pela vibração da estrutura no sensor de índice $j$, no domínio discreto de frequência. Quando o número de um sensor é selecionado, automaticamente o programa identifica e habilita o respectivo vetor coluna da matriz composta pelas respostas em frequência dos 36 sensores da rede. 


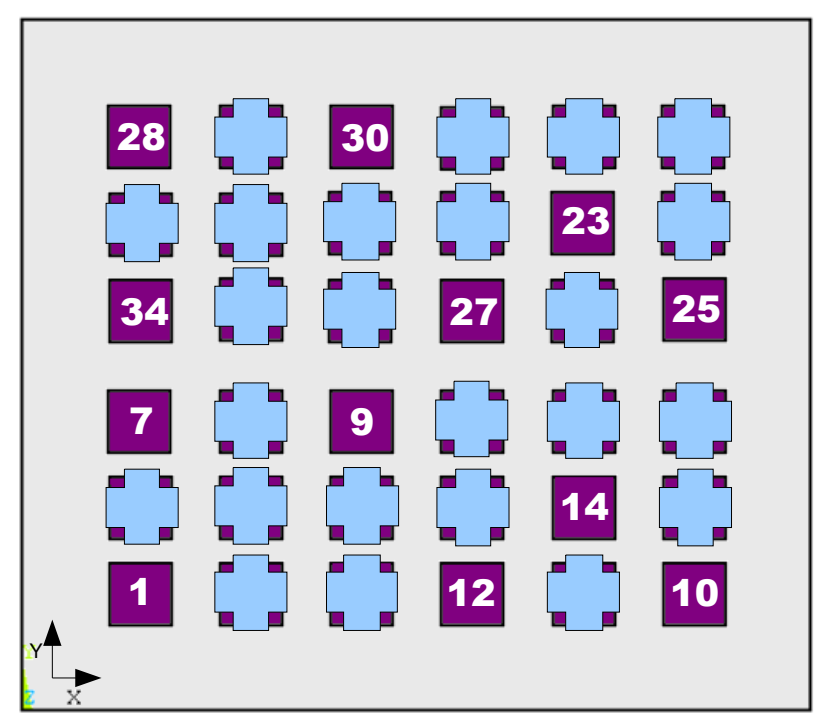

Figura 4.3 - Representação de uma topologia de 12 sensores selecionada para compor o espaço de soluções no processo de otimização topológica pelo método de busca extensiva: os sensores numerados representam apenas uma das 1.260.000 possíveis combinações formadas por 12 sensores, a partir do critério de seleção adotado. Todos os sensores encobertos estão descartados.

Os vetores correspondentes aos sensores selecionados são agrupados em uma matriz $\boldsymbol{Y}_{S}$, conforme a eq. (3.2), para o cálculo da matriz de coeficientes de ponderação $\boldsymbol{\alpha}^{\dagger}$. Os vetores $\boldsymbol{Y} \boldsymbol{\alpha}^{\dagger}$ são avaliados, e a topologia de rede associada é classificada de acordo com as funções objetivo $J_{1}$ e $J_{2}$.

\subsubsection{Resultados da otimização por busca extensiva}

As Figs. 4.4 até 4.7 apresentam os resultados da otimização topológica pelo método de busca extensiva. Os índices de desempenho dos filtros modais são avaliados com base na função objetivo $J_{1}$. Em cada figura estão representados os filtros modais ótimos e as respectivas topologias de rede associadas aos filtros. 


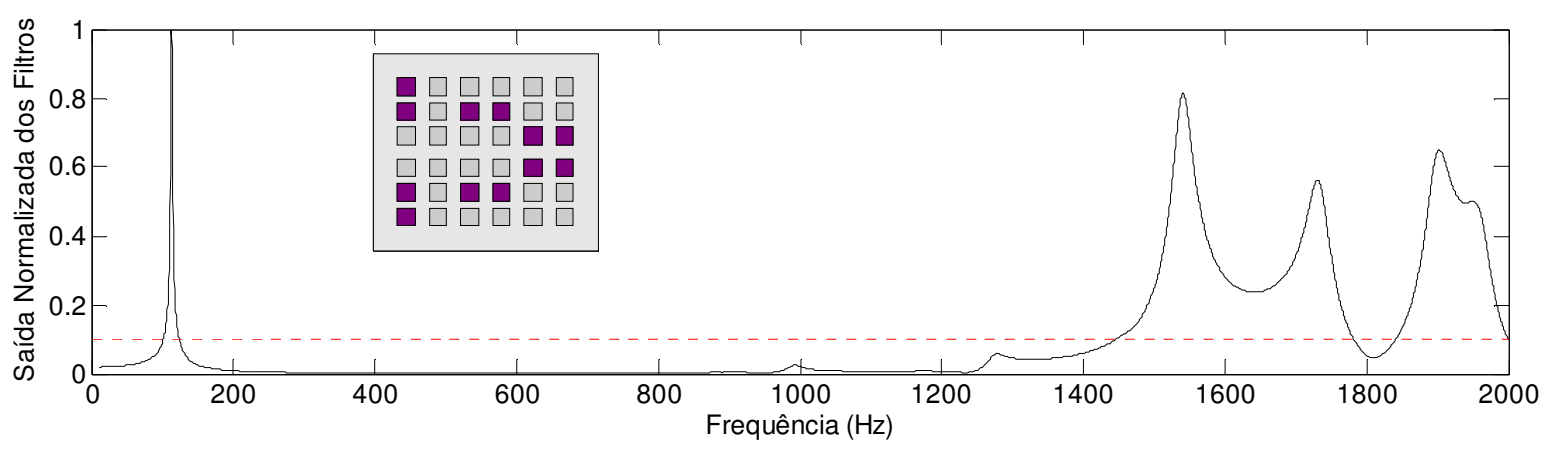

Figura 4.4 - Topologia de rede e filtro otimizado para o isolamento do primeiro modo de vibrar. A frequência máxima alcançada é $1446 \mathrm{~Hz}$.

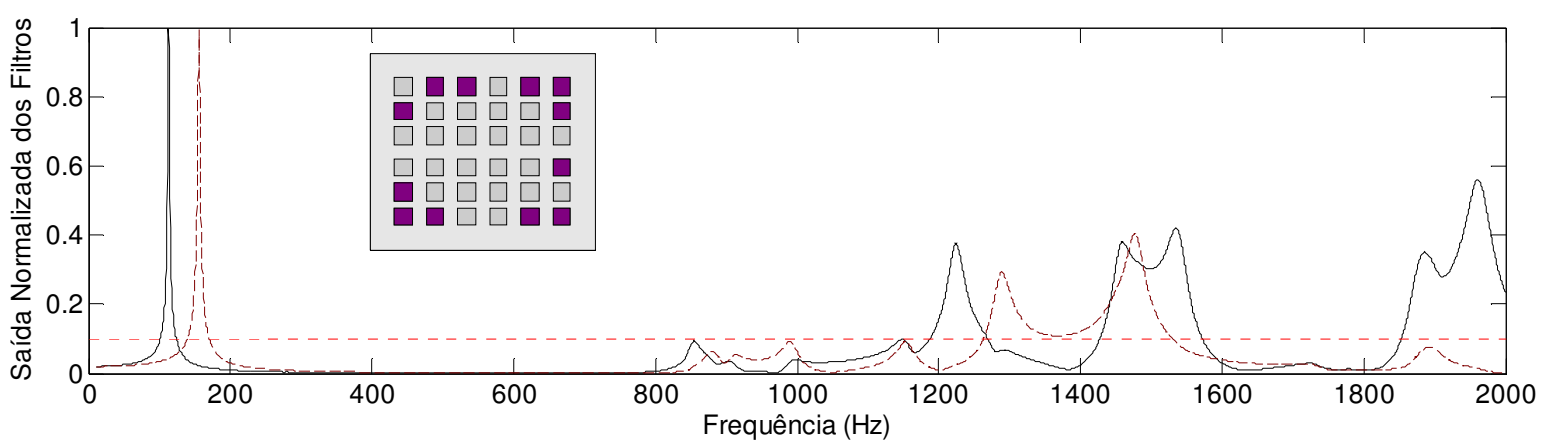

Figura 4.5 - Topologia de rede e filtros otimizados para o isolamento dos dois primeiros modos de vibrar. A frequência máxima alcançada é $1188 \mathrm{~Hz}$.

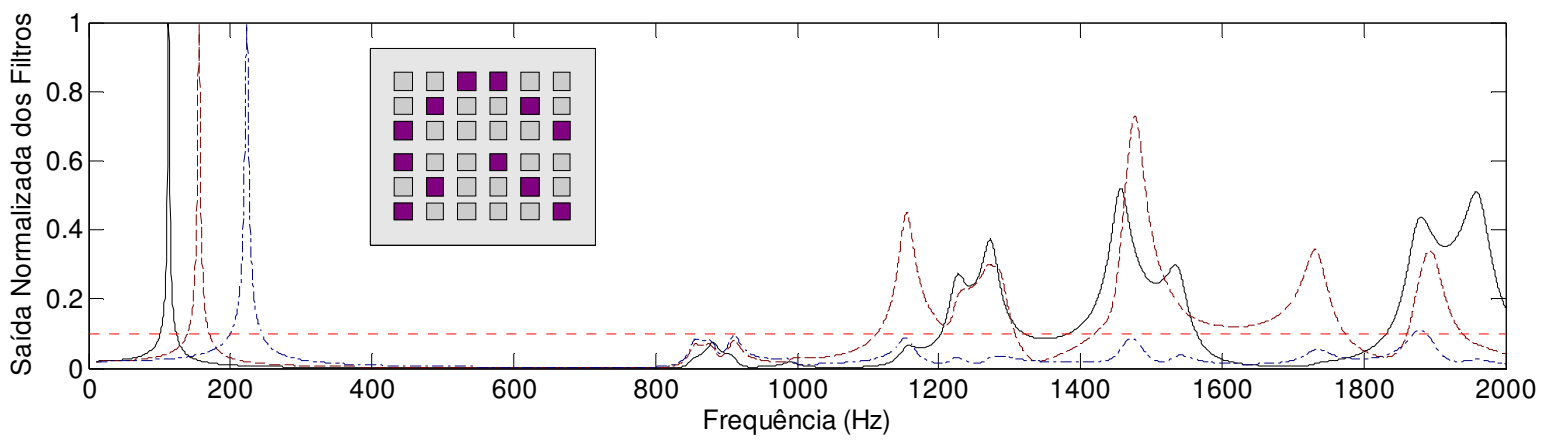

Figura 4.6 - Topologia de rede e filtros otimizados para o isolamento dos três primeiros modos de vibrar. A frequência máxima alcançada é $1113.5 \mathrm{~Hz}$. 


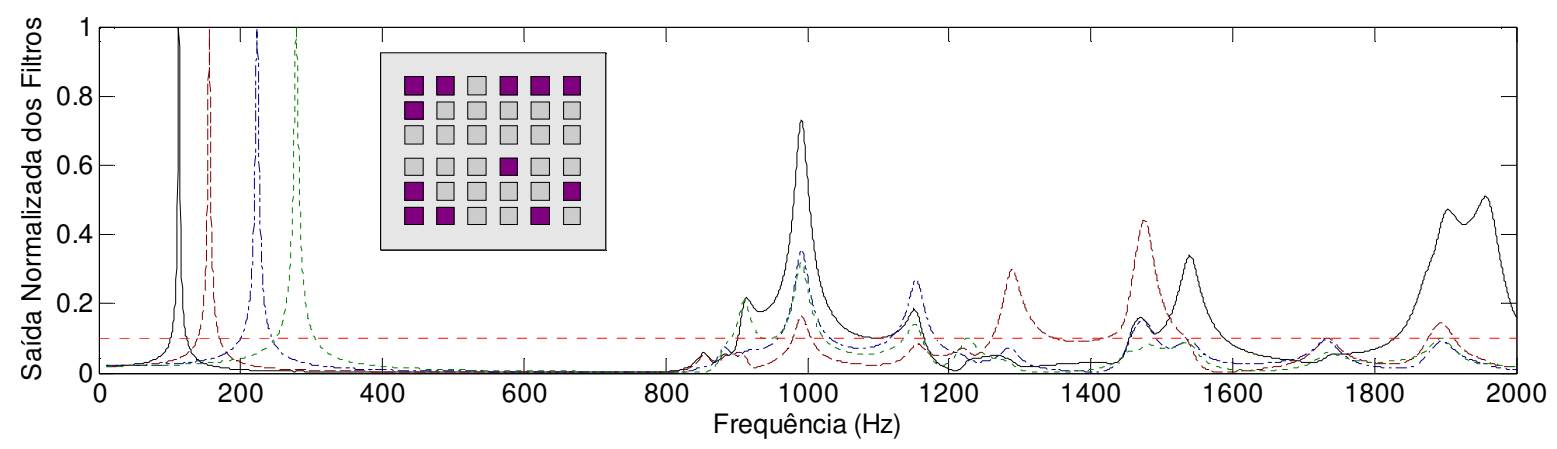

Figura 4.7 - Topologia de rede e filtros otimizados para o isolamento dos quatro primeiros modos de vibrar. A frequência máxima alcançada é $893 \mathrm{~Hz}$.

Os resultados mostram que até $800 \mathrm{~Hz}$, filtros modais de alto desempenho podem ser obtidos basicamente pela aplicação do método de mínimos quadrados ao cálculo dos coeficientes de ponderação dos sinais de tensão elétrica aquisitados nos sensores. Na faixa de frequência complementar, algum ganho de qualidade é alcançado pela otimização do posicionamento dos sensores. No entanto, esta proposta de otimização mostra-se pouco eficiente para a filtragem efetiva de modos ressonantes além de $800 \mathrm{~Hz}$.

Em particular, a otimização topológica ampliou significativamente a banda de frequência na qual o filtro modal para o isolamento do primeiro modo de vibrar apresenta baixos níveis de ruído, conforme a Fig. 4.4. No entanto, à medida que modos alvos adicionais são considerados no processo de filtragem, os erros tornamse significativos, já em frequências muito próximas a $800 \mathrm{~Hz}$.

Os resultados da otimização topológica indicam baixo desempenho para os filtros, a partir de quatro modos alvos. No entanto, nota-se um desempenho diferenciado no isolamento de alguns modos de vibrar. Por exemplo, a resposta do terceiro modo de vibrar, mostrada na Fig. 4.6, é naturalmente bem controlada em toda a banda de frequência, diferenciando-se das demais.

As Figs. 4.8 até 4.11 apresentam os resultados da otimização topológica pelo método de busca extensiva. Os índices de desempenho dos filtros modais são 
avaliados com base na função objetivo $J_{2}$. Em cada figura estão representados os filtros modais ótimos e as respectivas topologias de rede associadas aos filtros.

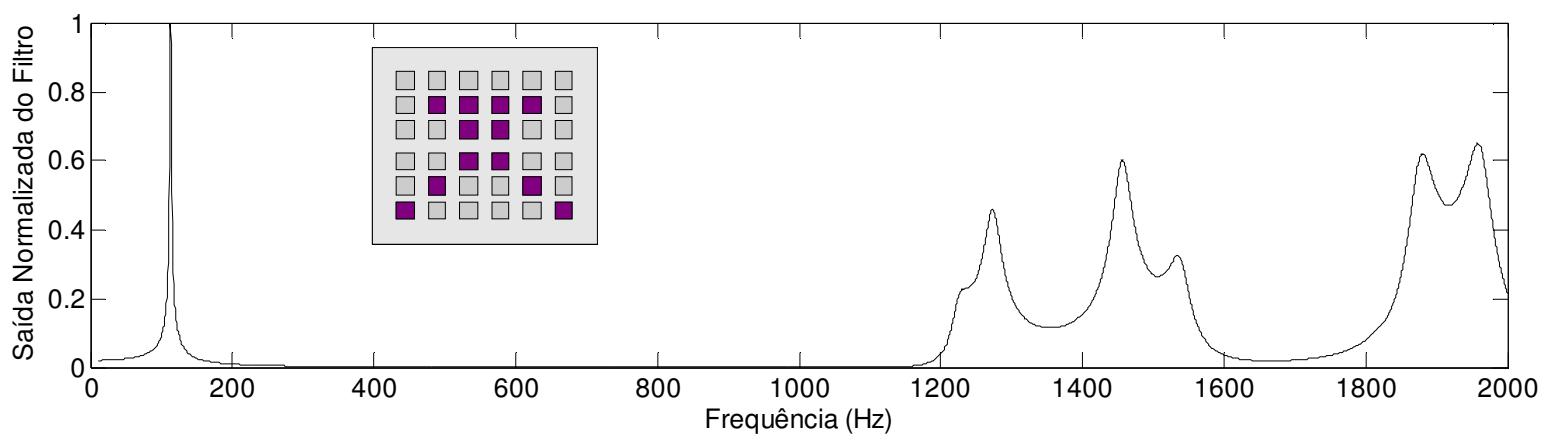

Figura 4.8 - Topologia de rede e filtro otimizado para o isolamento do primeiro modo de vibrar. O filtro apresenta desempenho ótimo até aproximadamente $1.200 \mathrm{~Hz}$.

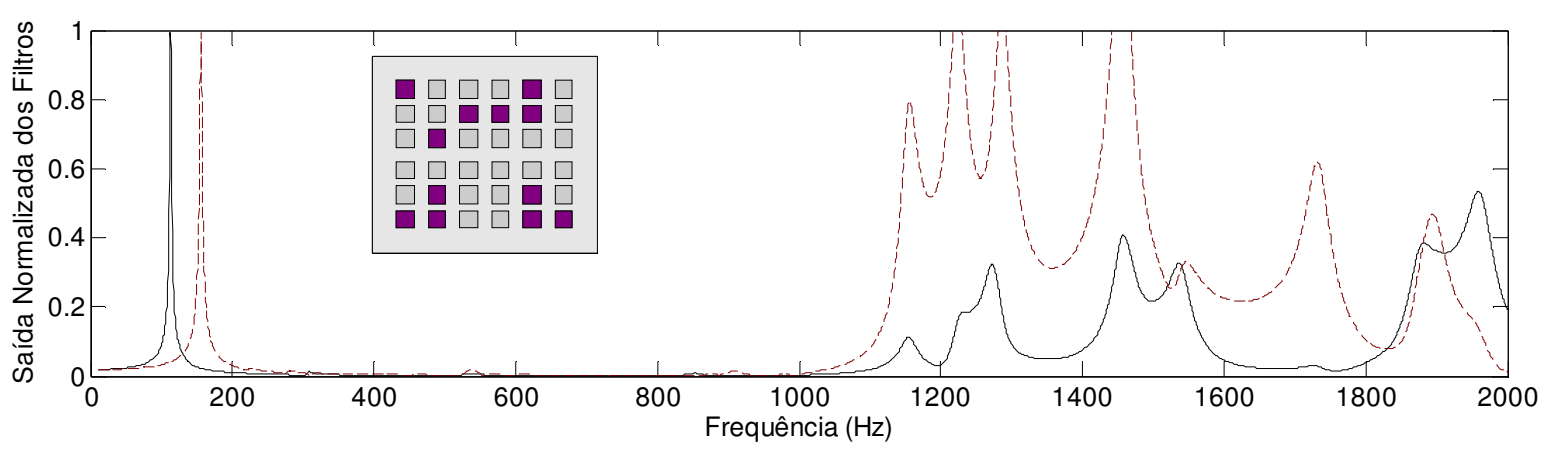

Figura 4.9 - Topologia de rede e filtros otimizados para o isolamento dos dois primeiros modos de vibrar. Os modos residuais são filtrados até $1000 \mathrm{~Hz}$. Erros inferiores a $2 \%$ são medidos na banda de frequência otimizada.

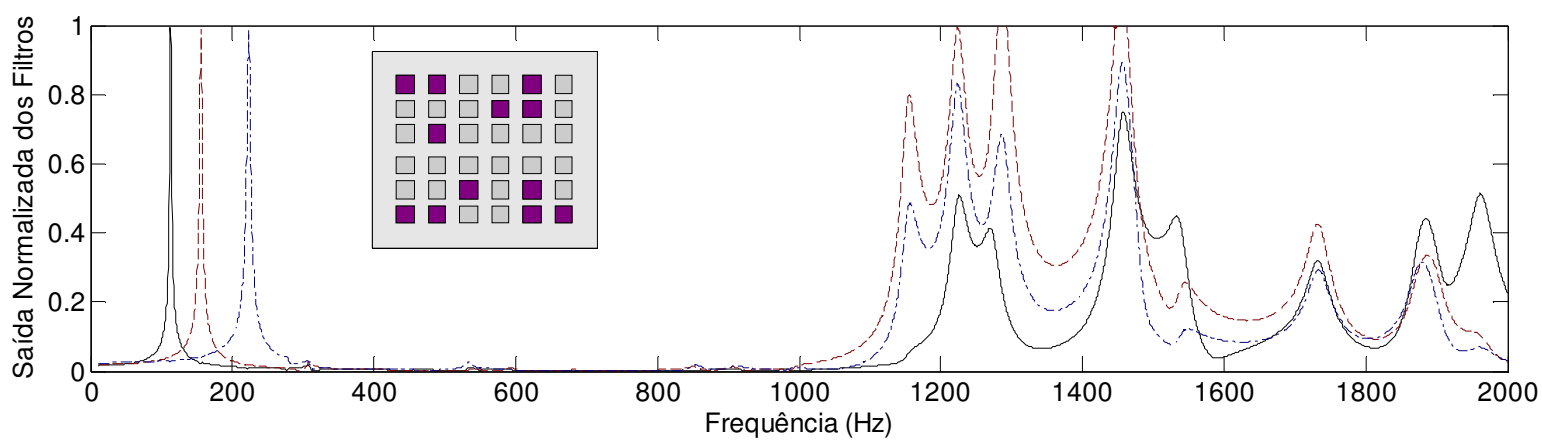

Figura 4.10 - Topologia de rede e filtros otimizados para o isolamento dos três primeiros modos de vibrar. Os modos residuais são filtrados até $1000 \mathrm{~Hz}$. Erros inferiores a 3,5\% são medidos na banda de frequência otimizada. 


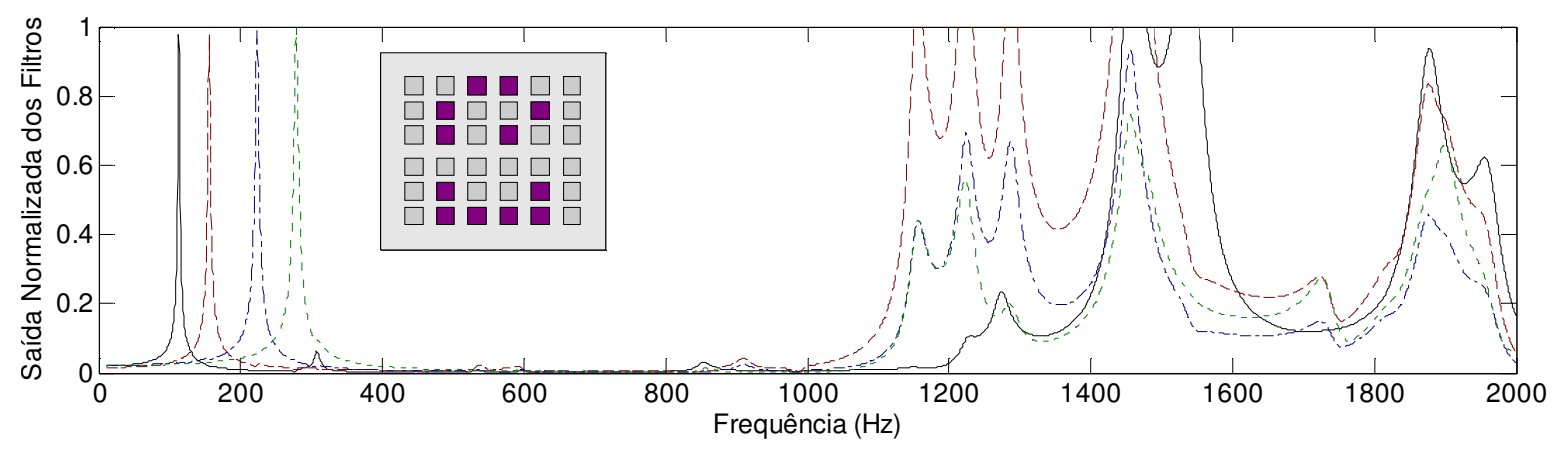

Figura 4.11 - Topologia de rede e filtros otimizados para o isolamento dos quatro primeiros modos de vibrar. Os modos residuais são filtrados até $1000 \mathrm{~Hz}$. Erros inferiores a 6,5\% são medidos na banda de frequência otimizada.

Os resultados mostrados nas Figs. 4.8 até 4.11 indicam a conveniência de se estender a banda de frequência no truncamento da matriz de FRF e utilizar a função objetivo $J_{2}$ para a filtragem eficaz de modos ressonantes em frequências mais altas.

Embora o filtro modal para o isolamento do primeiro modo de vibrar tenha sido projetado para um desempenho ótimo até $1000 \mathrm{~Hz}$, este apresentou alto desempenho até cerca de $1200 \mathrm{~Hz}$ (Fig. 4.8). Neste caso, a filtragem modal foi efetiva até o décimo quinto modo, de forma que cinco modos residuais adicionais (além de $800 \mathrm{~Hz}$ ) foram eficazmente filtrados.

A Fig. 4.9 mostra que filtros de alta qualidade para os dois primeiros modos de vibrar foram obtidos até $1000 \mathrm{~Hz}$. Isto significa que quatorze modos residuais foram filtrados (quatro modos adicionais), às custas de um erro inferior a $2 \%$ da amplitude das respostas dos modos alvos. O índice de erro no processo de filtragem é definido como o valor absoluto da diferença entre a resposta modal filtrada e a respectiva resposta de um sistema de um grau de liberdade.

As Figs. 4.10 e 4.11 mostram os desempenhos dos filtros projetados para isolar os modos $\{1,2,3\}$ e $\{1,2,3,4\}$, respectivamente. Nestes casos, filtros de alto desempenho também são obtidos até $1000 \mathrm{~Hz}$. No entanto, os erros residuais distribuídos na banda de frequência $[10,1000] \mathrm{Hz}$ aumentam progressivamente à medida que modos alvos adicionais são considerados: erros máximos de 3,5\% e 6,5\% 
foram verficados na filtragem simultânea dos modos $\{1,2,3\}$ e $\{1,2,3,4\}$, respectivamente.

As características gerais dos filtros modais obtidos por otimização topológica orientada pelas funções objetivo $J_{1}$ e $J_{2}$, nesta pré-análise do espaço de soluções via busca extensiva, devem ser esperadas na otimização topológica via algoritmo genético. No entanto, melhores índices de desempenho para cada uma das funções objetivos são esperados, uma vez que o algoritmo genético deverá prover uma pesquisa irrestrita no espaço de soluções.

\subsection{Otimização usando algoritmos genéticos}

\subsubsection{Implementação do AG em MATLAB}

Nesta seção discute-se a estratégia de otimização topológica de uma rede de sensores piezelétricos a partir do uso de um algoritmo genético. Há quatro etapas básicas para formalizar um processo de otimização em termos de um algoritmo genético: i) codificação das variáveis de projeto; ii) definição da função objetivo; iii) definição do espaço de soluções associado; e iv) definição e ajuste dos operadores genéticos. A codificação gênica adotada neste trabalho utiliza números inteiros: cada elemento no espaço de soluções é definido por uma sequência de doze números inteiros, cada qual representando o índice de um sensor, como ilustrado na Fig. 4.12, e de acordo com a indexação da Fig. 4.1.

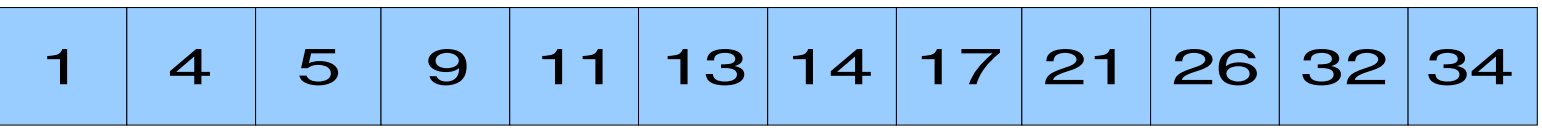

Figura 4.12 - Representação de uma combinação típica de sensores que define uma possível solução ótima para o problema de otimização topológica. 
Uma das restrições à pesquisa do espaço de soluções recai sobre a unicidade dos números inteiros que representam cada grupo de doze sensores selecionados para formar um indivíduo. Em outras palavras, a população inicial deve ser formada por um conjunto de combinações de doze sensores, de forma que cada uma delas seja formada por sensores distintos.

Para satisfazer tal condição, um vetor de 36 elementos (números de 1 até 36) é formado, de maneira que a posição de cada elemento na sequência seja definida aleatoriamente. Então, os doze primeiros elementos deste vetor são selecionados para compor um indivíduo na população. Esta operação é repetida para cada novo indivíduo gerado. A escolha dos números (genes) situados nas doze primeiras posições (locus) não implica em perda de generalidade ou escolha tendenciosa de qualquer grupo de sensores, uma vez que a distribuição dos sensores é equiprovável.

A operação de mutação consiste em substituir aleatoriamente um gene do indivíduo selecionado. Para tal, é definido um vetor de índices complementar ao vetor que agrupa os índices dos doze sensores selecionados para mutação. Um índice escolhido aleatoriamente no vetor selecionado para mutação é substituído por um dos 24 índices do conjunto complementar, que também é escolhido aleatoriamente. Esta estratégia, representada na Fig. 4.13, evita que a operação de mutação gere sequências com sensores repetidos.

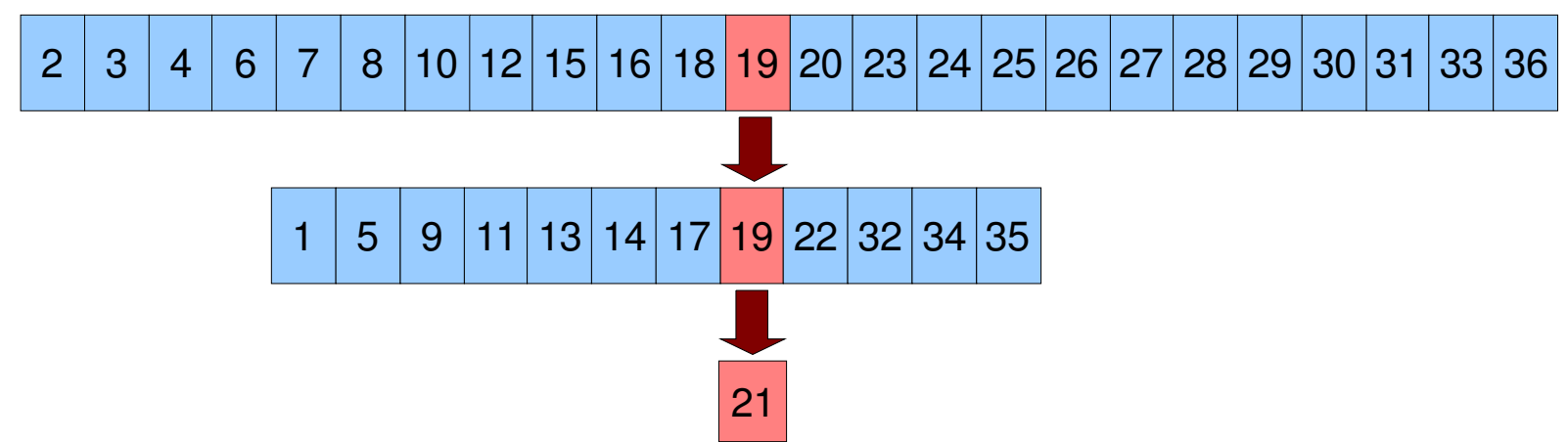

Figura 4.13 - Representação esquemática da operação de mutação: O sensor de índice 21 no indivíduo selecionado para mutação é substituído pelo sensor de índice 19, originalmente no conjunto de índices complementar, sendo ambos os índices escolhidos aleatoriamente. 
O operador de cruzamento (crossover) combina partes da sequência gênica de um indivíduo a partes dequela de outro indivíduo, sendo aleatório o ponto de corte nas sequências. Os indivíduos que apresentam repetição de ao menos um sensor são selecionados e eliminados antes que sejam avaliados. Desta forma, evita-se o cálculo desnecessário do índice de desempenho de combinações inviáveis, em favor de uma melhor eficiência do algoritmo.

O Genetic Algorithm and Direct Search Toolbox dispõe de algumas opções para a definição dos operadores de mutação e cruzamento. Conforme dito, o operador de mutação foi definido para um codificação adequada do problema de otimização topológica combinatorial. O operadores de seleção e cruzamento, por sua vez, foram usados na forma padrão do GADS.

O operador de cruzamento definido pela função Scattered (@cruzamentoscattered), Position independent cruzamento function, cria vetores binários (neste caso, com doze elementos), que são preenchidos estocasticamente por genes (dígitos) de valores 0 ou 1 . Cada vetor binário é, então, associado a dois indivíduos (pais) selecionados para cruzamento. O novo indivíduo (filho), gerado por cruzamento, recebe os genes de um pai situados nos locus correspondentes ao dígito 1, e os genes do outro pai correspondentes ao dígito 0, no vetor binário. A Fig. 4.14 representa esquematicamente a operação de cruzamento adotada neste trabalho.

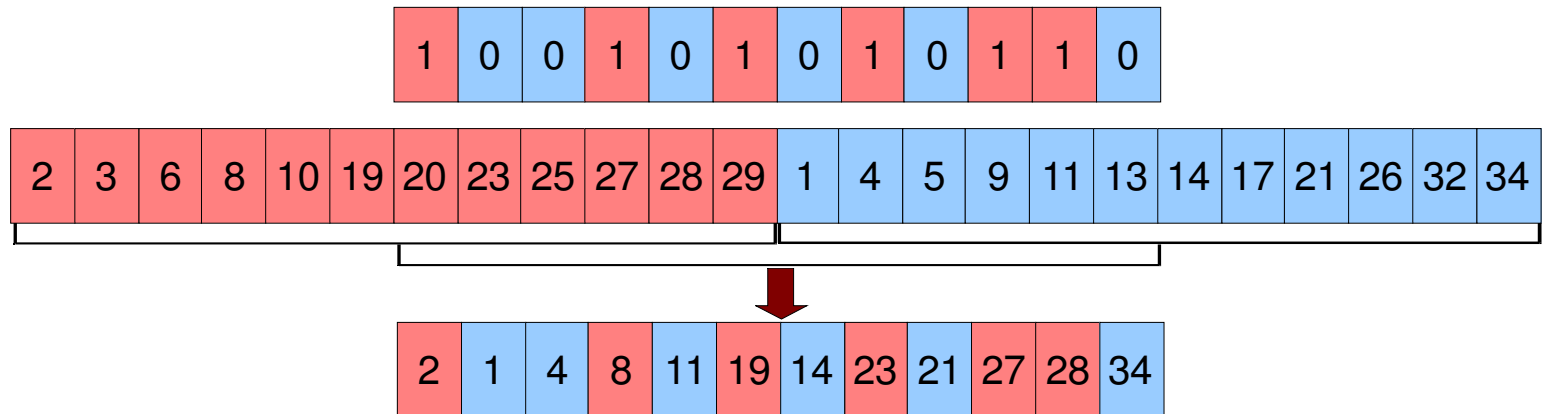

Figura 4.14 - Representação esquemática da operação de cruzamento: O dígito 1 no vetor binário está associado ao indivíduo (pai) da esquerda, enquanto que o dígito 0 está associado ao indivíduo da direta. O novo indivíduo (filho) é formado pelos genes de um pai correspondentes às posições do dígito $1 \mathrm{e}$ pelos genes do outro pai correspondentes às posições do dígito 0 no vetor binário. 
O operador de seleção é definido pela função Stochastic uniform (@selectionstochunif). Esta função estabelece uma linha segmentada, de forma que à cada pai corresponda um segmento sobre a linha, cujo comprimento é proporcional ao seu desempenho na otimização (fitness). O algoritmo move-se ao longo da linha em passos de tamanho igual. À cada passo é alocado para cruzamento o progenitor correspondente à seção alvejada. O primeiro passo é um número aleatório menor que o tamanho do passo padrão. Este é um processo de seleção estocástico, tal como a roulette wheel.

A partir da população inicial o algoritmo genético gera novas populações, chamadas de gerações, pelas operações de cruzamento, mutação, elitismo e seleção. Elitismo é o processo pelo qual os indivíduos mais aptos são preservados para a geração seguinte. Os indivíduos selecionados por elitismo formam um grupo seleto, denominado população de elite. A população de elite é mantida de geração a geração, até que as operações de cruzamento e mutação gerem indivíduos mais aptos para compor a nova população de elite. Este mecanismo garante que o material genético dos indivíduos mais aptos esteja disponível nas gerações seguintes para novas operações de cruzamento e mutação e auxilia na convergência do algoritmo genético.

Os principais parâmetros quantitativos são o tamanho da população, o número de gerações e as taxas de cruzamento, mutação e elitismo. O tamanho da população define o número de indivíduos, ou cromossomos, que são criados e avaliados em cada geração. Em geral, o tamanho da população é mantido constante durante o processo de otimização. Populações pequenas podem representar escassez de material genético e restringir a pesquisa no espaço de soluções. Por sua vez, populações grandes demandam alto custo computacional. Vários autores sugerem uma avaliação empírica sobre o tamanho adequado da população para cada problema, como forma de evitar a saturação do desempenho do AG a partir de certos tamanhos de população (GOLDBERG, 1983; HOLLAND, 1975). 
O critério de parada determina o término de uma simulação. Neste trabalho, define-se uma simulação como sendo um conjunto de gerações de invíduos que evoluem a partir de uma população inicial gerada estocasticamente e são avaliados de acordo com um critério de desempenho, ou função objetivo. Alguns critérios de parada se baseiam na taxa e convergência da pesquisa, ou na perda de diversidade do material genético, e podem definir simulações com diferentes números de gerações. O critério de parada por gerações forçadas consiste em definir um número fixo de gerações, criadas e avaliadas independentemente da taxa de convergência ou perda de diversidade gênica em cada simulação.

A taxa de convergência pode ser definida em termos da evolução da aptidão média ou máxima dos indivíduos avaliados durante um certo número de gerações. Se o ótimo global é conhecido, o valor da função objetivo pode ser usado como critério de parada. A taxa de cruzamento define a proporção de indivíduos que são selecionados para cruzamento em cada geração. Em algumas versões de AG, a taxa de cruzamento define a probabilidade de que pais selecionados sejam cruzados (pais não cruzados resultam em filhos que são cópias exatas de si próprios).

A taxa de mutação define a proporção em que os indivíduos são geneticamente alterados em cada geração. A taxa de mutação pode ser definida em termos do número de indivíduos que são mutados, ou do número de genes mutados em cada indivíduo (taxa de mutação gênica).

A todos os indivíduos de uma geração, exceto aqueles selecionados para elite, são aplicadas as operações de cruzamento ou mutação, em taxas bem definidas. Para criar uma nova geração, o GADS aloca cópias exatas dos indivíduos de maior aptidão no grupo de elite, aplica a operação de cruzamento em uma percentagem dos indivíduos restantes e a operação de mutação naqueles indivíduos que não estão no grupo de elite e que não foram selecionados para cruzamento.

Desta forma, as taxas de cruzamento e mutação estão definidas em termos do percentual de indivíduos selecionados para as respectivas operações, o que se traduz 
em uma alta taxa de mutação, quando comparada aos valores encontrados na literatura especializada. A taxa de mutação gênica pode representar um valor mais realista, na medida em que contabiliza o percentual de genes mutados.

Neste trabalho, define-se $T_{C}$ como sendo a taxa de cruzamento, $N$ o número de indivíduos na população, $\Sigma$ o número de indivíduos na elite, e $T_{g}$ a taxa de mutação gênica. A taxa de mutação gênica está relacionada aos demais parâmetros pela seguinte equação.

$$
T_{g}=\frac{\left(1-T_{c}\right)(N-\Sigma)}{12 N}
$$

A Tabela. 4.1 relaciona a taxa de mutação gênica à diferentes taxas de cruzamento, considerando uma população de 1000 indivíduos e $\Sigma=2$.

Tabela 4.1. Relação entre taxas de cruzamento e mutação gênica para uma população de 1000 indivíduos.

\begin{tabular}{|l|l|l|l|l|l|}
\hline Taxa de cruzamento $\left(T_{c}\right)$ & $30 \%$ & $40 \%$ & $50 \%$ & $60 \%$ & $70 \%$ \\
\hline Taxa de mutação gênica $\left(T_{g}\right)$ & $5,82 \%$ & $4,99 \%$ & $4,16 \%$ & $3,33 \%$ & $2,49 \%$ \\
\hline
\end{tabular}

O processo de ajuste dos parâmetros de configuração que tornam o algoritmo genético adequado a um projeto específico de otimização é, por si só, um problema de otimização. A rigor, os parâmetros devem ser avaliados simultaneamente, através de uma análise multi-paramétrica. A razão para tal é que o desempenho de um processo de otimização, em relação ao valor de um determinado parâmetro, depende do conjunto de valores fixados para os demais parâmetros correlacionados.

Algoritmos genéticos, em especial, são algoritmos evolutivos que apresentam desempenho sensível à forma como os operadores genéticos estão ajustados para um problema específico. Desta forma, não é aconselhável adotar valores de parâmetros encontrados na literatura, ou mesmo aqueles que são padrão em softwares de otimização. Uma pesquisa preliminar para a escolha de um conjunto de parâmetros 
que assegure ao algoritmo um bom nível de desempenho e robustez é necessária quando não há referências específicas na literatura. Neste trabalho, o conceito de desempenho em processos de otimização é avaliado com base em dois aspectos: i) a eficácia do algoritmo em convergir para ótimos globais; ii) a eficiência do processo de convergência. Em outras palavras, a habilidade do algoritmo em otimizar o processo de busca. A proporção adequada entre benefício (qualidade do resultado) e custo (tempo envolvido na simulação) é uma questão particular à cada projeto de otimização.

A Fig. 4.15 representa as principais etapas que definem a estrutura operacioanal de um processo de otimização utilizando algoritmos genéticos, sendo o término da simulação determinado pelo critério de parada adotado.

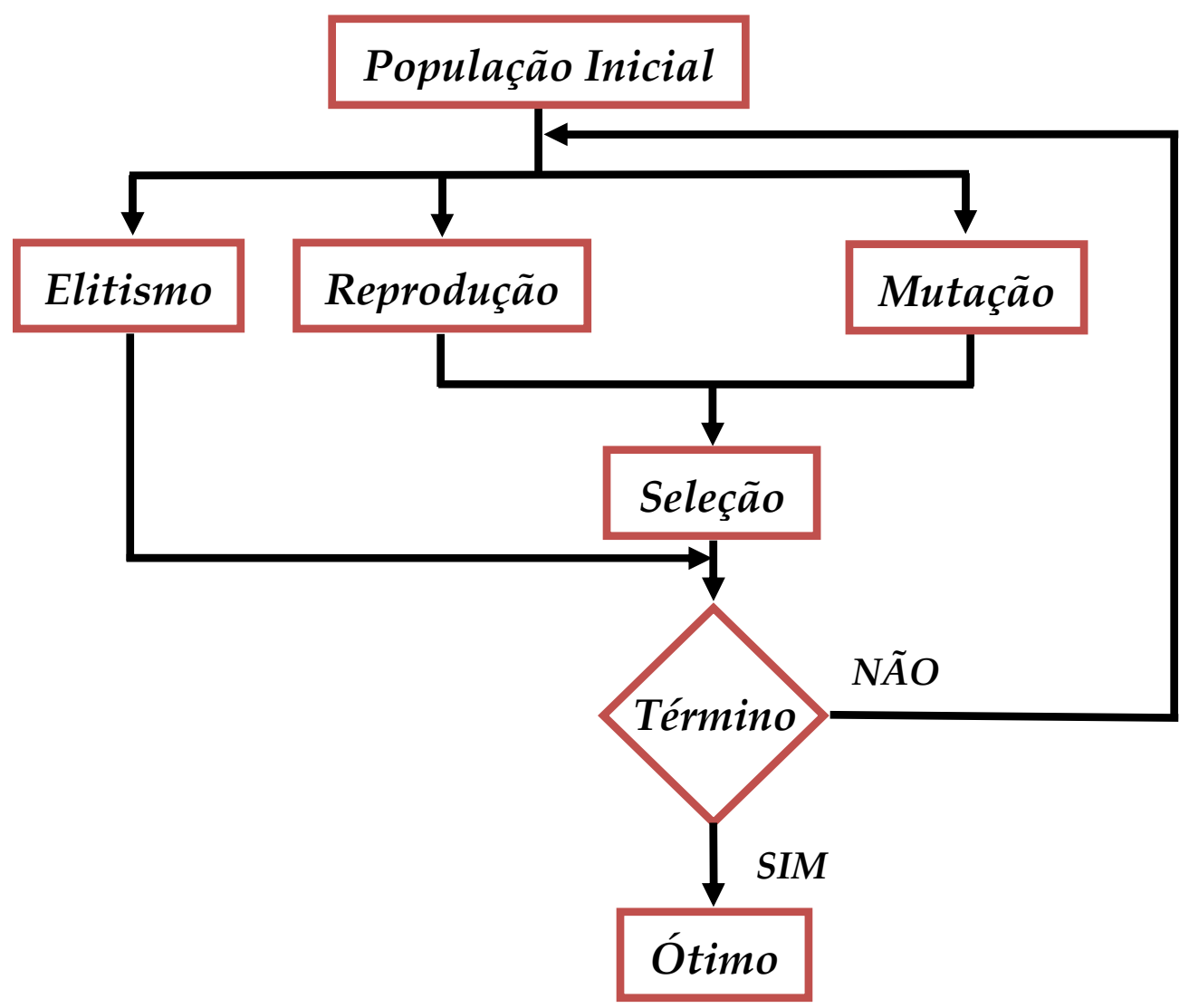

Figura 4.15 - Fluxograma básico para o processo de otimização topológica a partir de um algoritmo genético clássico. 
Os resultados da otimização apresentados neste trabalho foram obtidos em ambiente MATLAB, com o uso da ferramenta GADS (Genetic Algorithm and Direct Search Toolbox - Version 2.0.2 (R2006b) 03-Aug-2006) usando um computador Pentium 4, 3,20 GHz, 2,00 GB de RAM.

\subsubsection{Otimização dos parâmetros quantitativos do AG}

Nesta secção é apresentado um estudo para o ajuste dos parâmetros quantitativos do AG com base em otimização topológica orientada pela função objetivo $J_{1}$, utilizando como alvo os dois primeiros modos. Os parâmetros quantitativos considerados neste estudo são i) tamanho da população; ii) taxas de cruzamento: $T_{c}$; e iii) número de gerações forçadas: $N_{p}$.

A primeira análise consistiu em avaliar o comportamento evolutivo do AG na seleção de topologias de rede para o isolamento ótimo dos dois primeiros modos de vibrar, em termos do tamanho da população, para diferentes valores da taxa de cruzamento. Naturalmente, conforme dito, as taxas de cruzamento e mutação estão correlacionadas.

O critério de parada adotado consistiu na condição de estagnação do ótimo por cinco gerações consecutivas (convergência não forçada). Cada ponto nos gráficos da Fig. 4.16 é a média aritmética das frequências alcançadas em 10 simulações independentes (diferentes populações iniciais) para um dado tamanho da população.

O critério da média, comum em processos estocásticos, é usado como forma de se evitar o comportamento errático de dados tomados em pequenas amostragens. 


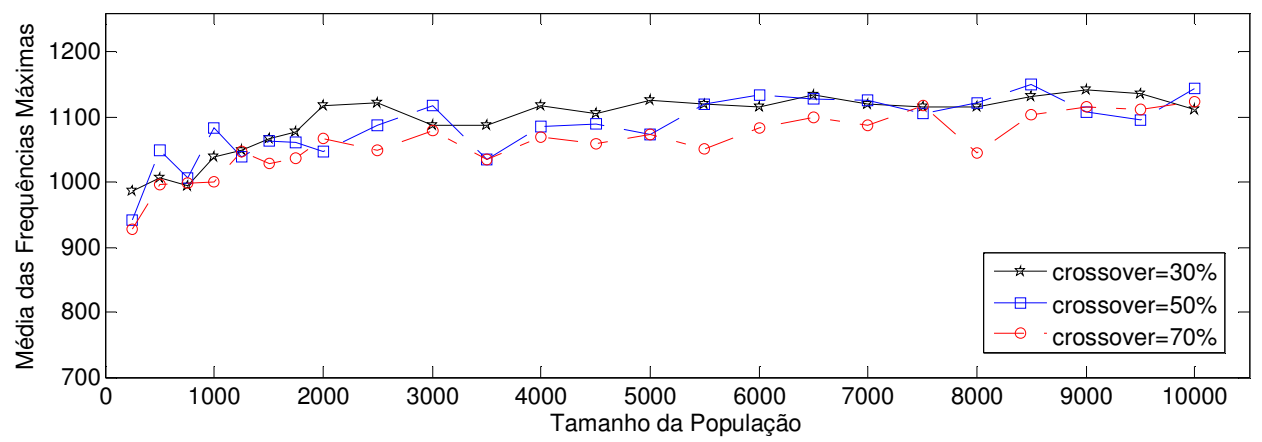

Figura 4.16 - Evolução do desempenho da média das frequências máximas em termos do tamanho da população, para diferentes taxas de cruzamento.

Como pode ser observado na Fig. 4.16, taxas menores de cruzamento se mostraram, na média, mais eficientes. Também, populações menores apresentaram maior taxa de evolução, a qual tende a se estabilizar para populações a partir de 3000 indivíduos.

A segunda análise consistiu em avaliar o papel do número de gerações forçadas na convergência da pesquisa. A Fig. 4.17 representa a evolução da média das frequências máximas em função do número de gerações forçadas $N_{p}$. Uma vez fixado $N_{p}$, foram executadas 3 simulações para cada um dos seguintes valores da taxa de cruzamento: $T_{c}=[30,50,70] \%$. A frequência média é definida pela média de três valores ótimos (o melhor em cada taxa de cruzamento). Novamente, o critério de média adotado objetiva suavizar o comportamento errático inerente a espaços amostrais reduzidos.

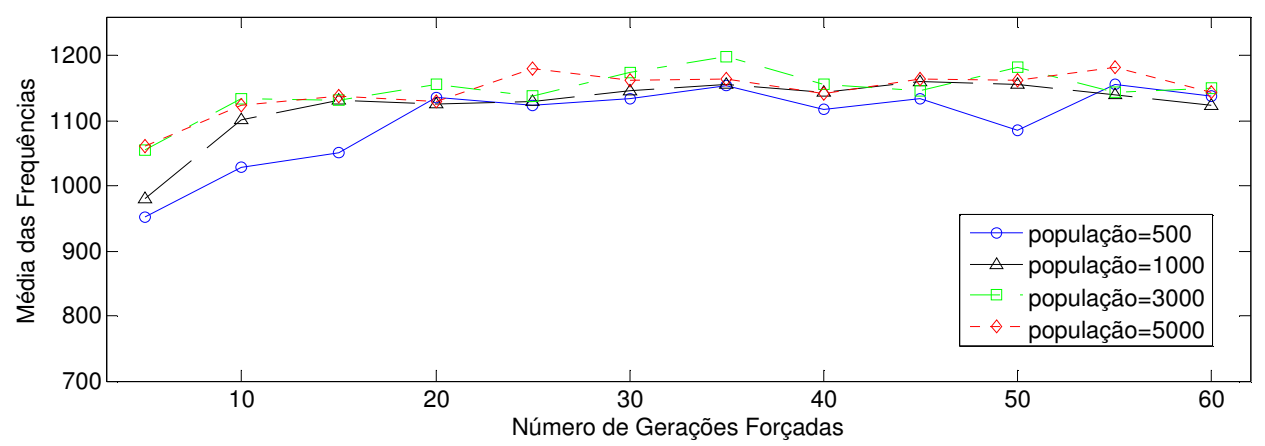

Figura 4.17 - Evolução do desempenho do algoritmo em função do número de gerações forçadas. 
A análise mostra que populações menores demandam um maior número de gerações até alcançarem o desempenho apresentado por populações maiores. A evolução da pesquisa, para as populações avaliadas, sugere que o número de gerações forçadas pode ser ajustado de forma a racionalizar o desempenho do AG, ou seja, definir uma proporção adequada entre desempenho e custo computacional. No caso em estudo, um valor entre 20 e 35 gerações forçadas pode ser considerado como um critério de parada aceitável.

A escala adotada nas Figs. 4.16 e 4.17 representa o limite factível para o desempenho do algoritmo; até $800 \mathrm{~Hz}$, todos os filtros estudados mostram-se igualmente eficazes, apresentando alta qualidade. O limite superior da escala, $1262 \mathrm{~Hz}$, define o máximo valor de frequência de validade do filtro, obtido no conjunto de simulações.

Com base neste estudo preliminar, o AG será aplicado em otimizações topológicas independentes objetivando o isolamento sequencial dos quatro primeiros modos de vibrar. As simulações envolveram populações de 1000, 2000, 3000, 4000 e 5000 indivíduos, e taxas de cruzamento de 30\%,40\%,50\%, 60\% e 70\% (aplicadas à cada tamanho de população). Foi adotado, como critério de parada, 35 gerações forçadas, independentemente da evolução do processo de otimização.

A Fig. 4.18 apresenta os resultados para o conjunto de simulações realizadas conforme descrito acima. São mostrados os valores máximos, médios e mínimos das máximas frequências alcançadas. Embora não sejam baseados em grande amostragem estatística, os resultados mostram que o desvio padrão das frequências ótimas (em relação à média) tendem a se estabilizar em valores baixos, à medida que o número de modos alvos considerados aumentam. De fato, a redução na faixa de frequência aceitável, para filtros com maior número de modos alvos, restringe as combinações de sensores aptas à função objetivo, e aproxima os valores ótimos à média, mesmo considerado um pequeno número de simulações. Para análise de custo-benefício, a média dos resultados encontrados foi dividida pelo tempo total 
necessário ao conjunto de simulações, ambos (média e tempo) relativos a um dado tamanho de população e a um conjunto específico de filtros. Independente do número de modos isolados, a relação benefício-custo do AG decresceu com o aumento no tamanho da população.
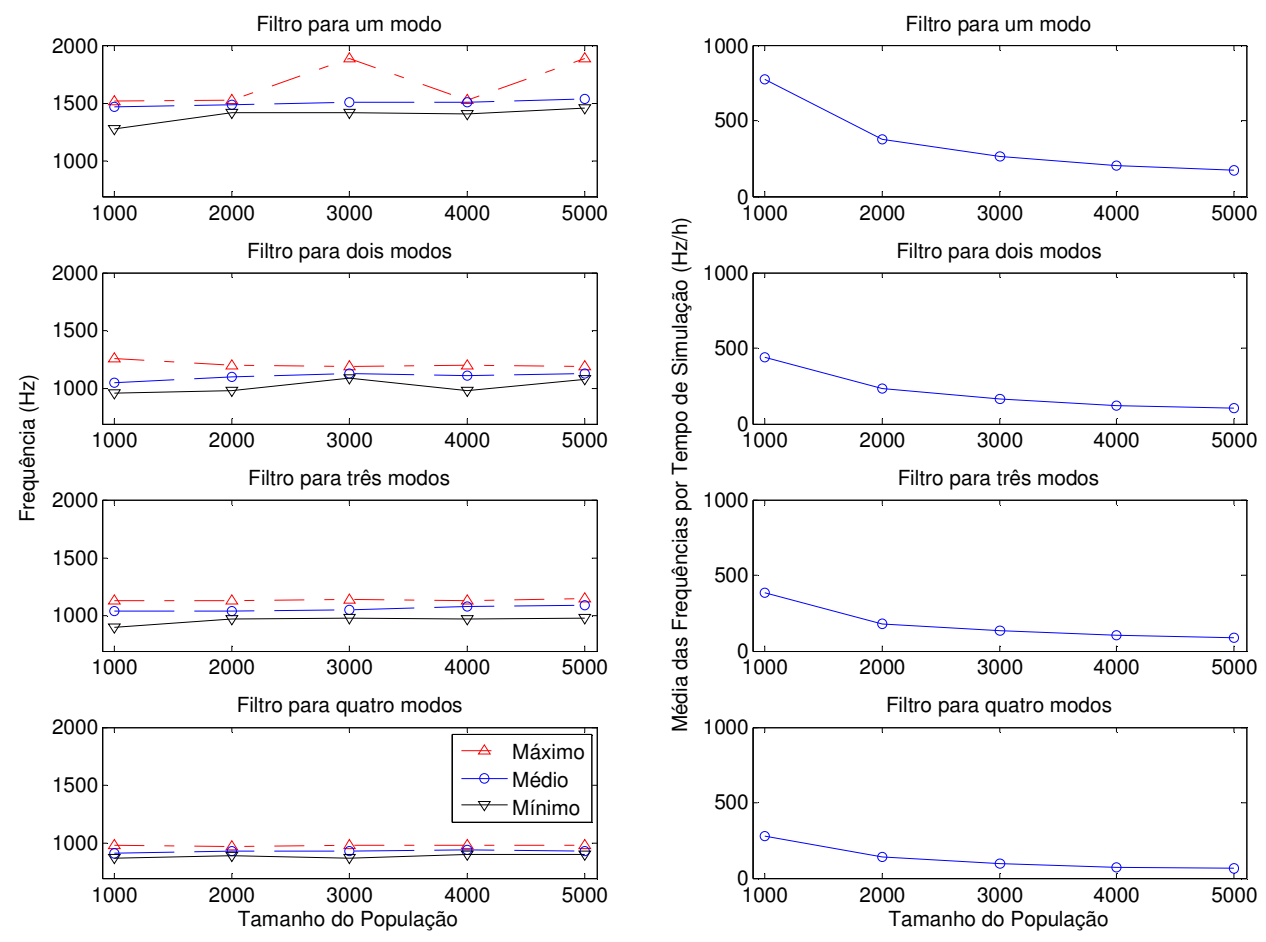

Figura 4.18 - Avaliação de desempenho e custo computacional do algoritmo genético para diferentes tamanhos de população.

O conjunto de análises realizadas, conforme descrito acima, cumprem dois objetivos: i) otimizar os parâmetros quantitativos de algoritmo genético aplicado à otimização topológica da rede de sensores, com base na função objetivo $J_{1}$; e ii) prover os resultados finais do processo de otimização.

É importante ressaltar que os parâmetros ótimos para a função objetivo $J_{1}$ não se aplicam à função objetivo $J_{2}$, na medida em que diferentes funções objetivos definem processos de modelagem distintos. Embora um estudo paramétrico similar não tenha sido realizado para a função objetivo $J_{2}$, os valores obtidos para a função 
objetivo $J_{1}$ podem ser usados como valores de partida para a configuração do AG, quando a função objetivo $J_{2}$ é adotada.

A otimização topológica orientada pela função objetivo $J_{2}$, para cada conjunto de filtros modais, consistiu de cinquenta simulações. Em cada simulação, uma população de 1500 indivíduos evolui por 35 gerações forçadas. Também foi utilizado o valor de $45 \%$ para a taxa de cruzamento. Estes parâmetros se mostraram adequados, na medida em que, na maioria dos casos, o algoritmo genético evoluiu rapidamente para o valor ótimo encontrado na pesquisa.

\subsubsection{Resultados da otimização usando AG}

As Figs. 4.19 até 4.22 apresentam os resultados da otimização topológica utilizando algoritmo genético. Os índices de desempenho dos filtros modais são avaliados com base na função objetivo $J_{1}$. Em cada figura estão representados os filtros modais ótimos e as respectivas topologias de rede das quais derivam os filtros.

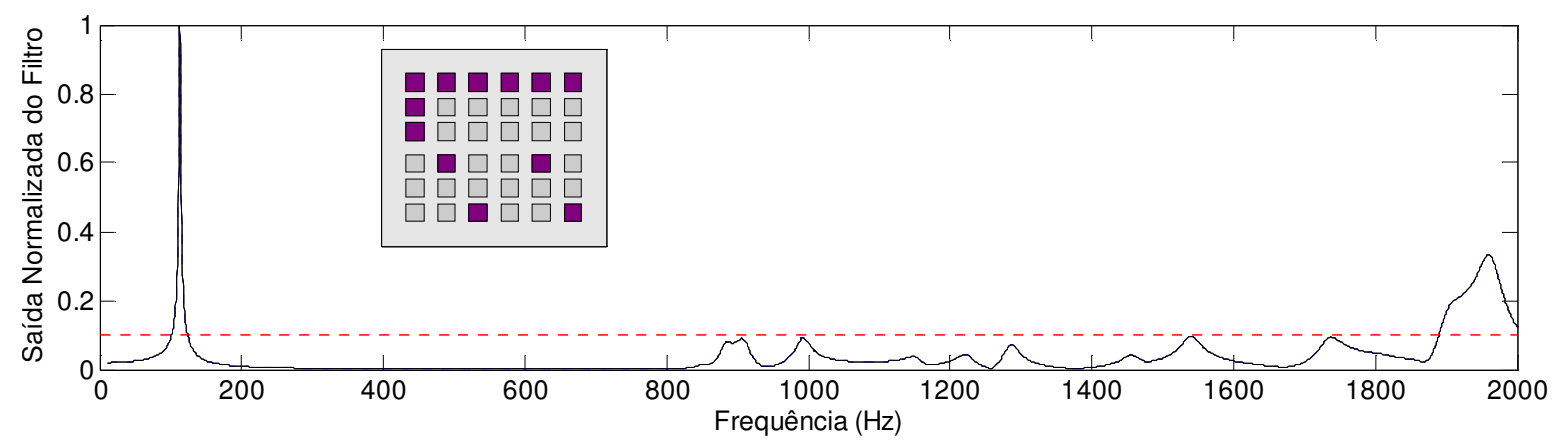

Figura 4.19 - Topologia de rede e filtro otimizado para o isolamento do primeiro modo de vibrar. A frequência máxima alcançada é $1890 \mathrm{~Hz}$. 


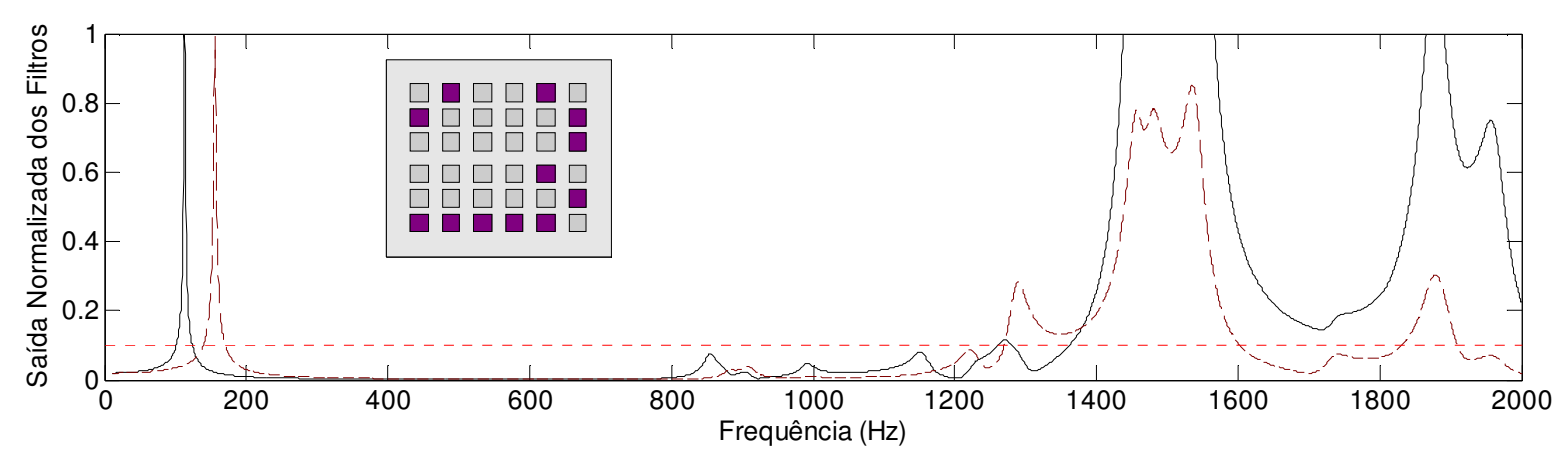

Figura 4.20 - Topologia de rede e filtros otimizados para o isolamento dos dois primeiros modos de vibrar. A frequência máxima alcançada é $1262 \mathrm{~Hz}$.

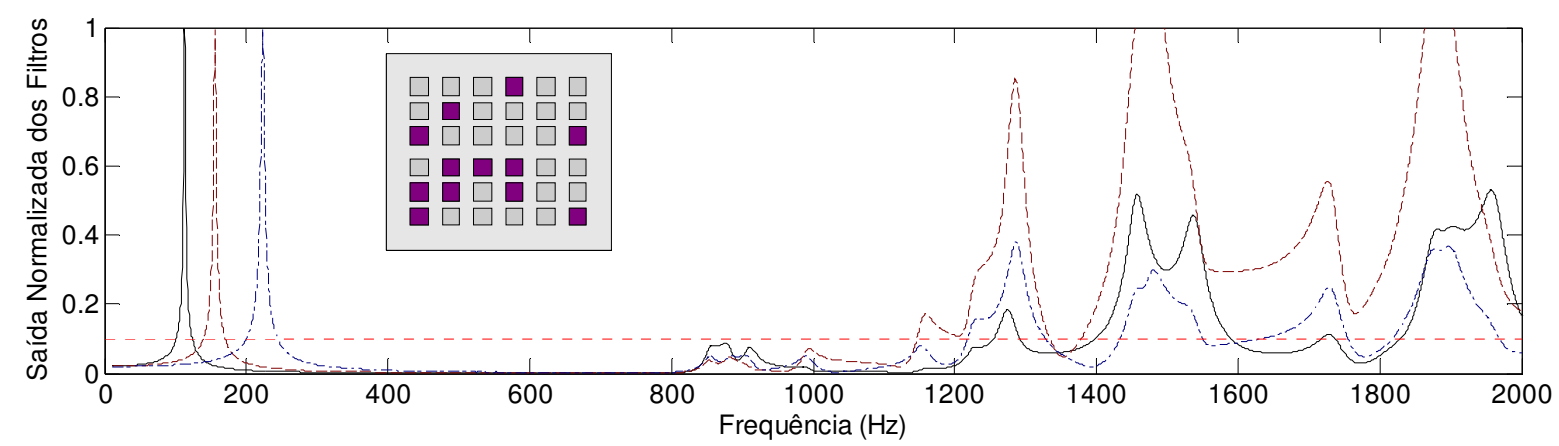

Figura 4.21 - Topologia de rede e filtros otimizados para o isolamento dos três primeiros modos de vibrar. A frequência máxima alcançada é $1147 \mathrm{~Hz}$.

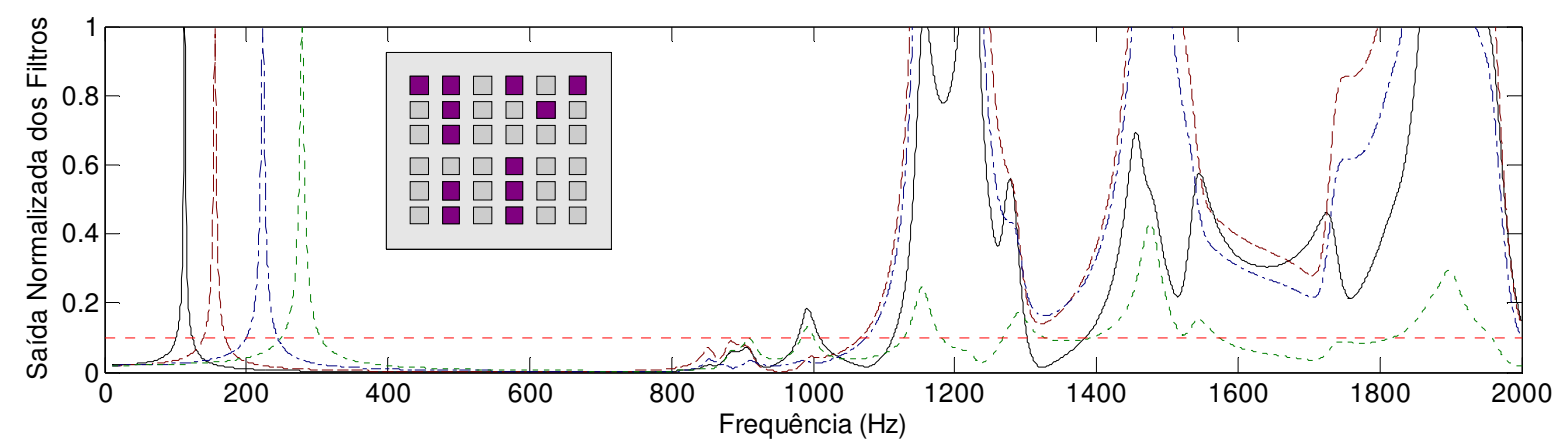

Figura 4.22 - Topologia de rede e filtros otimizados para o isolamento dos quatro primeiros modos de vibração. A frequência máxima alcançada é $980 \mathrm{~Hz}$.

As Figs. 4.23 até 4.34 apresentam resultados gerais da otimização topológica utilizando algoritmo genético, quando os índices de desempenho dos filtros modais são avaliados com base na função objetivo $J_{2}$. As figuras apresentam as topologias de rede otimizadas e os respectivos filtros modais derivados. 


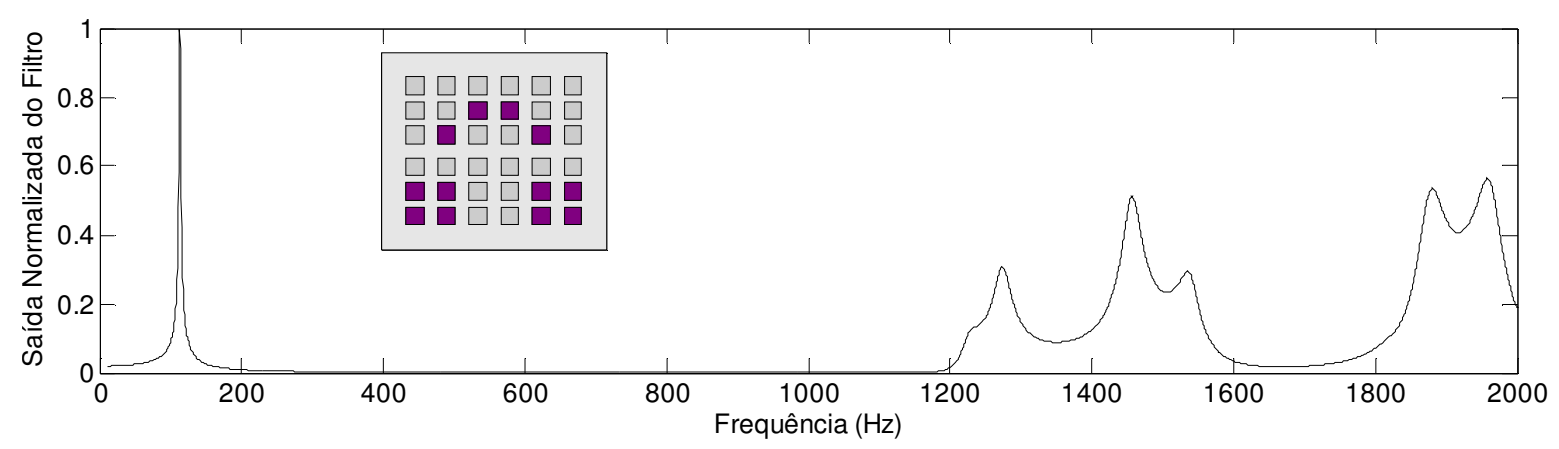

Figura 4.23 - Topologia de rede ótima e filtro modal projetado para isolar o primeiro modo de vibrar até $1000 \mathrm{~Hz}$, em escala linear.

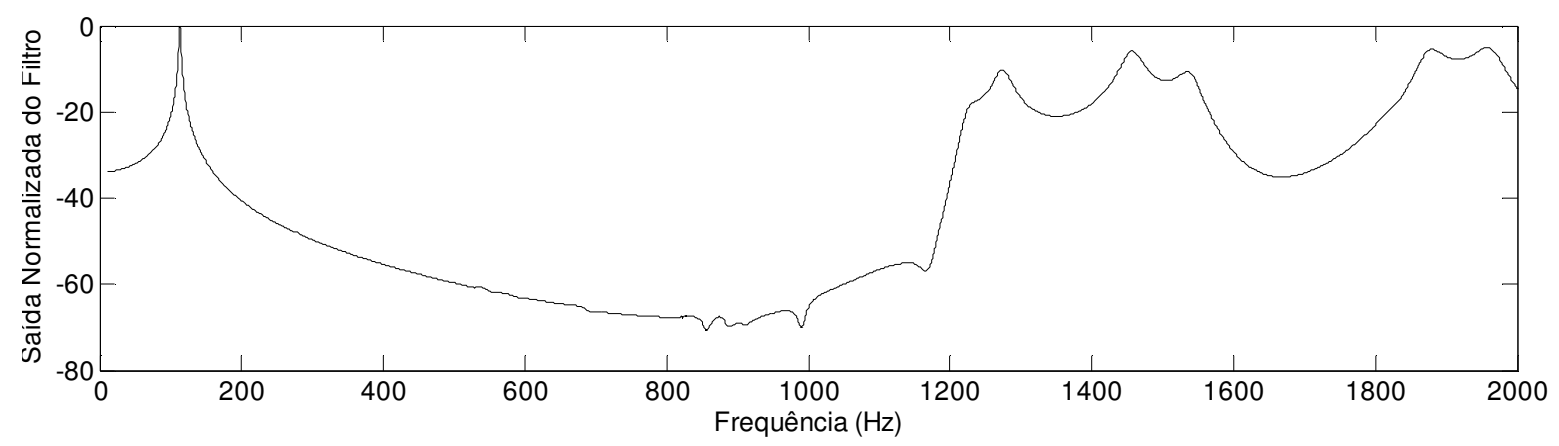

Figura 4.24 - Filtro modal projetado para isolar o primeiro modo de vibrar até $1000 \mathrm{~Hz}$, em escala logarítmica (dB).

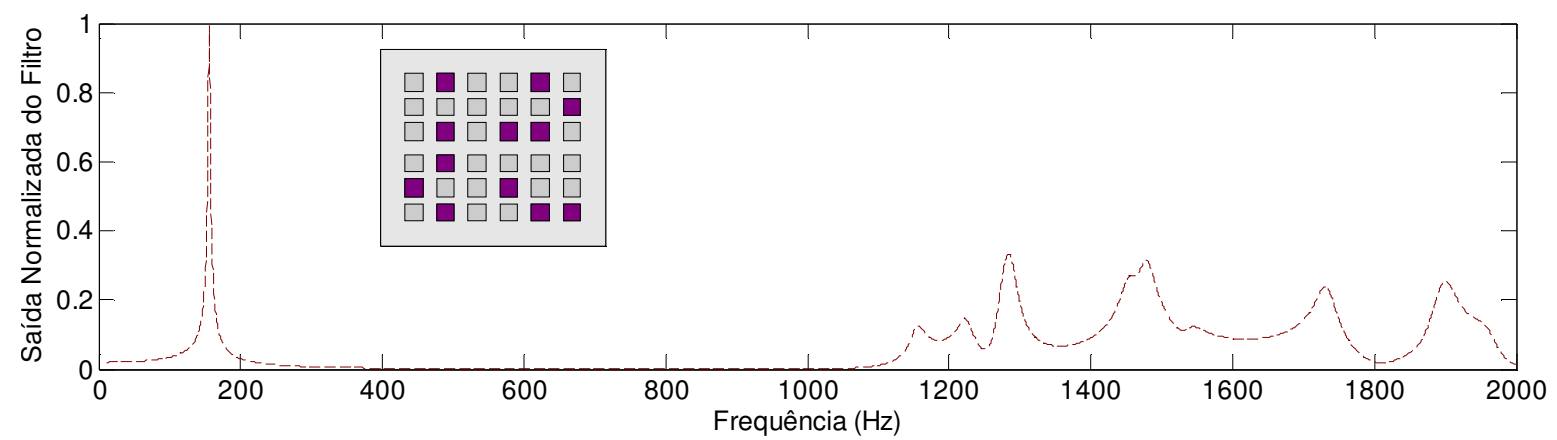

Figura 4.25 - Topologia de rede ótima e filtro modal projetodo para isolar o segundo modo de vibrar até $1000 \mathrm{~Hz}$. 


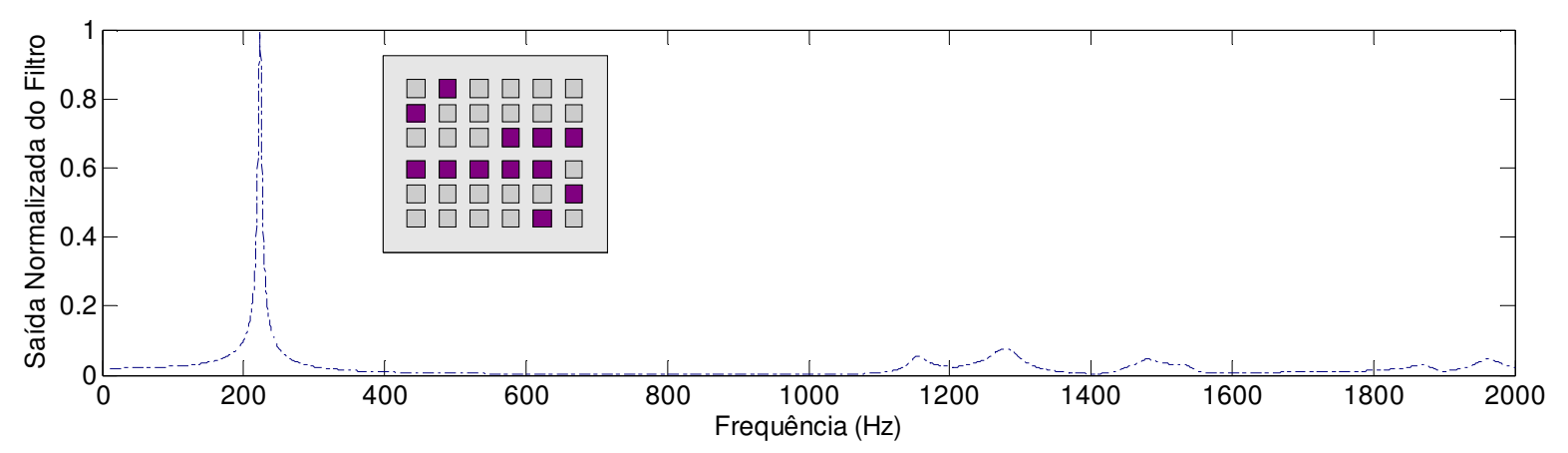

Figura 4.26 - Topologia de rede ótima e filtro modal projetado para isolar o terceiro modo de vibrar até $1000 \mathrm{~Hz}$.

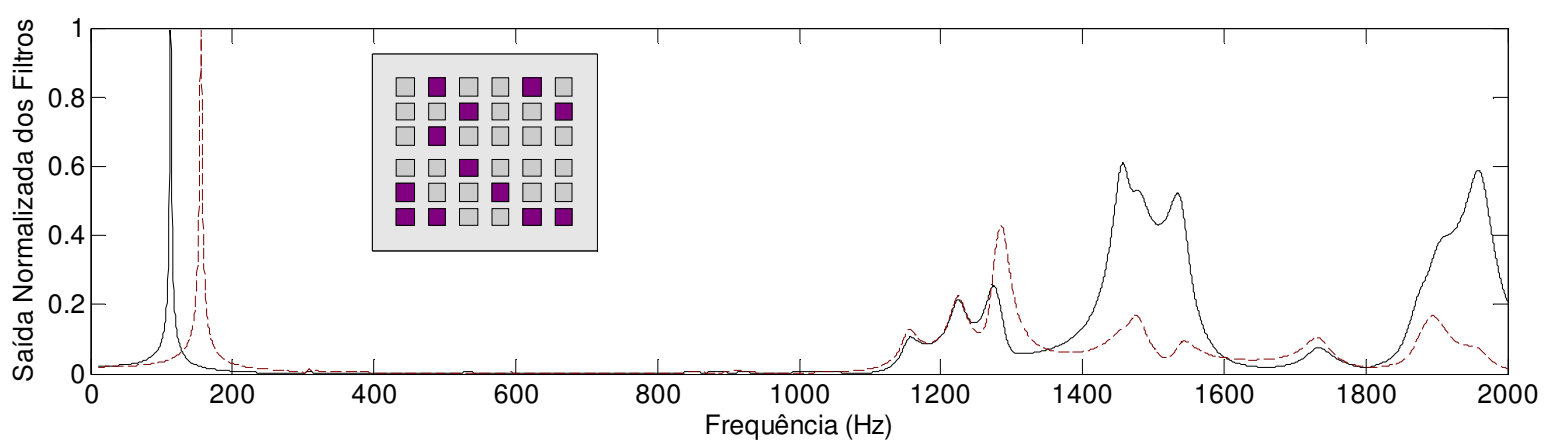

Figura 4.27 - Topologia rede e filtros otimizados para o isolamento dos dois primeiros modos de vibrar. Os modos residuais são filtrados até $1000 \mathrm{~Hz}$. Erros inferiores a 1,5\% são medidos na banda de frequência otimizada.

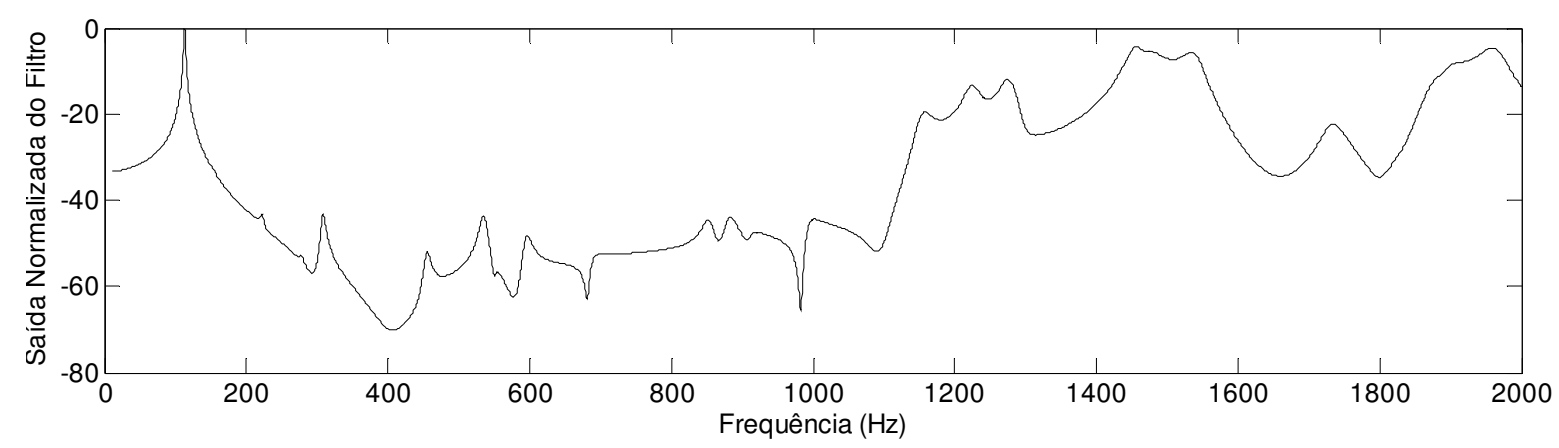

Figura 4.28 - Filtro para o primeiro modo de vibrar, obtido a partir da topologia de rede otimizada para isolar os dois primeiros modos de vibrar até $1000 \mathrm{~Hz}$, em escala logarítmica (dB). 


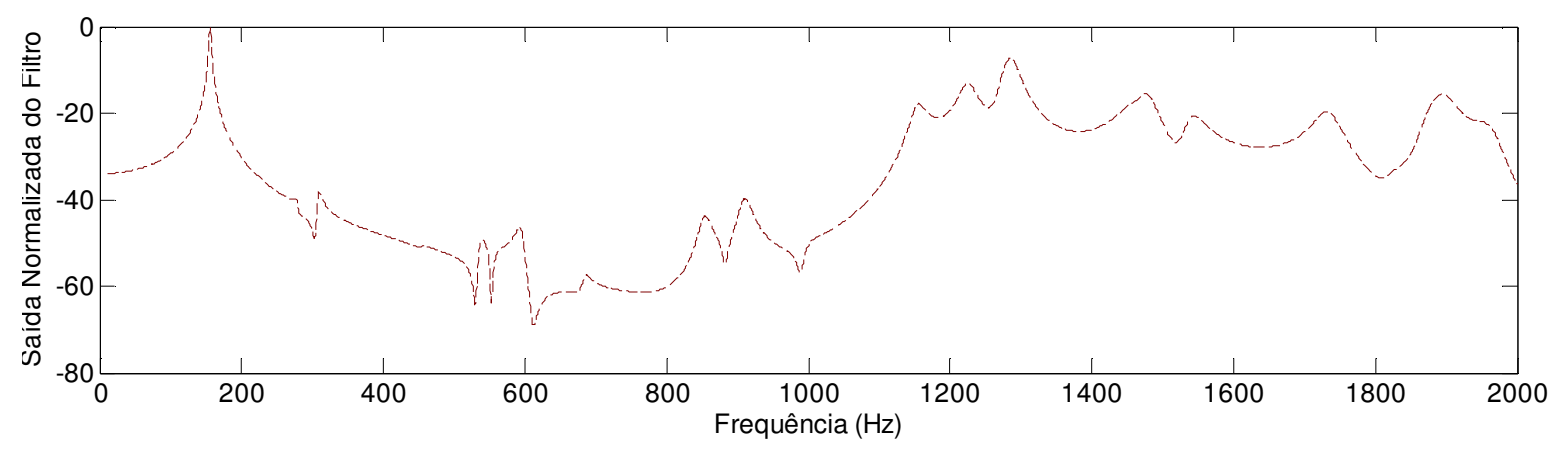

Figura 4.29 - Filtro para o segundo modo de vibrar, obtido a partir da topologia de rede otimizada para isolar os dois primeiros modos de vibrar até $1000 \mathrm{~Hz}$, em escala logarítmica (dB).

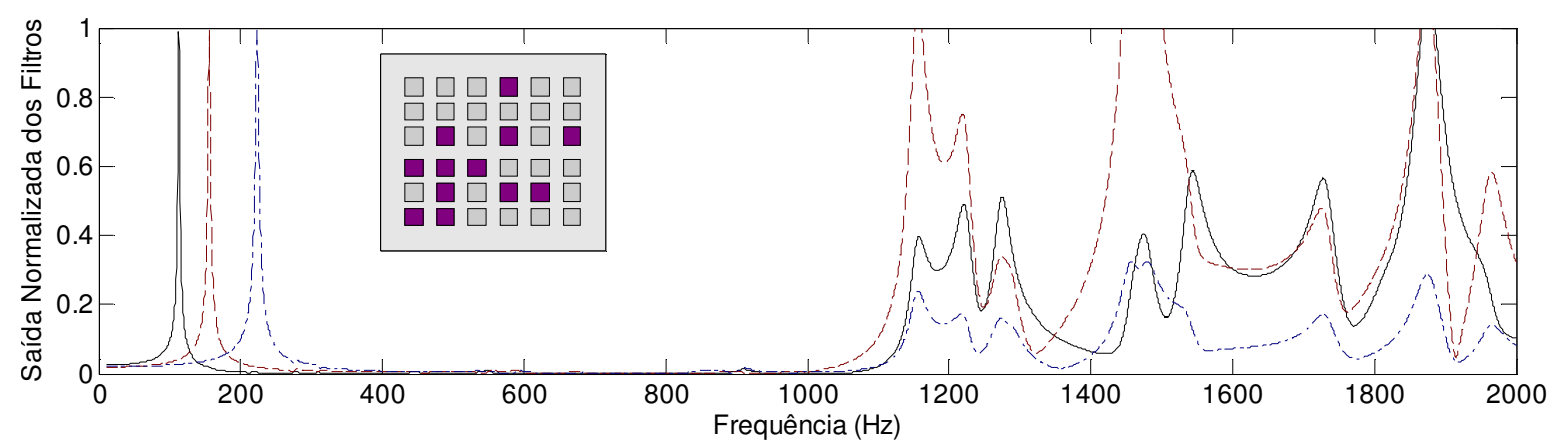

Figura 4.30 - Topologia de rede e filtros otimizados para o isolamento dos três primeiros modos de vibrar. Os modos residuais são filtrados até $1000 \mathrm{~Hz}$. Erros inferiores a $2 \%$ são medidos na banda de frequência otimizada.

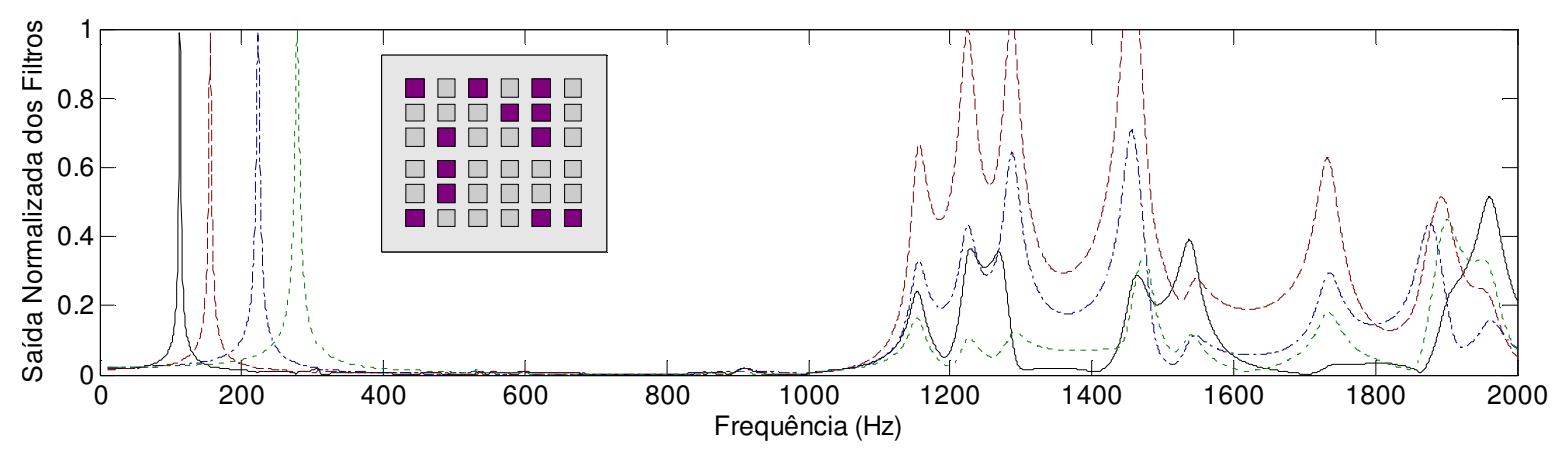

Figura 4.31 - Topologia de rede e filtros otimizados para o isolamento dos quatro primeiros modos de vibrar. Os modos residuais são filtrados até $1000 \mathrm{~Hz}$. Erros inferiores a 2,5\% são medidos na banda de frequência otimizada. 


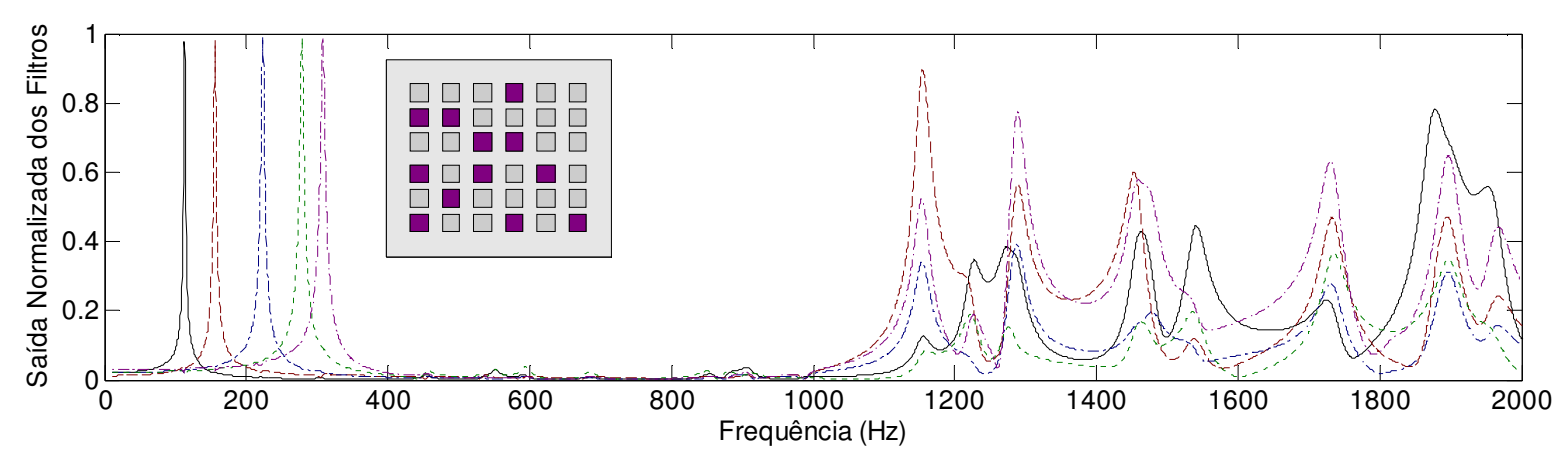

Figura 4.32 - Topologia de rede e filtros otimizados para o isolamento dos cinco primeiros modos de vibrar. Os modos residuais são filtrados até $1000 \mathrm{~Hz}$. Erros inferiores a $4 \%$ são medidos na banda de frequência otimizada.

As Fig. 4.33 e 4.34 mostram os resultados da otimização topológica objetivando maximizar o desempenho dos filtros modais para o isolamento dos modos $\{1,2\}$ e $\{1,2,3\}$ até $1200 \mathrm{~Hz}$, respectivamente. Embora a faixa de frequência para otimização tenha sido ampliada em $200 \mathrm{~Hz}$, apenas um modo residual foi adicionado à otimização até $1000 \mathrm{~Hz}$.

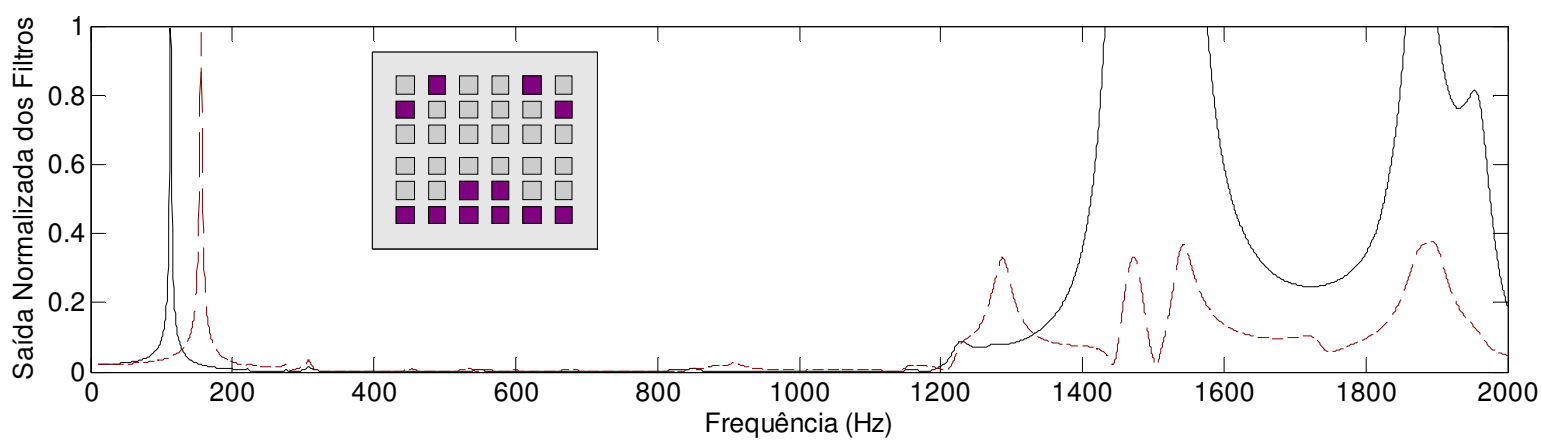

Figura 4.33 - Topologia de rede e filtros otimizados para o isolamento dos dois primeiros modos de vibrar até a frequência máxima de $1200 \mathrm{~Hz}$. Erros residuais pouco superiores a 2,5\% são medidos na banda de frequência otimizada. 


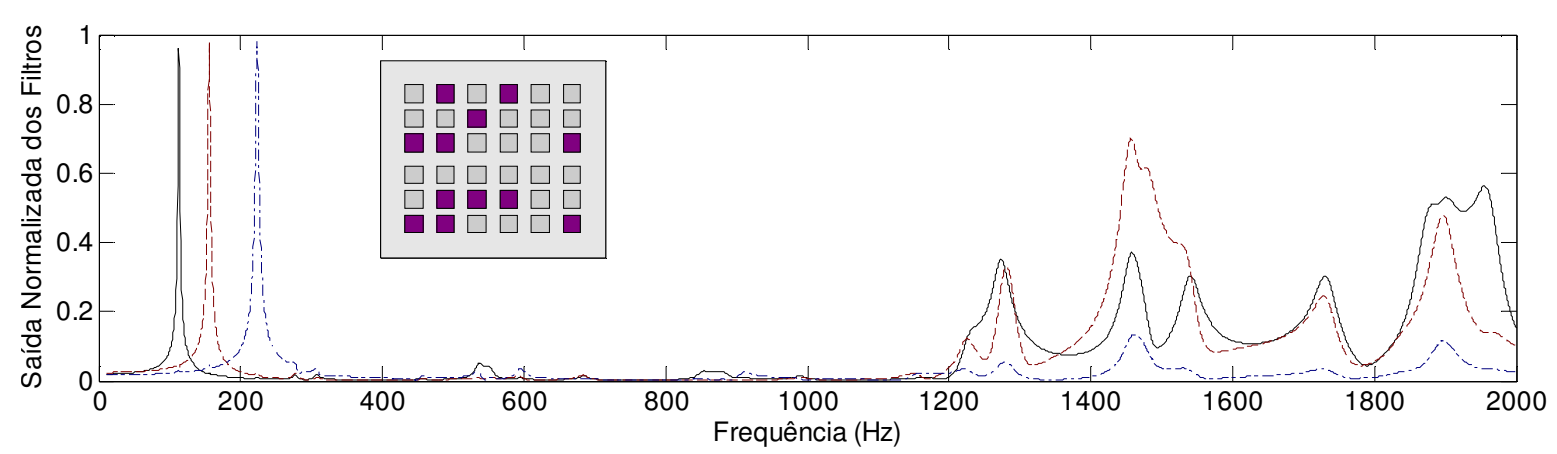

Figura 4.34 - Topologia de rede e filtros otimizados para o isolamento dos três primeiros modos de vibrar até a frequência máxima de $1200 \mathrm{~Hz}$. O erro residual máximo na banda de frequência otimizada está em torno de 5\%.

O conjunto de resultados apresentados mostram que o índice de desempenho de um conjunto de filtros modais é definido pelo ponto de truncamento da matriz de FRF e pela topologia de rede, ou posicionamento dos sensores.

Neste trabalho, busca extensiva restrita e algoritmo genético concorrem em um processo de otimização topológica combinatorial, consoantes a dois critérios de otimização distintos. Pela comparação dos resultados das otimizações topológicas por busca extensiva e algoritmo genético, relativas às funções objetivo $J_{1}$ e $J_{2}$, vê-se que os filtros modais de mais alto desempenho foram obtidos via otimização por algoritmo genético. Embora o algoritmo genético tenha melhorado os resultados e reduzido o custo computacional do processo de otimização combinatorial, as características dos filtros se mostraram dependentes da forma como as variáveis de projeto são definidas (truncamento da matriz de FRF e função objetivo adotada).

A Fig. 4.19 mostra que o AG encontrou uma topologia que satisfaz a função objetivo $J_{1}$ até $1890 \mathrm{~Hz}$, no entanto, erros significativos já são encontrados em frequências próximas a $800 \mathrm{~Hz}$. A característica de os filtros apresentarem ruídos significativos a partir de $800 \mathrm{~Hz}$ é atribuída à função objetivo $J_{1}$, e mostra que otimização topológica não é suficiente para minimizar a amplitude dos modos ressonantes em frequências mais altas. Daí, a banda de truncamento da matriz de FRF ser ampliada. 
As Figs. 4.23 até 4.32 mostram que uma redução significativa na amplitude de alguns modos de vibrar ressonantes em frequências além de $800 \mathrm{~Hz}$ foi alcançada. No entanto, a eficácia da otimização topológica orientada pela função objetivo $J_{2}$ também é dependente da relação entre o número de modos alvos que se desejam isolar e o número de modos residuais que se desejam filtrar. Não obstante, a inclusão de novos modos residuais no processo de filtragem, pelo alargamento da banda de frequência no truncamento da matriz de FRF, tende a deteriorar o desempenho dos filtros, mesmo quando poucos modos alvos são considerados.

Os erros residuais presentes na filtragem dos modos $\{1\},\{2\}$, e $\{3\}$, até $1000 \mathrm{~Hz}$, são considerados insignificantes para propósitos gerais de aplicação dos filtros. Para o isolamento simultâneo dos dois primeiros modos de vibrar, foi verificado um erro residual inferior a 1,5\% da amplitude normalizada dos modos alvos até $1000 \mathrm{~Hz}$. As Figs. 4.24, 4.28 e 4.29, evidenciam a ação dos filtros sobre cada modo residual, quando são considerados os modos alvos $\{1\}$ e $\{1,2\}$, respectivamente. A visualização dos filtros em escala logarítmica $(\mathrm{dB})$ pode ser válida para uma melhor definição acerca da contribuição relativa de cada modo ressonante para a norma do erro residual.

Os filtros para o isolamento dos modos $\{1,2,3\}$ apresentaram erro residual máximo de $2 \%$, enquanto que os filtros para o isolamento dos modos $\{1,2,3,4\}$ apresentam erro residual máximo de 2,5\%. Os filtros para o isolamento dos modos $\{1,2,3,4,5\}$ apresentam erro residual máximo de $4 \%$. Estes podem ser considerados bons resultados para aplicações gerais dos filtros modais.

Finalmente, a Fig. 4.33 mostra o filtro modal ótimo para o isolamento dos modos $\{1,2\}$ até $1200 \mathrm{~Hz}$, representando a inclusão de um modo residual na banda de frequência além de $1000 \mathrm{~Hz}$. O erro residual encontrado é um pouco superior a 2,5\%, o que significa que o erro cometido na filtragem dos dois primeiros modos até $1200 \mathrm{~Hz}$ é aproximadamente aquele inerente à filtragem dos quatro primeiros modos até $1000 \mathrm{~Hz}$. A Fig. 4.34 representa o filtro modal ótimo para o isolamento dos modos 
$\{1,2,3\}$ até $1200 \mathrm{~Hz}$. Neste caso, o erro residual máximo está na faixa de $5 \%$, o que significa um erro superior aquele encontrado na filtragem dos cinco primeiros modos de vibrar até $1000 \mathrm{~Hz}$.

Os últimos resultados apresentados ajudam a evidenciar os limites aceitáveis para o desempenho dos filtros modais, embora estes limites sejam definidos de acordo com a precisão requerida em cada aplicação. De forma geral, para o sistema dinâmico considerado neste trabalho, o erro residual torna-se significativo quando mais que cinco modos alvos são considerados no processo de filtragem até $1000 \mathrm{~Hz}$, ou a banda de frequência é estendida além de $1200 \mathrm{~Hz}$ e mais que dois modos alvos são considerados.

\subsection{Efeito da eliminação das pastilhas inativas}

A estratégia de otimização adotada neste trabalho requer a ponderação dos sinais de tensão de uma sub-rede de doze sensores, selecionados entre aqueles 36 que definem uma rede aproximadamente regular, de acordo com projetos específicos de filtros modais. O objetivo implícito nesta estratégia é reduzir o custo computacional inerente à otimização topológica baseada em simulações numéricas.

O processo de otimização topológica seleciona os doze sensores a serem ativados e descarta os vinte e quatro sensores restantes. Naturalmente, a implementação prática dos filtros modais requer que apenas aqueles sensores que definem as topologias de rede otimizadas sejam efetivamente colados sobre a estrutura.

A retirada ou inclusão de um sensor modifica a rigidez global da estrutura e desloca suas frequências de ressonância. Não obstante, é necessário estudar o comportamento dos filtros modais obtidos a partir da estrutura remodelada com um número reduzido de sensores. 
Uma vez definida a topologia ótima, o desempenho dos filtros modais devem ser reavaliados por simulação numérica, antes de uma validação experimental. É possível otimizar várias topologias de rede de doze sensores a partir da rede composta por trinta e seis sensores e manter sobre a estrutura um conjunto de topologias otimizadas de acordo com diferentes projetos de filtros modais. Naturalmente, algumas topologias apresentarão sensores em comum.

Nas validações numéricas considera-se o caso em que apenas uma rede de doze sensores é mantida sobre a estrutura. Este caso representa a maior variação de rigidez global da estrutura, em termos do número de sensores, para o projeto de otimização proposto. Para um número fixo de sensores, a rigidez global depende da distribuição relativa dos sensores sobre a estrutura, de forma que cada topologia selecionada requer uma validação numérica.

Os resultados da otimização topológica mostram que a inclusão de um único modo de vibrar pode alterar completamente a configuração topológica da rede que melhor isola o conjunto de modos alvos em uma faixa prescrita de frequência.

A validação numérica consiste em comparar o desempenho dos filtros modais obtidos a partir da topologia de rede otimizada, considerando-se dois casos: i) todos os trinta e seis sensores estão sobre a placa, conforme o modelo original; ii) a placa é remodelada de forma a retirar os vinte e quatro sensores descartados pela otimização e manter apenas os doze sensores que definem a topologia de rede ótima.

Os filtros modais obtidos em ambos os modelos foram comparados para quatro casos (topologias distintas). A validação da metodologia de otimização topológica combinatorial requer uma boa concordância entre os filtros modais derivados dos modelos estruturais contendo doze e trinta e seis sensores sobre a placa. 
a)

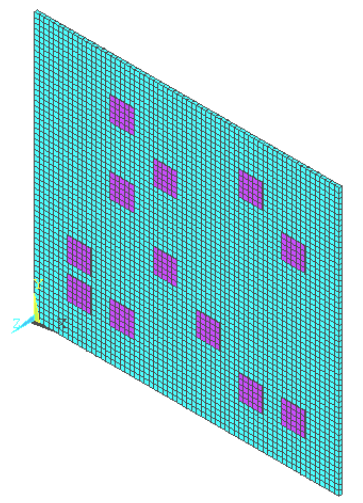

d)

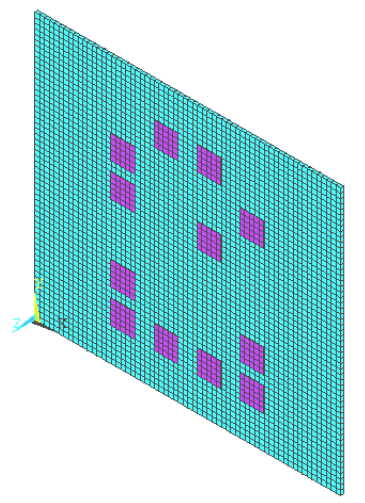

b)

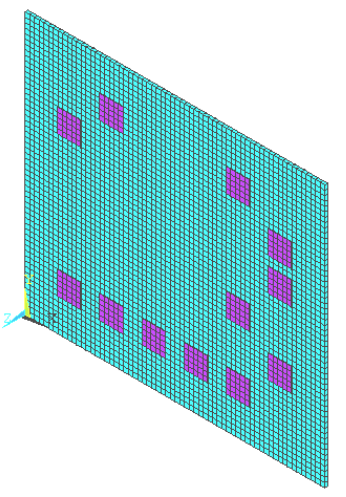

c)

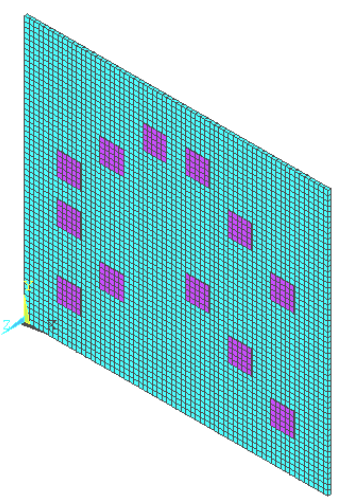

Figura 4.35 - Placa de alumínio remodelada a partir de diferentes topologias de rede otimizadas para diferentes conjuntos de filtros modais.

A Fig. 4.35 ilustra o modelo placa-pastilhas reconstruída para quatro diferentes topologias otimizadas. Os doze sensores que definem as topologias de rede selecionadas são mantidos (sensores ativos) e os vinte e quatro restantes são descartados.

As Figs. 4.36 até 4.39 mostram os efeitos da variação de rigidez no modelo de elementos finitos sobre o desempenho dos filtros modais obtidos a partir das topologias de rede representadas na Fig. 4.35. A Fig. 4.36 considera a validação numérica para a topologia de rede mostrada na Fig. 4.35(a), para o isolamento dos modos $\{1,2\}$, que é resultado de otimização topológica por algoritmo genético, com base na segunda função objetivo. 


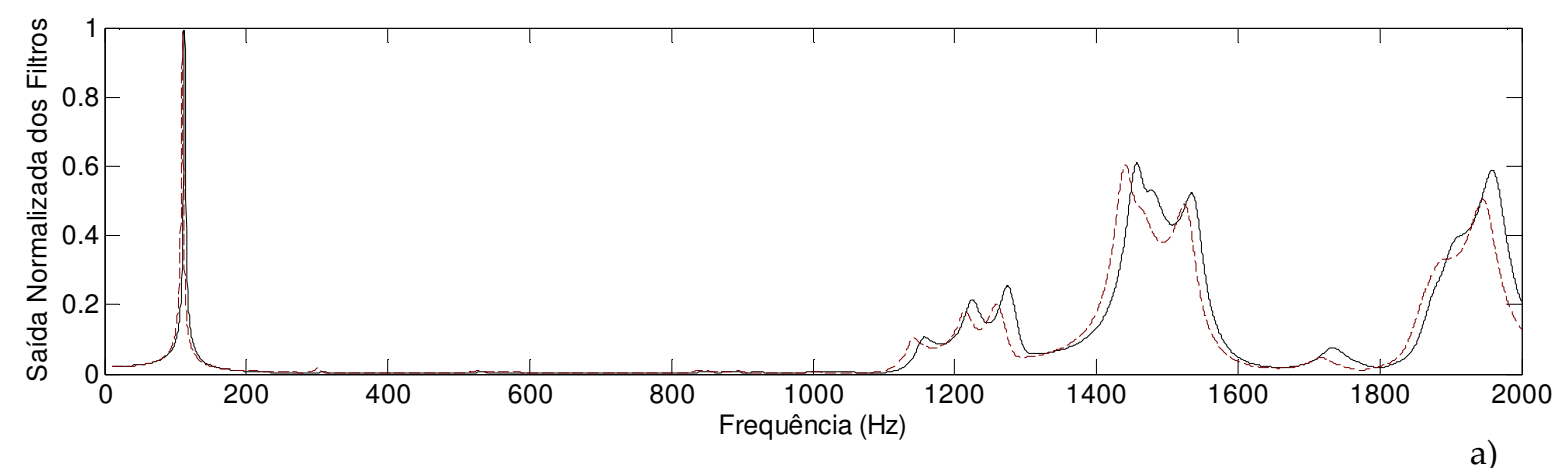

a)

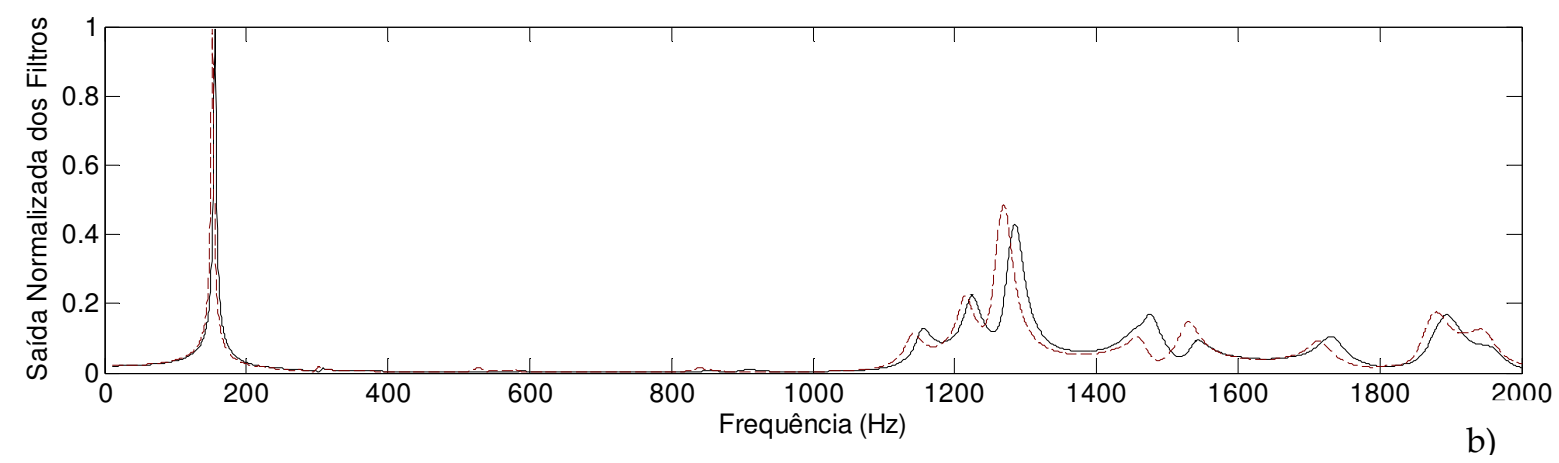

Figura 4.36 - Comparação entre os filtros modais projetados para isolar o primeiro e o segundo modos de vibrar com (-) e sem (--) os vinte e quatro sensores sensores inativos. a) primeiro modo, b) segundo modo.

A Fig. 4.37 considera a validação numérica para a topologia de rede apresentada na Fig. 4.35(b), para o isolamento dos modos $\{1,2\}$, que é resultado de otimização topológica por algoritmo genético, com base na função objetivo $J_{1}$. 

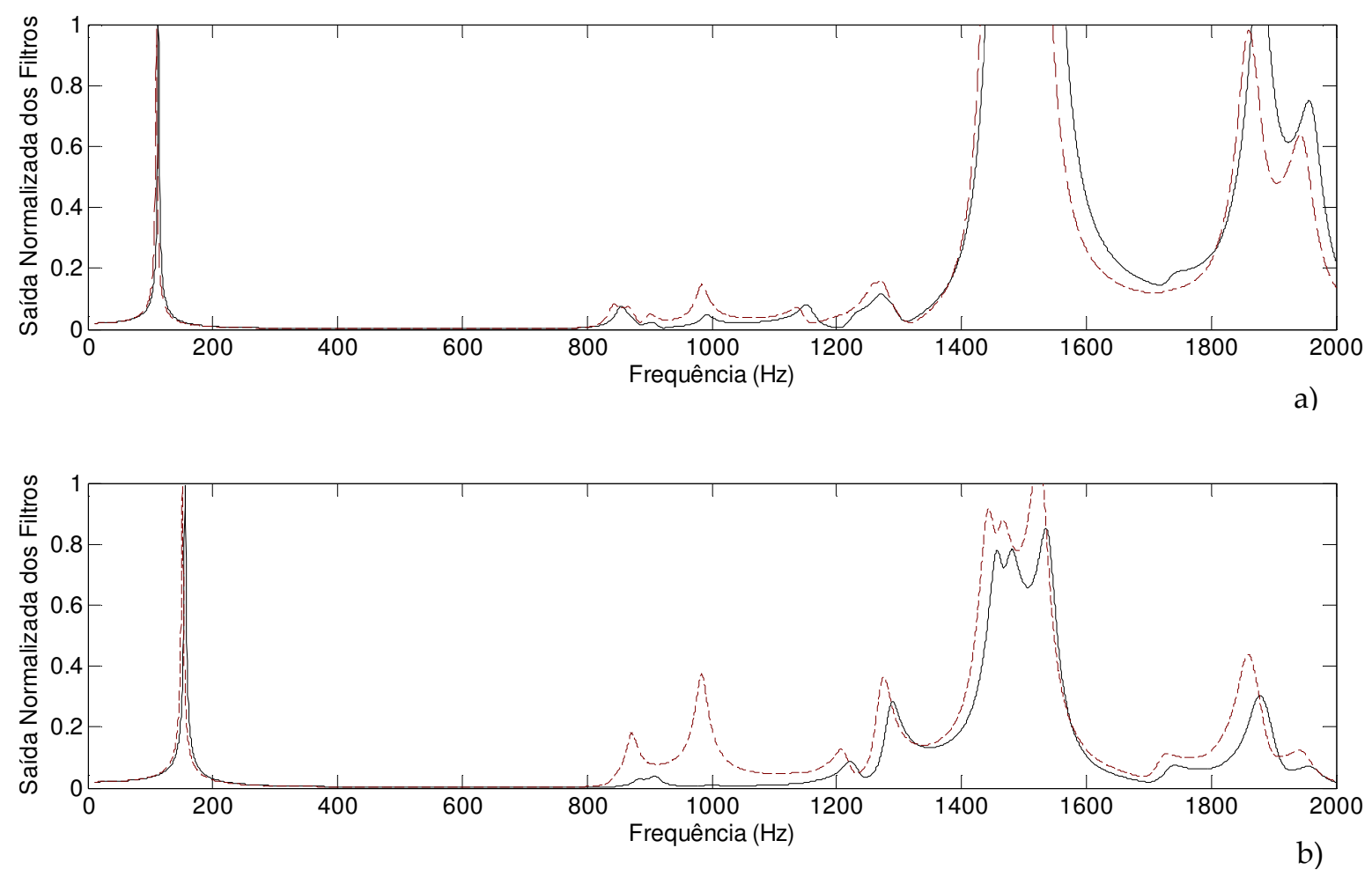

Figura 4.37 - Comparação entre os filtros modais projetados para isolar o primeiro e o segundo modos de vibrar com (-) e sem (--) os vinte e quatro sensores sensores inativos. a) primeiro modo, b) segundo modo.

A Fig 4.38 considera a validação numérica para a topologia de rede mostrada na Fig. 4.35(c), para o isolamento dos modos $\{1,2,3\}$, que é resultado de otimização topológica utilizando busca extensiva, com base na função objetivo $J_{1}$. 

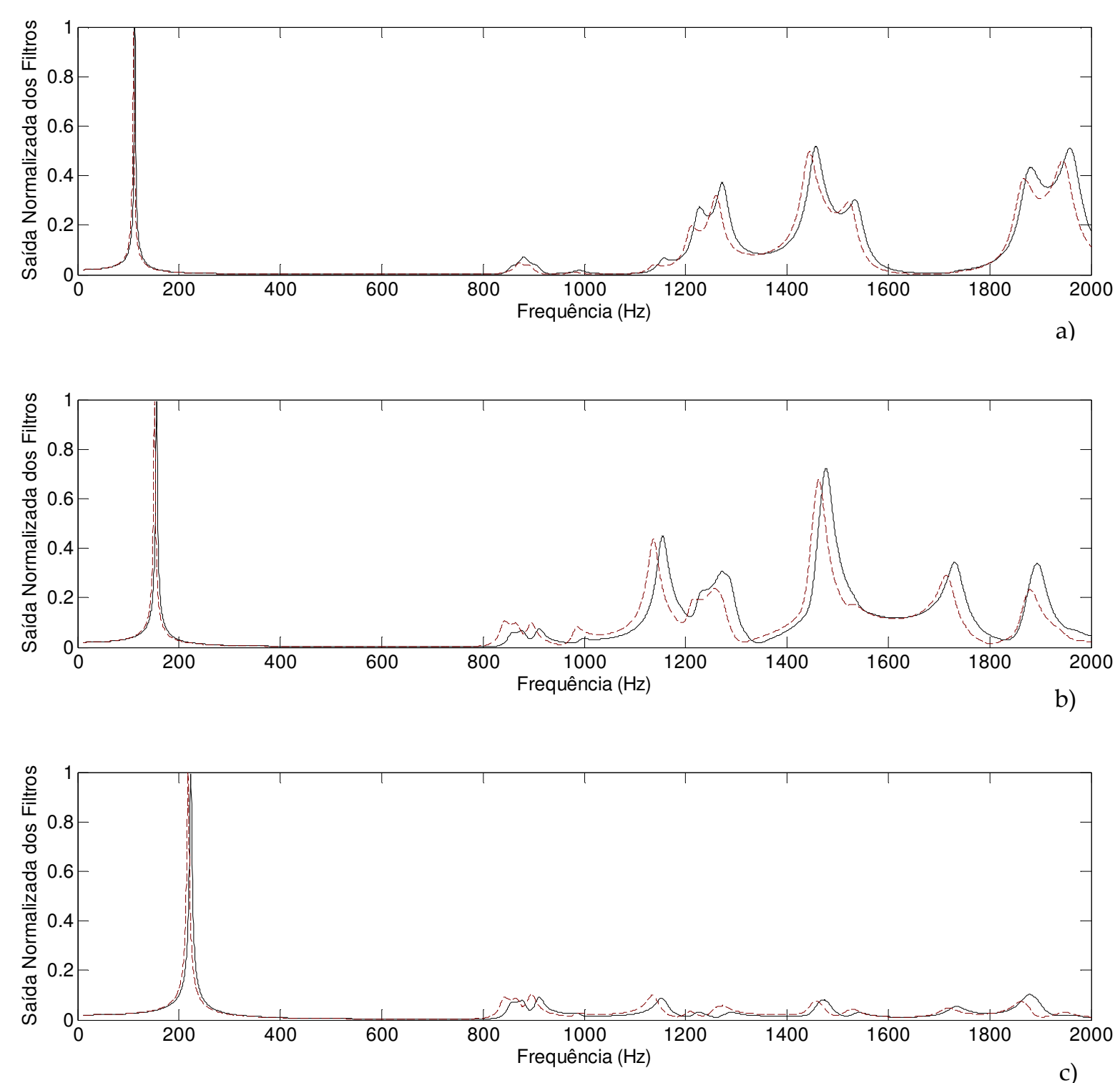

Figura 4.38 - Comparação entre os filtros modais projetados para isolar o primeiro, segundo e o tercerio modos de vibrar com (-) e sem (--) os vinte e quatro sensores sensores inativos. a) primeiro modo, $b$ ) segundo modo, c) terceiro modo.

A Fig 4.38 considera a validação numérica para a topologia de rede mostrada na Fig. 4.35(d), para o isolamento dos modos $\{1,2,3,4\}$, que é resultado de otimização topológica por busca extensiva, com base na função objetivo $J_{2}$. 

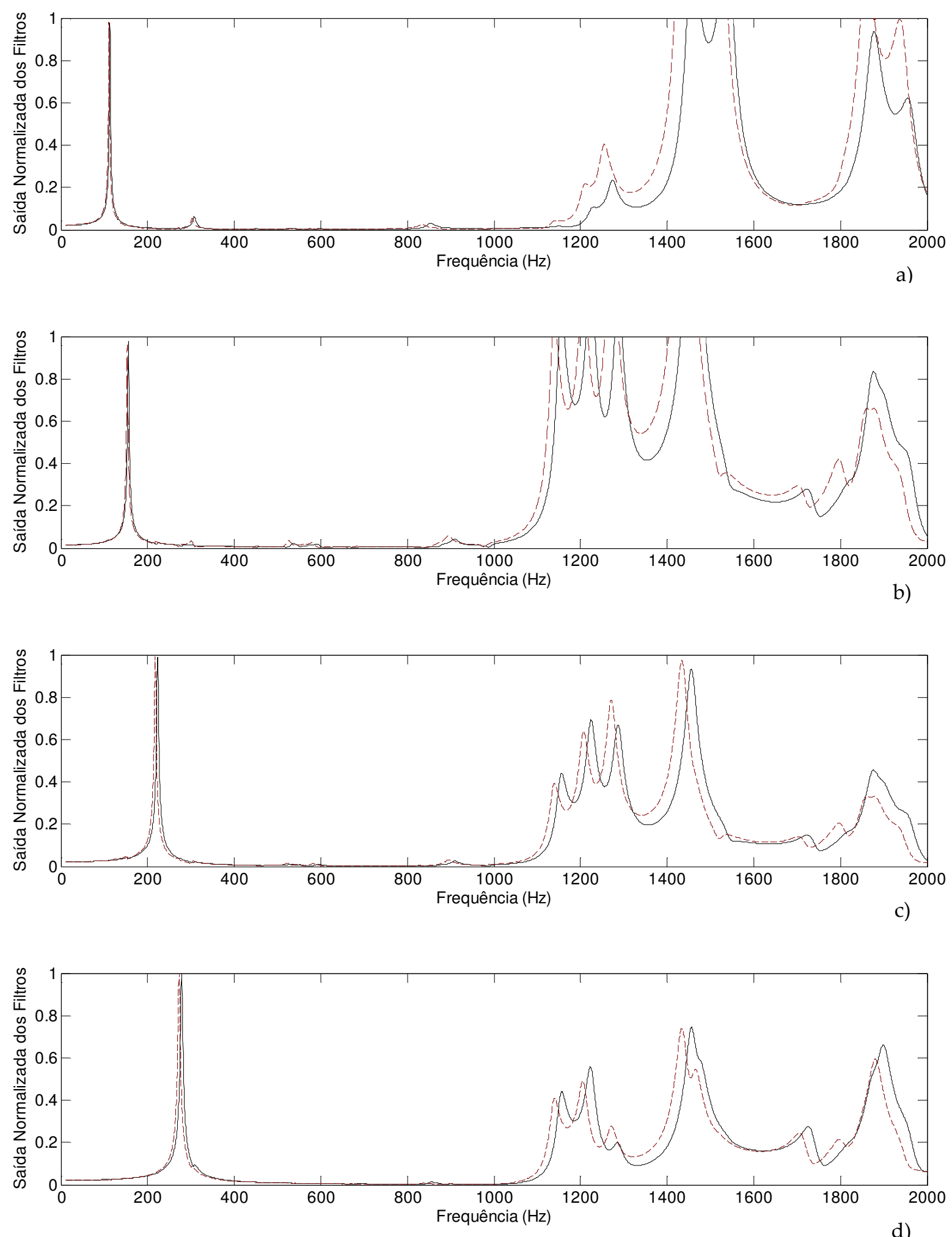

Figura 4.39 - Comparação entre os filtros modais projetados para isolar o primeiro, segundo, tercerio e o quarto modos de vibrar com (-) e sem (--) os vinte e quatro sensores sensores inativos. a) primeiro modo, b) segundo modo, c) terceiro modo e d) quarto modo. 
As Figs. 4.36, 4.38 e 4.39 indicam um boa concordância entre os filtros modais. Os erros relativos encontrados podem ser considerados pequenos para invalidar os resultados obtidos. No entanto, a Fig. 4.37 mostra desvios significativos na comparação das respostas filtradas para o primeiro e o segundo modos, que certamente invalidam o objetivo da otimização para aquela topologia em particular.

Como se observa na Fig. 4.35(b), os sensores selecionados estão concentrados nas partes inferior e lateral direita da placa. Esta distribuição topologicamente irregular pode alterar as respostas de alguns modos de forma mais significativa.

Contudo, é possível forçar a convergência entre os filtros, pela redefinição a banda de frequência para o truncamento da matriz de FRF, e o cálculo de novos coeficientes de ponderação para os filtros.

A Fig. 4.40 mostra os filtros da Fig. 4.37 recalculados na banda de frequência $[0,1000] \mathrm{Hz}$. Os filtros apresentam boa concordância para os dois modos de vibração considerados. Em especial, os filtros para o segundo modo apresentam um bom desempenho até cerca de $1200 \mathrm{~Hz}$, quando recalculados a partir de uma topologia otimizada para um desempenho ótimo até $800 \mathrm{~Hz}$. 

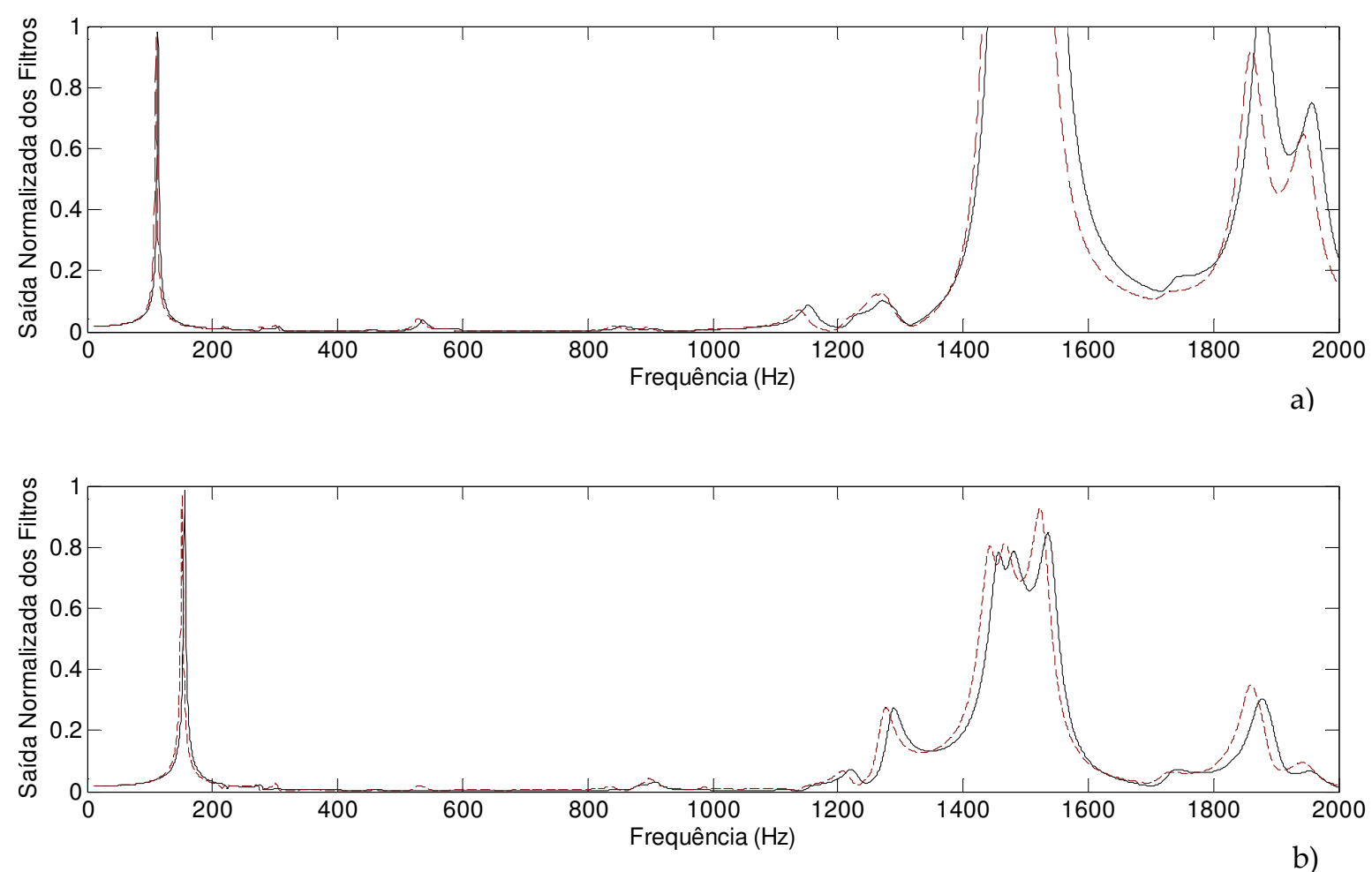

Figura 4.40 - Comparação entre os filtros modais projetados para isolar o primeiro, segundo, tercerio e o quarto modos de vibração com (-) e sem (-) os vinte e quatro sensores sensores inativos. Neste caso, a matriz de resposta em frequência é truncada em $1000 \mathrm{~Hz}$. a) primeiro modo, b) segundo modo.

Este resultado mostra que o ajuste entre os filtros pode ser favorecido em bandas de frequência cujos modos residuais tenham sido filtrados pelo método de mínimos quadrados. Estes resultados apontam para a validade geral da metodologia de otimização topológica adotada e mostram a conveniência do uso da função objetivo $J_{2}$, a qual pressupõe uma boa concordância entre os filtros apenas na faixa de frequência definida para a otimização. 


\section{Conclusões e Perspectivas}

\subsection{Conclusões}

Os resultados apresentados mostram que em certas bandas de frequência o desempenho de um filtro modal discreto pode ser altamente sensível ao número e ao posicionamento dos sensores, e sugere um processo de otimização topológica como forma de assegurar um índice de desempenho aceitável para aos filtros.

Há um limite operacional na banda de frequência para o qual filtros modais obtidos a partir de técnicas de ponderação dos sinais de tensão apresentam alto desempenho médio. A tentativa de filtrar modos ressonantes além deste limite, em geral, degrada o desempenho global do filtro. No caso da placa retangular considerada neste trabalho, as simulações numéricas mostraram que é possível obter filtros modais de alto desempenho médio até $800 \mathrm{~Hz}$, usando uma rede regular composta por doze sensores. Este resultado garante um alto desempenho na filtragem de alguns dos dez primeiros modos de vibrar.

O ponto de truncamento da matriz de FRF define o número de modos de vibrar na banda de frequência e a relação entre o número de sensores ativos na rede e o número de modos efetivamente filtrados na FRF truncada foi usada como um parâmetro para quantificar o desempenho médio dos filtros.

A partir de uma análise estatística utilizando 10.000 topologias de rede aleatórias foi possível concluir que são necessários 16 sensores para isolar 
eficazmente um conjunto seleto de modos alvos até a frequência máxima de $1000 \mathrm{~Hz}$, que encerra os 14 primeiros modos de vibrar.

Por outro lado, otimização topológica pode ser usada para alargar a banda de frequência na qual filtros modais derivados a partir de um número fixo de sensores apresentam alto desempenho, ou minimizar o número de sensores necessários para assegurar filtros modais de alto desempenho em uma banda limitada de frequência.

As simulações numéricas realizadas neste trabalho basearam-se na utilização de duas estratégias de otimização topológica: busca extensiva e algoritmo genético. Cada uma destas estratégias utilizaram em comum dois critérios independentes (funções objetivo) para avaliar o desempenho dos filtros modais derivados de cada uma das topologias de rede selecionadas.

De fato, um grande esforço foi devotado à concepção de métodos de busca e otimização adequados ao problema de otimização combinatorial em estudo. A estratégia de busca extensiva adotada teve por objetivo dar uma visão geral do potencial da otimização topológica sobre o desempenho dos filtros modais. Os resultados alcançados pela análise de um sub-espaço de soluções reduzido indicou a viabilidade da implementação de um método de otimização robusto.

O uso de um algoritmo genético permitiu a pesquisa irrestrita do espaço de soluções associado. A implementação de AG exigiu a codificação adequada do problema de otimização topológica combinatorial e uma pesquisa preliminar para a configuração de parâmetros quantitativos. Em todos os projetos de filtro avaliados, o algoritmo genético alcançou os melhores resultados e se mostrou uma ferramenta adequada para o problema de otimização combinatorial. A pesquisa com algoritmo genético mostra de forma mais clara o papel da função objetivo no processo de otimização.

A função objetivo orienta o processo de busca pela topologia de rede ótima e deve ser concebida de acordo com os objetivos reais da otimização. O desempenho do algoritmo genético com diferentes funções objetivo sugere que estas podem 
suavizar a anatomia do espaço de soluções e favorecer a convergência da pesquisa para o ótimo global.

Para a função objetivo $J_{1}$, a matriz de resposta em frequência é truncada em $800 \mathrm{~Hz}$ (os coeficientes de ponderação são calculados para filtrar os modos residuais até $800 \mathrm{~Hz}$, desconsiderando os demais). O critério de otimização consiste em encontrar uma topologia de rede que seja eficaz em manter a resposta ponderada abaixo de $10 \%$ da amplitude da resposta dos modos residuais na banda de frequência complementar $[800,2000] \mathrm{Hz}$. Neste caso, o desempenho alcançado na filtragem dos modos residuais além $800 \mathrm{~Hz}$ se dá exclusivamente pelo efeito de posicionamento dos sensores.

A função objetivo $J_{2}$ procura a topologia da rede de sensores que minimiza a norma do erro residual na banda de frequência em que todos os modos residuais foram considerados pré-filtrados pelo método de mínimos quadrados. Para tal, a matriz de FRF foi truncada em $1000 \mathrm{~Hz}$.

Embora a qualidade dos resultados deva ser avaliada com base no critério de otimização, o resultado significativo parece ser a filtragem efetiva dos modos residuais adicionais, mantendo o desempenho global dos filtros na banda de frequência operacional. Neste sentido, destacam-se os resultados obtidos pela utilização do algoritmo genético com critério de otimização definido pela função objetivo $\mathrm{J}_{2}$ : a otimização selecionou topologias de redes de doze sensores capazes de isolar até o quarto modo de vibrar na banda de frequência $[10,1000] \mathrm{Hz}$, com pequeno erro residual. Desta forma, quatro modos residuais além da frequência limite para o desempenho médio esperado para uma rede de doze sensores foram filtrados, com erro residual inferior a 3\%, o que pode ser considerado um bom resultado.

Também é válido destacar que os filtros ótimos, em geral, estão associados a redes de sensores irregulares e assimétricas, cujas topologias não podem ser concebidas intuitivamente. 
Ademais, a estratégia de ponderação dos sinais de tensão pelo método de mínimos quadrados baseado na decomposição QR da matriz complexa de resposta em frequência se mostrou adequada. Algumas simulações numéricas sugerem uma economia de 30\% no tempo de cálculo, em relação ao uso do método de mínimos quadrados baseado na decomposição em valores singulares.

A estratégia de otimização topológica combinatorial baseada na seleção de uma sub-rede de sensores a partir de uma rede-mãe (doze sensores selecionados entre trinta e seis) se mostrou adequada aos objetivos deste trabalho. O espaço de soluções gerado pelas combinações das respostas dos trinta e seis sensores, tomados doze a doze, apresentou a variedade de índices de desempenho necessária para justificar o custo computacional do processo de otimização topológica.

Simulações numéricas com a placa remodelada mostraram que a retirada das vinte e quatro pastilhas inativas (descartadas pela otimização) não alterou significativamente a rigidez global da estrutura placa-sensores. Este resultado é uma importante validação da metodologia de otimização pois, na prática, avalia-se uma grande variedade de topologias de rede de sensores com o custo computacional inerente à simulação de um único modelo de elementos finitos.

Como conclusão final, os resultados numéricos apontam para a eficácia da otimização topológica como forma de maximizar o desempenho dos filtros modais obtidos a partir de um número limitado de sensores. Este fato é altamente desejável, na medida em que uma rede regular exigiria um maior número de sensores para alcançar tal desempenho. A otimização do número de sensores reduz os custos e a complexidade técnica de projetos que envolvem aplicações de filtros modais. 


\subsection{Lista de publicações}

PAGANI JR., C.C.; TRINDADE, M.A. (2007). Modelagem por elementos finitos de placas com sensores piezelétricos aplicada ao desenvolvimento de filtros modais. In: ENCONTRO DE MODELAGEM COMPUTACIONAL, 10., 2007, Nova Friburgo. Anais... Nova Friburgo: IPRJ/UERJ. p.1-10.

. (2008a). Projeto e otimização do desempenho de filtros modais baseados em redes de sensores piezelétricos. In: SIMPÓSIO DE MECÂNICA COMPUTACIONAL, 7., 2008, Belo Horizonte. Anais... Belo Horizonte: ABMEC.

(2008b). Otimização topológica de redes de sensores piezelétricos para o projeto de filtros modais. In: IBERIAN LATIN AMERICAN CONGRESS ON COMPUTATIONAL METHODS IN ENGINEERING, 29., 2008, Maceió. Anais... Maceió: ABMEC/UFAL.

. (2009a). Design of adaptive modal filters using piezoelectric sensors arrays. In: INTERNATIONAL SYMPOSIUM ON DYNAMICS PROBLEMS OF MECHANICS, 13., 2009, Angra dos Reis. Proceedings... Rio de Janeiro: ABCM.

. (2009b). Topology optimization of piezoelectric sensors arrays applied to modal filters design. In: ECCOMAS THEMATIC CONFERENCE SMART'09, 4. 2009, Porto. Proceedings... Porto: Faculdade de Engenharia da Universidade do Porto.

. (2009c). Uncertainty analysis in the design of modal filters using piezoelectric sensor arrays. In: INTERNATIONAL CONGRESS OF MECHANICAL ENGINEERING, 20., 2009, Gramado. Proceedings... Rio de Janeiro: ABCM.

(2009d). Optimization of modal filters based on arrays of piezoelectric sensors. Smart Materials and Structures, Bristol, v.18, n.9, art.n. 09 5046, sept.

TRINDADE, M.A. et al. (2008). Structural vibration control using piezoelectric materials. In: BRAZIL AFOSR WORKSHOP ON ADVANCED STRUCTURAL MECHANICS AND COMPUTATIONAL MATHEMATICS, 2008, Campinas. Proceedings... Campinas: UNICAMP. 


\subsection{Perspectivas de trabalhos futuros}

A sequência natural ao desenvolvimento de um trabalho científico baseado em modelagem analítica e simulação numérica envolve a validação experimental dos resultados obtidos. Alguns resultados preliminares, porém conclusivos, indicam que os filtros modais são bastante robustos a variações do valor nominal dos coeficientes de ponderação dos sensores. Também é de grande interesse prático e acadêmico estudar o comportamento dos filtros modais para pequenas variações locais nas posições dos sensores. É importante notar que a estratégia de otimização topológica adotada se consistiu em minimizar o número de sensores necessários para derivar filtros modais de alto desempenho em um faixa prescrita de frequência. Neste sentido, espera-se que as topologias compostas por doze sensores sejam topológicamente pouco robustas, o que justifica o esforço de otimização. Não obstante, um estudo estatístico para se determinar o valor médio e o intervalo de confiança dos filtros modais para pequenas perturbações nas topologias de rede otimizadas pode revelar uma margem de confiabilidade para o posicionamento dos sensores.

A generalização deste estudo envolve o estudo de estruturas similares em diferentes condições de contorno e a substituição da força de excitação mecânica controlada por atuadores piezelétricos. Alguns resultados preliminares indicam uma maior dificuldade no isolamento dos primeiros modos de vibrar de uma placa livre excitada por um atuador piezelétrico, dada a sua capacidade limitada de atuação para valores realísticos de tensão elétrica. No entanto, melhores resultados poderão ser obtidos em condições específicas de engaste.

A utilização de sensores e atuadores piezelétricos integrados para fins de controle ativo de vibrações pode exigir otimizações multiobjetivas, a partir de uma função objetivo que considere simultâneamente o desempenho dos sensores e atuadores. Finalmente, a viabilidade da aplicação de filtros modais derivados a partir 
do posicionamento ótimo dos sensores sobre uma estrutura dever ser avaliada para aplicações em controle estrutural integrado e monitoramento de falhas estruturais, ou mesmo para outras aplicações que sejam beneficiadas pelo uso de filros modais de alto desempenho. 


\section{Referências}

ABREU, G.L.C.M.; STEFFEN JR.; V. (2004). Finite element modeling of plate with localized piezoelectric sensors and actuators. Journal of the Brazilian Society of Mechanical Sciences, Rio de Janeiro, v.26, n.2, p.117-128.

ALLIK, H.; HUGHES, T.J.R. (1970). Finite element method for piezoelectric vibration. International Journal for Numerical Methods in Engineering, London, v.2, n.2, p.151-157, Apr./June.

ANDERSON, E.H.; HAGOOD, N.W. (1994). Simultaneous piezoelectric sensing/actuation: analysis and application to controlled structures. Journal of Sound and Vibration, London, v.174, n.5, p.617-639, July.

BEASLEY, D.; BULL, D.; MARTIN, R. (1993). An overview of genetic algorithms part 1: fundamentals. University Computing, New York, v.15, n.2, p.58-69.

BEGG, D.W.; LIU, X. (2000). On simultaneous optimization of smart structures - part II: algorithms and examples. Computer Methods in Applied Mechanics and Engineering, Amsterdam, v.184, n.1, p.25-37, Mar.

BENJEDDOU, A. (2000). Advances in piezoelectric finite elements modeling of adaptive structural elements: a survey. Computers \& Structures, New York, v.76, n.1/3, p.347-363, June.

CALLEN, H.B. (1960). Thermodynamics. New York: Wiley.

CHEN, C.Q.; SHEN, Y.P. (1997). Optimal control of active structures with piezoelectric modal sensors and actuators. Smart Materials and Structures, Bristol, v.6, n.4, p.403-409, Aug.

CHOPRA, I. (2002). Review of state of art of smart structures and integrated system. AIAA Journal, Easton, v.40, n.11, p.2145-2187.

CICOGNA, T.R. (2008). Identificação de matrizes de funções de resposta em frequência multidirecionais em estruturas complexas. 215p. Tese (Doutorado). Escola de Engenharia de São Carlos, Universidade de São Paulo, São Carlos, 2008. 
COSTA, L. et al. (2007). Modeling and numerical study of actuator and sensor effects for a laminate piezoelectric plate. Computers and Structures, Maryland Heights, v.85, n.7/8, p.385-403, Apr.

DE JONG, K.A. (2006). Evolutionary computation: unified approach. Cambridge: MIT.

DERAEMAEKER, A.; PREUMONT, A. (2005). Vibration based damage detection using large array sensors and spatial filters. Mechanical Systems and Signal Processing, London, v.20, n.7, p.1615-1630, Oct.

FRECKER, M.I. (2003). Recent advances in optimization of smart structures and actuators. Journal of Intelligent Material Systems and Structures, Thousand Oaks, v.14, n.4/5, p.207-216, Apr./May.

FRIPP, M.L.; ATALLA, M.J. (2001). Review of modal sensing and actuation techniques. The Shock and Vibration Digest, Thousand Oaks, v.33, n.1, p.3-14.

FRISWELL, M. ( 2001). On the design of modal actuators and sensors. Journal of Sound and Vibration, London, v.241, n.3, p.361-372, Mar.

GODOY, T.C. (2008). Modelagem de placas laminadas com materiais piezelétricos conectados a circuitos shunt resistivo-indutivo. 128p. Dissertação (Mestrado) Escola de Engenharia de São Carlos, Universidade de São Paulo, São Carlos, 2008.

GOLDBERG, D. (1989). Genetic algorithms in search, optimization, and machine learning. Reading: Addison Wesley.

HA, S.K.; KEILERS, C.; CHANG, F.K. (1992). Finite element analysis of composite structures containing distributed piezoceramic sensors and actuators. AIAA Journal, Reston, v.30, n.3, p.772-780, Mar.

HAN, J.H.; LEE, I. (1999). Optimal placement of piezoelectric sensors and actuators for vibration control of a composite plate using genetic algorithms. Smart Materials and Structures, Bristol, v.8, n.2, p.257-267, Apr.

HERNANDES, J.A.; ALMEIDA, S.F.M.; NABARRETE, A. (2000). Steffening effects on the free vibration behavior of composite plates with PZT actuators. Composite Structures, Oxford, v.49, n.1, p.55-63, May. 
HOLLAND, J.H. (1975). Adaptation in natural and artificial systems. Ann Arbor: University of Michigan Press.

IEEE Standard on piezoelectricity. (1987). New York, n. 176.

JAFFE, B.; ROTH, R.S.; MARZULLO, S. (2954). Piezoelectric properties of lead zirconate-lead titinate solid-solution ceramics. Journal of Applied Physics, Menasha, v.25, p.809-8, June.

KAILIN, J.; FRISWELL, M. (2007). Distributed modal sensors for rectangular plate structures. Journal of Intelligent Material Systems and Structures, Thousand Oaks, v.18, n.9, p.939-948, Sept.

KOGL, M.; BUCALEM, M.L. (2005). Analysis of smart laminates using piezoelectric MITC plate and shell elements. Computers and Structures, New York, v.83, n.15/16, p.1153-1163, June.

LAM, K.Y. et al. (1997). A finite-element model for piezoelectric composite laminates. Smart Materials and Structures, Bristol, v.6, n.5, p.583-591, Oct.

LEE, A.C.; CHEN, S.T. (1994). Collocated sensor/acutuator positioning and feedback design in the control of flexible structure system. Journal of Vibration and Acoustics, New York, v.116, n.2, p.146-154, Apr.

LEE, C.K.; MOON, F.C. (1990). Modal sensors/actuators. Journal of Applied Mechanics, New York, v.57, n.2, p.434-441, June.

LIMA JR., J.J. (1999). Modelagem de sensores e atuadores piezelétricos com aplicações em controle ativo de estruturas. 241p. Tese (Doutorado) - Universidade Estadual de Campinas, Campinas, 1999.

LIPPMANN, G. (1881). On the principle of energy conservation. Annales de Chimie et de Physique, França, v.24, p.145-178.

MALVERN, L.E. (1969). Introduction to the mechanics of a continuous mediun. New Jersey: Prentice-Hall.

MEIROVITCH, L.; BARUH, H. (1982). Control of self-adjoint distributed-parameter system. AIAA Journal of Guidance and Dynamics, Reston, v.5, n.1, p.60-66.

PREUMONT, A. et al. (2003). Spatial filters in structural control. Journal of Sound and Vibration, London, v.265, n.1, p.61-79, July. 
REDDY, J.N. (1997). Mechanics of laminated composite plates and shells: theory and analysis. $2^{\text {nd }}$ ed. Boca raton: CRC Press.

ROBERTS, S. (1947). Dielectric and piezoelectric properties of barium titanate. Physical Review, Washington, v.71, n.12, p.890-895, June.

SADRI, A.M.; WRIGHT, J.R.; WYNNE, R.J. (1999). Modelling and optimal placement of piezoelectric actuators in isotropic plates using genetic algorithms. Smart Materials and Structures, Bristol, v.8, n.4, p.490-498, Aug.

SHELLEY, S.J. (1991). Investigation of discrete modal filters for structural dynamic applications. Ph.D. Thesis - University of Cincinnati, Cincinnati, 1991.

SILVA, E.C.N.; KIKUCHI, N. (1999). Design of piezoelectric transducers using topology optimization. Smart Material and Structures, Bristol, v.8, n.3, p.350-364, June.

STASZEWSKI, W.J. et al. (2000). Fail-safe sensor distributions for impact detection in composite materials. Smart Materials and Structures, Bristol, v.9, n.3, p.298-303, June.

STRANG, G. (1993). Introduction to linear algebra. Wellesley: Wellesley-Cambridge Press.

SUMALY, H.; CUDNEY, H.H. (1991). Experimental investigation of piezoelectric film used as modal sensors. In: INTERNATIONAL MODAL ANALYSIS CONFERENCE, 9., 1991, Forenze. Proceedings... Shcenectady: Union College. v.2, p.1174-1180.

SYLVAIN, T.; GUILLAUME, U.R. (2007). Modal analysis computation using 3D piezoelectric finite elements from ansys and SDTools. Paris: Supméca.

TRINDADE, M.A. (2007). Optimization of active-passive damping treatments using piezoelectric and viscoelastic materials. Smart Materials and Structures, Bristol, v.16, n.6, p.2159-2168, Dec.

TRINDADE, M.A.; BENJEDDOU, A. (2007). On the evaluation of effective electromechanical coupling coefficients for structures with piezoelectric elements. In: ECCOMAS THEMATIC CONFERENCE ON SMART STRUCTURES AND MATERIALS, 3., 2007, Gdansk. Proceedings... Gdansk: [s.n]. p.1-16. 
TRINDADE, M.A.; BENJEDDOU, A.; OHAYON, R. (2001a). Finite element modelling of hybrid active-passive vibration damping of multilayer piezoelectric sandwich beams - part I: formulation. International Journal for Numerical Methods in Engineering, London, v.51, n.7, p.835-854, July.

. (2001b). Finite element modelling of hybrid active-passive vibration damping of multilayer piezoelectric sandwich beams - part II: system analysis. International Journal for Numerical Methods in Engineering, London, v.51, n.7, p.855-864, July.

TZOU, H.S.; TSENG, C.I. (1990). Distributed piedzoelectric sensor/actuator design for dynamic measurement/control of distributed parameter systems: a piezoelectric finite element approach. Journal of sound Vibration, london, v.138, n.1, p.17-38, Apr.

TZOU, H.S.; WAN, G.C.; TSENG, C.I. (1989). Dynamics and distributed vibration controls of flexible manipulators: integrated distributed sensing and active piezoelectric actuator. In: IEEE INTERNATIONAL CONFERENCE ON ROBOTICS AND AUTOMATION, 1989, Arizona. Proceedings... New York: IEEE. p.1716-1725.

VARADAN, V.V.; CHIN, L.C.; VARADAN, V.K. (1993). Finite-element modeling of flextensional electroacoustic transducers. Smart Materials and Structures, Bristol, v.2, n.4, p.201-207, Dec.

WORDEN, K.; BURROWS, A.P. (2001). Optimal sensor placement for fault diagnosis. Engineering Structures, Guildford, v.23, n8, p.885-901, Aug.

WORDEN, K.; BURROWS, A.P.; TOMLINSON, G.R. (1995). A combined neural and genetic approach to sensor placement. In: INTERNATIONAL MODAL ANALYSIS CONFERENCE, 13., 1995, Nashville. Proceedings... Bellingham: SPIE. p.1727-1736. (SPIE, 2460).

YANG, Y.; JIM, Z.; SOH, C.K. (2006). Integrated optimization of control system for smart cylindrical shells using modified GA. Journal of Aerospace Engineering, New York, v.19, n.2, p.68-79, Apr. 